Florida International University FIU Digital Commons

3-21-2018

\title{
Special and General Education Teachers' Assessment of Their Participation in a Peer Assistance and Review (PAR) Program
}

Alexandre Lopes

Florida International University, loralopes@aol.com

DOI: $10.25148 /$ etd.FIDC006563

Follow this and additional works at: https://digitalcommons.fiu.edu/etd

Part of the Educational Assessment, Evaluation, and Research Commons, and the Special Education and Teaching Commons

\section{Recommended Citation}

Lopes, Alexandre, "Special and General Education Teachers' Assessment of Their Participation in a Peer Assistance and Review (PAR) Program" (2018). FIU Electronic Theses and Dissertations. 3691.

https://digitalcommons.fiu.edu/etd/3691 


\section{FLORIDA INTERNATIONAL UNIVERSITY}

Miami, Florida

A dissertation submitted in partial fulfillment of the requirements for the degree of DOCTOR OF EDUCATION

in

EXCEPTIONAL STUDENT EDUCATION

by

Alexandre Lopes

2018 
To: Dean Michael R. Heithaus

College of Arts, Sciences and Education

This dissertation, written by Alexandre Lopes, and entitled Special and General Education Teachers' Assessment of Their Participation in a Peer Assistance and Review (PAR) Program, having been approved in respect to style and intellectual content, is referred to you for judgment.

We have read this dissertation and recommend that it be approved.

$\begin{array}{r}\hline \text { Kyle Bennett } \\ \hline \text { Linda Blanton } \\ \hline \text { Peter Cistone } \\ \hline \text { Elizabeth Cramer, Major Professor }\end{array}$

Date of Defense: March 21, 2018

The dissertation of Alexandre Lopes is approved.

Dean Michael R. Heithaus

College of Arts, Sciences and Education

Andrés G. Gil

Vice President for Research and Economic Development and Dean of the University Graduate School

Florida International University, 2018 
(C) Copyright 2018 by Alexandre Lopes

All rights reserved. 


\section{DEDICATION}

I dedicate this dissertation to Enir and Zilda Lopes, to Lucia Lora, and to John

Paul Sam. Without their unconditional love and support, I would not have made it this far. 


\section{ACKNOWLEDGMENTS}

I am grateful to Dr. Linda Blanton, Dr. Elizabeth Cramer, and Dr. Diana ValleRiestra for having selected me as one of the recipients of the Project Empowering Diverse Urban Change Agents Through Education (EDUCATE) Grant. Without their knowledge and continuous support, I would not be where I am today.

I also am grateful to the members of my dissertation committee. My deepest appreciation goes to Dr. Elizabeth Cramer, who believed in me, and who did not allow me to give up. I owe a debt of gratitude to Dr. Linda Blanton, who patiently guided me in building the foundation of the present dissertation study. Additionally, I would like to express my gratitude to Dr. Kyle Bennett for always providing me with constructive

feedback. Finally, I would like to thank Dr. Peter Cistone for assisting me in considering different perspectives when analyzing my work. 


\title{
ABSTRACT OF THE DISSERTATION \\ SPECIAL AND GENERAL EDUCATION TEACHERS' ASSESSMENT OF THEIR \\ PARTICIPATION IN A PEER ASSISTANCE AND REVIEW (PAR) PROGRAM
}

\author{
by
}

Alexandre Lopes

Florida International University, 2018

Miami, Florida

\section{Professor Elizabeth Cramer, Major Professor}

Traditional teacher evaluation systems have failed to (a) show variations in teacher effectiveness, (b) determine teachers' professional development needs, and (c) align evaluation of teacher effectiveness with compensation, retention, and dismissal. Furthermore, traditional teacher evaluation systems have failed to establish teaching practices that positively affect student learning - an issue of critical importance for students with disabilities.

The literature indicates that Peer Assistance and Review (PAR), grounded in social network theory, is regarded by many as a viable option to compensate for the disadvantages of traditional teacher evaluation systems. PAR has the potential to provide (a) frequent and meaningful observations, (b) adequate feedback, and (c) continuous assistance in the areas in which teachers need to improve.

This dissertation study examined special and general education teachers' assessment of their participation in a PAR program taking place in a large urban school district in the Southeast region of the United States. The research questions central to this study are the following: (a) How do special education teachers and general education 
teachers rate the extent to which their participation in a PAR program impacts their teaching?, (b) Is there a statistically significant difference between the manner in which special education teachers and general education teachers rate the extent to which their participation in a PAR program impacts their teaching in targeted areas? and (c) How do special education teachers describe their experiences as a participating teacher in a PAR program?

A mixed-methods sequential explanatory design was selected to conduct this dissertation study. In order to answer the first two research questions, the researcher conducted a survey with special and general education teachers who participated in a PAR program. Furthermore, in order to answer the final research question, the researcher conducted semi-structured interviews with special education teachers who participated in the program. Descriptive statistics and $t$-tests for independent samples were conducted with survey responses, and a constant comparative method was used to analyze the interview data. 


\section{TABLE OF CONTENTS}

CHAPTER

PAGE

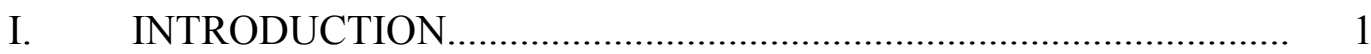

Peer Assistance and Review.............................................................. 5

Theoretical Grounding........................................................................ 7

Evaluation of Special Education Teacher Effectiveness........................ 8

Issues with Current Evaluation Approaches................................ 10

Peer Assistance and Review and Special Education..................... 12

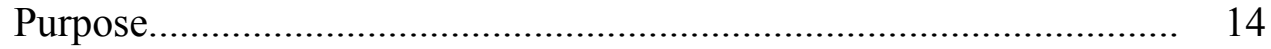

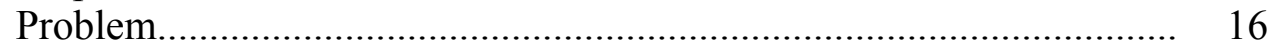

Research Questions........................................................................ 17

Definition of Terms...................................................................... 18

II. LITERATURE REVIEW......................................................... 19

Social Network Theory and Peer Assistance and Review.................... 19

Collaboration Toward Improvement in Professional Practice and 20

Student Achievement.

Trust as a Means to Exchange Knowledge and Best Practices..... 25

Evaluation of Teacher Effectiveness and Peer Assistance and Review. 28

Peer Assistance and Review as a Potential Alternative to $\quad 30$

Counteract the Disadvantages of Traditional Teacher

Evaluation Systems.

Peer Assistance and Review and the Performance Evaluation $\quad 34$

of Special Education Teachers.

Summary

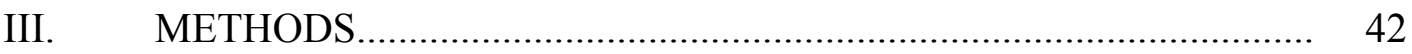

Research Questions......................................................................... 42

Research Design........................................................................... 44

Rationale for Selecting a Sequential, Mixed-Methods Design.... $\quad 44$

Phases of the Study .................................................................... 45

Phase 1: Quantitative ...................................................... 46

Phase 2: Qualitative....................................................... 47

Setting............................................................................. 48

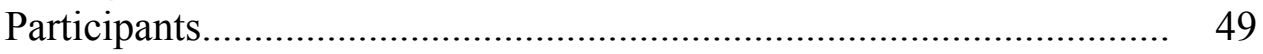

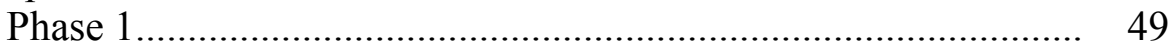

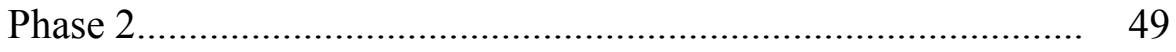

Data Collection......................................................................... 50

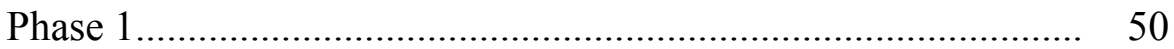

The survey instrument...................................................... 51

Content validity.............................................................. 56

Internal consistency........................................................ 56

The pilot test............................................................... 57

Administration of survey................................................... 57 


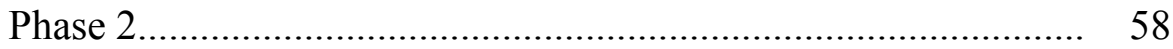

Interview protocol................................................... 58

Interview procedures................................................... 60

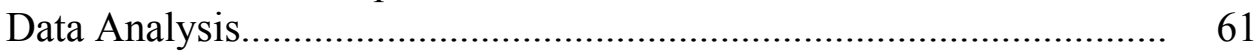

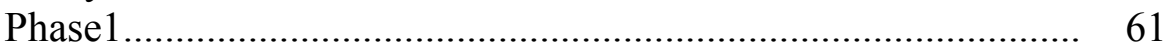

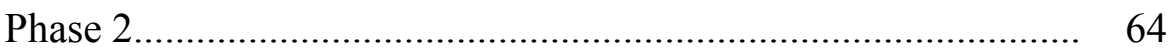

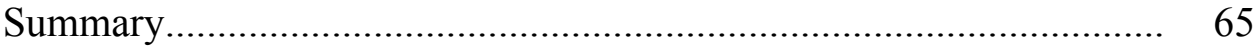

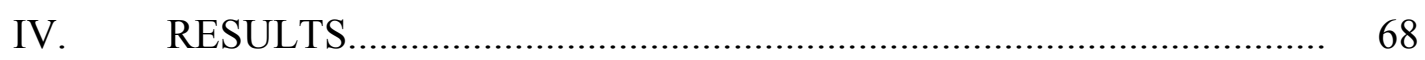

Description of Study Sample............................................................ $\quad 70$

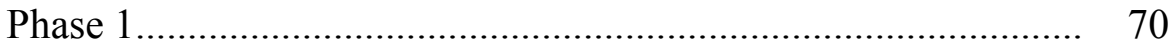

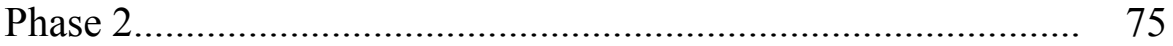

Phase 1 Data Analysis and Result..................................................... 76

Research Question 1.............................................................. 76

Impact on targeted areas of teaching................................. $\quad 76$

Special education teachers.......................................... 78

Knowledge of learners......................................... 79

Instructional planning........................................... 79

Instructional delivery and engagement................ 80

Assessment of learners........................................ 80

Communication................................................ 80

Learning environment......................................... 81

Overall professionalism........................................ 81

General education teachers........................................... 81

Knowledge of learners........................................ 84

Instructional planning......................................... 84

Instructional delivery and engagement................ 84

Assessment of learners......................................... 85

Communication.................................................. 85

Learning environment.......................................... 85

Overall professionalism..................................... 86

Differences between special and general education 86 teachers.

Evaluative feedback and professional development 91 opportunities.

Special education teachers.......................................... 91

Evaluative feedback........................................... 92

Professional development opportunities.............. 92

General education teachers............................................ 94

Evaluative feedback............................................ 94

Professional development opportunities.............. 95

Differences between special and general education 96 teachers.

Evaluative feedback........................................... 98

Professional development opportunities............ 98 
Research Question 2............................................................... 99

Phase 2 Data Analysis and Result........................................................ 109

Research Question 3............................................................. 109

Participant profiles....................................................... 111

Consulting teachers.......................................................... 115

Consulting teachers' consistency....................................... 116

Consulting teachers' area of certification.......................... 120

Formal observations...................................................... 125

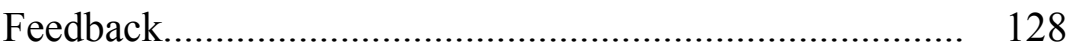

Embedded professional development................................ 130

Professional development................................................ 132

New teachers........................................................... 133

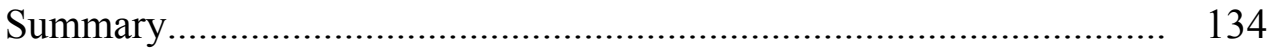

V. DISCUSSION AND CONCLUSION ........................................... 138

Summary of the Investigation.......................................................... 138

Demographics and Level of Satisfaction............................................ 140

Research Questions...................................................................... 142

Impact of the PAR Program on Targeted Areas of Teaching....... 143

Evaluative Feedback and Professional Development 146

Opportunities

Special Education Teachers as Participating Teachers in a PAR 148

Program

Consulting teachers..................................................... 148

Consulting teachers' consistency...................................... 149

Consulting teachers' area of certification........................... 150

Formal observations...................................................... 151

Feedback and embedded professional development.......... 152

Professional development................................................ 153

New teachers........................................................... 154

Limitations....................................................................... 154

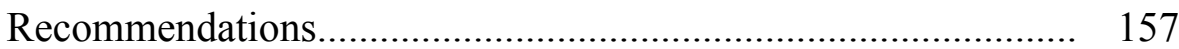

Recommendations for Future Research................................... 159

Summary.................................................................... 161

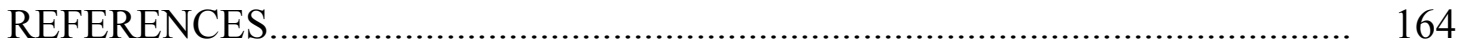

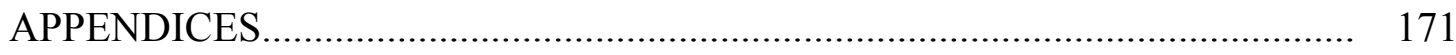

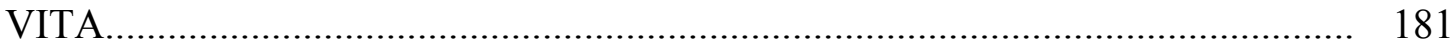




\section{CHAPTER I}

\section{INTRODUCTION}

Historically, most teacher evaluation systems have been unreliable in predicting future teacher performance (Glazerman et al., 2010), have been binary (satisfactory or unsatisfactory), and have failed to provide teachers with the necessary feedback for them to grow in their professional practice (Burdette, 2011a; Weisberg, Sexton, Mulhern, \& Keeling, 2009). Currently, infrequent classroom observations conducted by untrained evaluators and a pro forma tenure process are the norm (Corcoran, 2010). Despite the growing consensus that effective teachers are the key to education reform, education stakeholders have not been able to come to an agreement concerning how to measure teacher effectiveness or how to recognize least and most effective teachers. Furthermore, policies that guide teacher evaluation have failed to link it to improvement in teacher practices; consequently, teacher evaluations have not led to improvement in student learning (Burdette, 2011a).

To gain a better understanding of issues relating to variations in effectiveness among the nation's teachers, Weisberg, Sexton, Mulhern, and Keeling (2009) conducted a study with 15,000 teachers and 1,300 administrators in 12 districts across four states. According to the survey responses provided by those teachers and administrators, in districts where a binary (satisfactory or unsatisfactory) teacher evaluation system existed, $99 \%$ of teachers received a rating of satisfactory. Using their findings, Weisberg et al. (2009) concluded that teachers are considered interchangeable and that districts, failing to recognize variations in teacher effectiveness, also fail to determine the professional 
development needs of their instructional workforce and to align evaluation of teacher effectiveness with compensation, retention, and dismissal.

The failure of school districts to recognize and act on teacher effectiveness did not go unnoticed to the Obama administration, who, in its blueprint for revising the Elementary and Secondary Education Act (ESEA), established that states will develop an extensive teacher evaluation system that will recognize and reward teachers, among other factors, on the basis of student achievement (U.S. Department of Education, 2010). The blueprint for reform represents a significant change in the criteria for determining teacher effectiveness established by the ESEA reauthorization of 2001 (No Child Left Behind), which determined that every school district be required to hire highly qualified teachers (U.S. Department of Education, 2001). The determination of whether or not teachers were highly qualified, according to the ESEA reauthorization of 2001, was to be determined by professional requirements, such as degrees attained (U.S. Department of Education, 2001). However, the Obama administration, through Race to the Top, determined that teacher evaluation systems need to include more differentiation among teacher ratings and base a significant amount of their criteria for classification of teacher effectiveness on measures that indicate teachers' value-added to student achievement on standardized assessments (U.S. Department of Education, 2010), a criterion that was not included in previously used measures of teacher effectiveness.

Traditionally, measures of teacher effectiveness have involved one or more of the following criteria: "scores on licensing tests, routes into teaching, nature of certification, National Board Certification, teaching experience, quality of undergraduate institution, relevance of undergraduate coursework, extent and nature of professional development" 
(Glazerman et al., 2010, p. 10), and classroom observations. These criteria, however, considered together or separately, do not give an indication of future teacher performance in a manner as reliable as that provided by value-added measures (Glazerman et al., 2010). Therefore - and as a result of Race to the Top stipulations - in recent years, a substantial number of districts and states have adopted, to one degree or another, valueadded measures of teacher effectiveness to evaluate, advance, reward, and retain or dismiss teachers (Burdette, 2011a; Corcoran, 2010; Weisberg et al., 2009). Even so, concerns exist regarding the use of value-added measures to evaluate teacher effectiveness.

Value-added models can be applied only to those teachers who teach grades and subjects being tested (Corcoran, 2010; Weisberg et al., 2009). Also, as a consequence of the systematic omissions and repetitions of tested standards, they can lead teachers to "teach to the test" (Corcoran, 2010). Moreover, the value-added of a teacher can vary substantially depending on the test used (Corcoran, 2010). Furthermore, while valueadded models might be efficient in identifying the most and the least effective teachers, they are less reliable in differentiating among those teachers whose performances fall in the middle of the performance spectrum (Weisberg et al., 2009). Additionally, the valueadded of a teacher fluctuates because of the fact that (a) the assignment of students to teachers is not random and (b) the value-added of a teacher cannot be isolated completely from all the socio-economic factors that affect student achievement (Darling-Hammond, Amrein-Beardsley, Haertel, \& Rothstein, 2012). Finally, the fact that value-added models decrease in accuracy and consistency when used with teachers who share the 
responsibility for educating a single student is of particular concern to the field of special education (Blanton, Sindelar, \& Correa, 2006; Jones, Buzick, \& Turkan, 2013).

In spite of these concerns, however, value-added models currently are one of the prominent indicators of teacher effectiveness, and there is a growing consensus among education practitioners, researchers, and policymakers that teacher evaluation systems should include some form of value-added measure in addition to evidence of quality teacher practices (Darling-Hammond et al., 2012). The growing consensus is a result of existing discontent with traditional models of teacher evaluation that recognize most teachers as being satisfactory in their performance and that fail to (a) train administrators and other evaluators on how to objectively evaluate teachers, (b) reward their most effective teachers, (c) address poor performance, and (d) identify and support the professional development needs of their teachers while recognizing variations in teacher effectiveness (Weisberg et al., 2009).

Classroom observations are another prominent indicator of teacher effectiveness (Jones et al., 2013). While value-added models can help determine groups of teachers who have contributed to student achievement, classroom observations can provide a true and reliable reflection of a teacher's classroom practice throughout the year. Furthermore, the feedback that classroom observations can provide to teachers - if provided in a timely and meaningful manner (Darling-Hammond et al., 2012) - can considerably assist them in their professional growth. Nevertheless, for classroom observations to provide a true and reliable reflection of a teacher's classroom practice, they must be conducted two or more times throughout the year and be implemented by expert individuals who look at a variety of data sources to evaluate teacher performance (Darling-Hammond et al., 2012). 
Nonetheless, the typical classroom observation is short and infrequent (Weisberg et al., 2009). Furthermore, observation approaches are not standardized and, because of time constraints, only reflect a small sample of a teacher's performance (Blanton et al., 2006; Jones et al., 2013).

Other indicators of teacher effectiveness include videotapes of teachers, evaluation of artifacts of teacher practice, and student surveys. In addition, edTPA (formerly known as the Teacher Performance Assessment), a performance assessment for teachers entering the profession, measures teacher candidates' ability not only to plan instruction to meet learning standards but also to differentiate instruction for diverse learners, including English Language Learners and students with disabilities (Stanford Center for Assessment, Learning and Equity, 2013). Finally, Peer Assistance and Review (PAR), an initiative in which teachers are assisted and evaluated by their peers, is being used in some educational districts throughout the nation (Johnson \& Fiarman, 2012; Johnson \& Papay, 2010; Papay \& Johnson, 2012). Because of the timely and meaningful feedback that it provides teachers, PAR is regarded by a number of scholars as one approach to make up for the shortcomings of traditional teacher evaluation systems (e.g., Donaldson et al., 2008; Humphrey, Koppich, Bland, \& Bosetti, 2011; Johnson \& Fiarman, 2012; Johnson \& Papay, 2010; Papay \& Johnson, 2012).

\section{Peer Assistance and Review}

In addition to providing teachers with timely and meaningful feedback, PAR assists teachers in their professional growth. In PAR, expert teachers (i.e., consulting teachers) assist and evaluate their peers (i.e., participating teachers) with the goal of helping them improve in their performance and meet district standards. Districts with 
fully established PAR programs tend to retain more novice teachers and to dismiss underperforming ones (Johnson \& Papay, 2010; Papay \& Johnson, 2012). In addition, administrators and teachers have reported that the instructional capacity of their districts has improved as a result of (a) the assistance and review provided to participating teachers by consulting teachers and (b) the continuous dialogue implemented by PAR regarding what represents good teaching practice (Johnson \& Papay, 2010; Papay \& Johnson, 2012).

In districts where PAR programs have been established, consulting teachers are given sufficient time to conduct frequent and thorough teacher observations, which is not the case when administrators are the only ones responsible for that aspect of the teacher evaluation process (Goldstein, 2007a; Johnson \& Fiarman, 2012). In addition, consulting teachers have the appropriate subject matter expertise to provide participating teachers with meaningful feedback, which is important to assist teachers in their professional growth but lacking in traditional teacher evaluation systems (Goldstein, 2007a; Johnson \& Fiarman, 2012).

Another aspect of PAR that differs from traditional teacher evaluation systems is that it is perceived as a fair practice by most participating teachers. The perception is a consequence of three main reasons: (a) consulting teachers bring the teacher perspective into the teacher evaluation system (Johnson \& Fiarman, 2012); (b) participating teachers trust and respect consulting teachers because these are selected through an open and rigorous process (Donaldson et al., 2008; Johnson \& Papay, 2010); and (c) the PAR programs are co-sponsored by local teacher union organizations (Goldstein, 2007a; Johnson \& Papay, 2010). 
The aforementioned qualities make PAR a credible teacher evaluation system, and one that is the focus of the current investigation. Moreover, PAR's benefits expand beyond the evaluation process - they also can be found in the assistance provided by consulting teachers to participating teachers with the goal of improving the latter's professional performance. By means of this assistance, PAR not only promotes teachers' professional growth but also elevates the degree of professionalism at both the educator and school level in districts where PAR is implemented (Johnson \& Fiarman, 2012).

\section{Theoretical Grounding}

In PAR, consulting teachers - through a process of collaboration (Humphrey et al., 2011) - not only evaluate participating teachers but also assist them in their professional development (Johnson \& Fiarman, 2012). A review of the literature regarding data use, social network theory, and the intersection of the former with the latter conducted by Daly (2012) indicated that a substantial number of studies support the fact that collaboration among teachers not only translates into student gains on achievement tests but also is beneficial to the professional development of the individuals involved in the collaboration process. Moreover, Marsh, McCombs, and Martorell (2010), using a social network study concerning the relationship between coaching and data use, indicated that coaches have the ability both to provide support regarding the interpretation of data and to assist in the development of instructional strategies using that interpretation. Furthermore, Daly stated that dyadic relationships embedded in social networks could facilitate the dissemination of system-wide decisions. Finally, Daly explained that among the relationships with which social network theory is concerned are 
the interactions that exist between members of a social network. According to Daly, at times, those interactions take the form of collaboration.

Social network theory, a theory grounded in the importance of the social relationship patterns that exist between members of a social network, serves as an effective conceptual framework to assist one in comprehending how social relationships can positively or negatively impact the use of data to support educational improvement (Daly, 2012). Social network theorists direct their attention to the fact that individuals' interpretation and use of data is affected by the social relationships they build with others in a manner that can support or constrict student learning gains (Borgatti \& Ofem, 2010), and it is these relationships that serve as the foundation for social network theory (Daly, 2012). Peer Assistance and Review is possible because of the relationships that exist between consulting and participating teachers. The expertise of consulting teachers, added to the training that they receive as coaches, can potentially assist participating teachers in working with underperforming students. Furthermore, the relationships found in PAR have been found to be built on trust and respect (Donaldson et al., 2008; Johnson \& Papay, 2010) and to not only promote teachers' professional growth but also further the level of professionalism of the educational systems in which PAR has been implemented (Johnson \& Fiarman, 2012).

\section{Evaluation of Special Education Teacher Effectiveness}

There is no consensus on how to evaluate special education teachers (Holdheide, Goe, Croft, \& Reschly, 2010). In fact, few states and districts have addressed the challenge of evaluating their special education instructional workforce (Council for Exceptional Children, 2012). Those states that have addressed the evaluation of special 
education teachers have reported doing so using one or a combination of the following evaluating measures: (a) students' scores on large-scale standardized assessments and student growth determined by multiple years of large-scale standardized assessment scores, (b) curriculum-based measures, (c) classroom observations, (d) teacher portfolios, (e) students' progress toward IEP goals, and (f) goal-driven professional development (Burdette, 2011a). Because of the lack of consensus regarding the evaluation of special education teachers, the Council for Exceptional Children (CEC; 2012) issued a position statement indicating that evaluation systems for special education teachers should use performance standards that are clearly defined, utilize multiple measures, provide teachers with frequent and meaningful feedback, and address the persistent challenge concerning the retention of special education teachers.

Special education teachers' roles vary considerably from school to school and, possibly, from student to student (Blanton et al., 2006; Holdheide et al., 2012; Jones et al., 2013; Sledge \& Pazey, 2013). The variety of roles makes it a challenge for special education teachers to have the quality of their teaching practice evaluated as a whole. In fact, in the responses provided by 35 states to a survey conducted with the goal of depicting states' work in the area of performance-based compensation as it relates to special education teachers, state directors of special education indicated that the variety of roles played by special education teachers and the range of ability of the students assigned to them make it difficult to measure their value-added (Burdette, 2011b). Therefore, it is fundamental that direct measures of teacher observation be used in the assessment of the quality of instruction of special education teachers (Brownell et al., 2009) and be conducted by evaluators trained to recognize and base their evaluation on 
the specific role(s) played by special educators (CEC, 2012; Sledge \& Pazey, 2013).

Nevertheless, no standard special education teacher observation practice can be found. In addition, because of time constraints, observations only cover small samples of teacher routines (Blanton et al., 2006; Jones et al., 2013).

With the goal of creating consensus on how to assess beginning special education teacher quality, Blanton et al. (2006) suggested that special education teacher education research should (a) use multiple research traditions, (b) focus on producing findings capable of linking measures of special education teacher quality to student outcomes and on using those findings to get the attention of policymakers, and (c) validate the use of teaching standards to assess special education teacher quality. These suggestions, if followed, might develop the solution for compliance with current and mandated accountability and performance standards in a manner that is suitable to the field of special education. Peer Assistance and Review also may be part of the solution. Studies have shown that districts in which PAR has been implemented tend to retain their novice teachers (Johnson \& Papay, 2010; Papay \& Johnson, 2012). With the subject knowledge of its consulting teachers, thorough and frequent observations, and meaningful feedback, PAR has the potential of serving as a viable evaluation of special education teacher effectiveness.

\section{Issues with Current Evaluation Approaches}

Value-added models, currently used as one of the main indicators of teacher effectiveness, raise particular concern for special educators (CEC, 2012). Teachers with large numbers of low-performing students are at a disadvantage when evaluation of teacher effectiveness is based entirely on the scores of a single administration of an 
achievement test (Blanton et al., 2006; Burdette, 2011b; CEC, 2012; Jones et al., 2013). In addition, the usually insufficient sample of special education teachers and students in education databases makes refined statistical analyses difficult (Blanton et al., 2006; Jones et al., 2013). Moreover, when more than one teacher works with the same student (e.g., co-teaching, consulting, working with teams of teachers), no evidence exists that value-added models can accurately predict the individual performance of those teachers using that student's test scores (Burdette, 2011b; CEC, 2012; Holdheide et al., 2012). Furthermore, because students with disabilities form a heterogeneous subgroup of students, who use testing accommodations that may vary from year to year, who in large part are underperforming, and whose profile changes over time (e.g., moving in and out of special education, moving from one disability category to another), the use of longitudinal statistical models is compromised, particularly when the student falls under a low- versus a high-incidence disability category (Buzick \& Laitusis, 2010; Holdheide et al., 2012).

Equally concerning is the inclusion of students with disabilities in value-added models when the student has a moderate to severe disability and, therefore, takes alternate assessments, which are scored on a scale other than the one on which general assessments are scored (Ahearn, 2009; Buzick \& Laitusis, 2010; CEC, 2012). Moreover, the use of alternate assessments occur in small sample sizes, which makes the teacher value-added estimate less reliable (Buzick \& Laitusis, 2010; Holdheide et al., 2012).

Another prominent indicator of teacher effectiveness that raises particular concern for special educators are classroom observations. School administrators - who are usually in charge of conducting classroom observations - lack the necessary expertise to evaluate 
teacher effectiveness as it relates to the instruction of students with disabilities (Blanton et al., 2006; Jones et al., 2013; Sledge \& Pazey, 2013). Consequently, the lack of expertise affects the reliability with which classroom observers may rate special education teachers (Jones et al., 2013; Sledge \& Pazey, 2013). Even the use of standard observation protocols - with or without modifications - to evaluate special education teachers does not provide a true representation of the roles that these teachers play in the education of students with disabilities (Sledge \& Pazey, 2013). When used without modifications, standard observation protocols do not capture the specific instructional practices used by special education teachers to instruct students with disabilities (Jones et al., 2013; Sledge \& Pazey, 2013). By contrast, when used with modifications, standard observation protocols may affect the accuracy of evaluations in a negative manner (Sledge \& Pazey, 2013).

\section{Peer Assistance and Review and Special Education}

Measures used to evaluate instructional practice must be appropriate for the evaluation of special education teachers, and evaluators must be trained not only on the evaluation system itself but also on the specific characteristics regarding special education practices (CEC, 2012). In addition, according to Holdheide et al. (2010), measures of teacher effectiveness become more credible when the teachers who are being evaluated see the individual in charge of their evaluation as a credible evaluator. Moreover, addressing the evaluation of special education teachers in particular, Holdheide et al. suggested that the credibility of the evaluator and the validity of the evaluation can be increased if peer-to-peer observations or evaluators are matched to specific academic disciplines. 
Credibility also was addressed by Daly (2012), who, in a literature review regarding data use and social network theory, referred to five studies that found that collaboration could not take place unless credibility was present among collaborators. In addition, citing five other studies, Daly stated that credibility led to trust and reciprocity among collaborators, which, in turn, allowed educators to be vulnerable with one another in order to evaluate their own instructional practice.

Peer Assistance and Review seems to have the potential to address the following three stances: (a) the importance of credibility in the evaluation of teacher effectiveness (Holdheide et al., 2010), (b) the significance of credibility as a condition for collaboration among educators (Daly, 2012), and (c) the need for evaluators of teacher effectiveness to be versed in special education practices (CEC, 2012). According to Goldstein (2007a) and Johnson and Fiarman (2012), in school districts where PAR is implemented, consulting teachers have the appropriate subject matter expertise to perform evaluations of, and to collaborate with, teachers in a manner that leads to their professional growth and, subsequently, to student learning gains. Furthermore, consulting teachers' level of credibility among participating teachers is high because of the open and rigorous process through which the former are selected (Donaldson et al., 2008; Johnson \& Papay, 2010).

In addition to potentially addressing challenges regarding the credibility and expertise of evaluators and collaborators and how those challenges may negatively impact not only the evaluation of special education teachers but also their professional growth, PAR has the capability of making classroom observations of special education practices more valid. According to Blanton et al. (2006), because of time constraints, evaluators base their evaluation of teacher effectiveness on minute samples of teacher 
performance. However, in districts where PAR programs have been established, consulting teachers are given sufficient time to conduct frequent and thorough teacher observations (Goldstein, 2007a; Johnson \& Fiarman, 2012) and have the ability to provide teachers with timely and meaningful feedback (Johnson \& Papay, 2010; Papay \& Johnson, 2012).

\section{Purpose}

Traditional teacher evaluation systems have failed to show variations in teacher effectiveness. More importantly, traditional teacher evaluation systems have failed to determine teachers' professional development needs and to align evaluation of teacher effectiveness with compensation, retention, and dismissal (Weisberg et al., 2009). Seventy-three percent of the teachers surveyed in the study conducted by Weisberg et al. (2009) indicated that their evaluations did not identify a single area in need of improvement. In addition, only $45 \%$ of those teachers who indicated that their evaluation identified an area in need of improvement stated that they were provided with some kind of assistance.

The relationship between traditional teacher evaluation systems and professional development also has been reported as an area of concern by the Measures of Effective Teaching (MET) project, launched by the Bill \& Melinda Gates Foundation (2010) to improve the quality of information regarding teacher effectiveness and to establish teaching practices that positively affect student learning - an issue of critical importance for students with disabilities, who, as a group, exhibit low performance on school achievement tests (Jones et al., 2013). After reviewing videotaped classroom observations, analyses of student assessment data, tests of pedagogical content 
knowledge, and student surveys of more than 3,000 general education teacher volunteers from several states, researchers from several organizations associated with the MET project (i.e., Dartmouth College, Harvard University, Stanford University, University of Chicago, University of Michigan, University of Virginia, University of Washington, Educational Testing Service, RAND Corporation, the National Math and Science Initiative, the New Teacher Center, Cambridge Education, Teachscape, Westat, and the Danielson Group) concluded that the teachers participating in the project were not provided with meaningful feedback to help them improve. On the basis of its findings, the MET project determined that school districts that do not use their teacher evaluation systems to support the professional growth and development of their educators fail to achieve their true potential.

Addressing how teacher evaluation systems evaluate the performance of special education teachers in particular, Burdette (2011a), after analyzing the survey responses received from administrators responsible for the implementation of the Individuals with Disabilities Education Act (IDEA) in 30 states, arrived at findings similar to those found by the MET project (Bill \& Melinda Gates Foundation, 2010). According to Burdette (2011a), the teacher evaluation system in the thirty participating states, for the most part, had been binary, classifying special education teachers' effectiveness as either satisfactory or unsatisfactory, thus failing to provide special educators with feedback that could assist them in improving their educational practice, and, thus, the achievement of students with disabilities.

Peer Assistance and Review, grounded in social network theory, is regarded by many as a viable option to compensate for the disadvantages of traditional teacher 
evaluation systems (e.g., Donaldson et al., 2008; Humphrey et al., 2011; Johnson \& Fiarman, 2012; Johnson \& Papay, 2010; Papay \& Johnson, 2012). The perspective is a result of a system such as PAR to provide frequent and meaningful observations (Goldstein, 2007a; Johnson \& Fiarman, 2012), adequate feedback (Godstein, 2007a; Johnson \& Fiarman, 2012), and continuous assistance in the areas in which teachers need to improve (Johnson \& Fiarman, 2012). The perspective also is a consequence of a system such as PAR to increase the retention of good teachers and the quality of instruction in the districts where it is implemented because of the amount of collaboration that exists between the program's participating and consulting teachers (Johnson, Papay, Fiarman, Munger, \& Qazilbash, 2010). Additionally, the open and rigorous process through which consulting teachers are selected brings credibility to the collaborative relationships between PAR consulting and participating teachers (Donaldson et al., 2008; Johnson \& Papay, 2010). Furthermore, the teacher perspective that is brought into the teacher evaluation system by consulting teachers elevates the credibility of teacher evaluation systems as a whole (Johnson \& Fiarman, 2012). Finally, the findings regarding the credibility that PAR brings to collaborative relationships and to teacher evaluation systems concur with the conclusion of six studies reviewed by Daly (2012), which found that relationships that promote credibility are essential for educators to examine instructional practices in a mutual and rigorous manner.

\section{Problem}

The present study will examine and compare how special and general education teachers in a large urban school district in the Southeast region of the United States rate their participation in a PAR program. Furthermore, the current study will investigate how 
special education teachers describe their experiences as a participating teacher in a PAR program.

\section{Research Questions}

1. How do special education teachers and general education teachers rate the extent to which their participation in a PAR program impacts their teaching?

a. Are there differences in how special education teachers and general education teachers rate the extent to which their participation in a PAR program impacts their teaching in targeted areas (i.e., knowledge of learners, instructional planning, instructional delivery and engagement, assessment of learners, communication, learning environment, and overall professionalism)?

b. Are there differences in how special education teachers and general education teachers rate the evaluative feedback and professional development opportunities offered to them during their participation in a PAR program?

2. Is there a statistically significant difference between the manner in which special education teachers and general education teachers rate the extent to which their participation in a PAR program impacts their teaching in targeted areas?

3. How do special education teachers describe their experiences as a participating teacher in a PAR program? 


\section{Definition of Terms}

The current section provides definitions of terms used in the present study. The definitions include explanations of terms and acronyms used in the field of education. Consulting Teacher. Teachers selected through an open and rigorous process who are released from classroom duties in order to mentor new and provide intervention to seasoned teachers participating in a PAR program. Consulting teachers also are responsible, in part, for the summative evaluation of the new teachers they mentor and the seasoned ones to whom they provide intervention (Goldstein, 2004).

Participating Teacher. New and seasoned teachers participating in a PAR program who receive mentoring from a consulting teacher and whose summative evaluation, in part, is conducted by a consulting teacher (Goldstein, 2004).

Peer Assistance and Review (PAR). Initiative in which a teacher selected through and open and rigorous process (consulting teacher) provides mentoring, feedback, and embedded professional development opportunities to teachers (participating teachers) for whose summative evaluation they are partially responsible (Goldstein, 2004).

Peer Assistance and Review (PAR) Panel. Panel composed of consulting teachers and administrators who meet regularly to discuss practice challenges and the mentoring and assessing of teachers participating in PAR programs (Goldstein, 2009). 


\section{CHAPTER II}

\section{LITERATURE REVIEW}

In the current chapter, the researcher reviews the existing literature on peer-topeer evaluation of teachers, with a focus on Peer Assistance and Review (PAR), its grounding in social network theory, and its use with both general and special education teachers. The researcher begins by addressing studies that focus on the importance of collaboration and trust in the social relationship patterns that exist between members of a social network. Then, the researcher summarizes studies that focus on the collaboration existent between consulting and participating teachers in PAR and on how the quality of such collaboration ultimately affects teachers' professional growth and student achievement. Next, the researcher addresses studies that concentrate on the challenges faced by traditional methods of evaluating the effectiveness of general as well as special education teachers. In addition, the researcher reviews studies that refer to PAR as a potential solution for such challenges as the inability of traditional teacher evaluation systems to (a) provide multiple and thorough classroom observations conducted by expert individuals, (b) align teacher performance evaluation to professional development, and (c) provide teachers with meaningful feedback. Finally, the researcher synthesizes the connections made among the various groups of literature reviewed.

\section{Social Network Theory and Peer Assistance and Review}

In his review of the literature concerning social network theory, Daly (2012) cites five studies conducted at elementary schools that concluded that, by making mutual relationships possible, collaboration facilitates the exchange of knowledge and best practices between educators, which ultimately leads to gains in student achievement. Peer 
Assistance and Review studies also indicate that the collaboration that exists between consulting and participating teachers is beneficial to the instructional practice of participating teachers and to the academic achievement of their students (Goldstein, 2007b; Humphrey, Koppich, Bland, \& Bosetti, 2011; Johnson et al., 2010; van Lier, 2008).

Daly (2012), however, cites five other studies to caution that, unless collaboration is filled with trust, it is likely that the knowledge and best practices held by one of the members of the collaborative dyad will not be incorporated into the professional practice of the other. Peer Assistance and Review studies also indicate that trust is a significant prerequisite for the collaboration between consulting and participating teachers to succeed in promoting professional growth and in generating increase in student achievement (Goldstein, 2005; Johnson et al., 2010; Yusko \& Feiman-Nemser, 2008).

\section{Collaboration Toward Improvement in Professional Practice and Student}

\section{Achievement}

According to Daly (2012), collaboration facilitates conversations that lead to the exchange of knowledge and best practices. Moreover, Daly cites five studies whose findings indicate that, when collaboration happens in an environment that is supportive, open, and filled with trust, teachers tend to discuss more intricate topics, to take risks, and to be innovative. Furthermore, a substantial number of studies reviewed by Daly found that these types of collaboration not only contributed to the professional development of the individuals involved in the collaborative process but also led to student gains on achievement tests. 
A study that was not part of the review conducted by Daly (2012), but that also indicated that collaboration was beneficial to student achievement and to the professional development of the individuals involved in the collaborative process, is one that Johnson et al. (2010) carried out in seven school districts across the country currently using PAR as part of their teacher performance evaluation system. Johnson et al. found in their research that the success of PAR lies on the program's collaborative intent, on the fact that it uses teaching practice standards, and on the rigorous and transparent process through which the program selects its consulting teachers, making them trusted and respected by their participating counterparts. By visiting seven school districts and reviewing the districts' local policies, Johnson et al. sought to expand, in a qualitative manner, what is known about PAR. In order to do so, Johnson et al. interviewed 25 to 30 individuals and stakeholders from each one of the seven districts participating in the study, including the districts' superintendent or assistant superintendent, the president of the local teachers' union, other district and union representatives, consulting teachers, and district as well as school administrators.

On the basis of the interviews conducted, Johnson et al. (2010) concluded that PAR, because of the amount of collaboration that exists between the program's participating and consulting teachers, typically increases the retention of good teachers and the quality of instruction in the districts where it is implemented. In addition, Johnson et al. found that PAR increases the rate of dismissal of ineffective teachers, which is a consequence of the collaboration that exists among union representatives, district administrators, and consulting teachers. Together, union representatives, district administrators, and consulting teachers make decisions regarding not only how to support 
and evaluate teachers but also how to determine when to let go of those who are ineffective. Furthermore, Johnson et al. pointed out that PAR enhances the quality of tenure decisions because the program ensures that teacher performance evaluations use solid teaching standards and focus on assisting teachers in improving upon their instructional practice. Finally, Johnson et al. indicated that PAR, by having consulting teachers be responsible for evaluating their participating counterparts, makes the job of school administrators more feasible, facilitates the development of teacher leaders, and creates a culture that is devoted to improvement in instructional practices and student achievement. Nevertheless, Johnson et al. also concluded that all seven PAR programs studied showed a substantial amount of potential but that none had completely realized the extent of that potential. Johnson et al. explained that even though the rate of dismissal of ineffective teachers in the districts studied was higher than the one of districts not implementing PAR, it was still small because administrators were reluctant to refer ineffective teachers to the program. Furthermore, some of the districts participating in the study could not find the resources to support all teachers, and some others assigned their consulting teachers a caseload that was so large that they made it impossible for those teachers to provide their participating counterparts with the support they needed.

A study conducted by Humphrey, Koppich, Bland, and Bosetti (2011) in the school districts of Poway and San Juan in California - where PAR programs were being implemented - also indicated that collaboration increased student achievement and was beneficial to the professional development of collaborating teachers. The investigation carried out by Humphrey et al. (2011) revolved around (a) the ability of PAR programs to increase and, at the same time, evaluate the effectiveness of teachers, (b) the types of 
contributions that PAR programs can make to the professional development of teachers and to the teaching culture in general, and (c) the types of contributions that PAR programs can make to labor-management relationships. In order to answer these questions, Humphrey et al. (a) conducted a meeting and preliminary phone interviews with district and union members to review the history of the program in both districts, (b) examined existing documentation, (c) randomly selected redacted files of teachers who had participated in the programs and analyzed those files in a qualitative as well as quantitative manner, (d) interviewed union and district leaders as well as individuals serving as consulting teachers, (e) conducted on-site interviews and focus groups with an array of program participants using semi-structured interview protocols, and (f) observed consulting teachers providing assistance to their participating counterparts as well as conducting reviews of their instructional practice and attended follow-up conferences between the two members of the collaborative dyad.

Using the findings of their investigation, Humphrey et al. (2011) arrived at several conclusions. Regarding the degree with which PAR programs can simultaneously increase and evaluate teacher effectiveness, Humphrey et al. concluded that peer collaboration not only can, but also should, be implemented in conjunction with peer evaluation. Humphrey et al. explained that implementing both simultaneously rather than separately can more effectively improve instructional practices and, consequently, enhance student achievement. Concerning the contributions that PAR programs make to the teaching culture and professional development, Humphrey et al. found that, in PAR, consulting teachers not only provided an adequate amount of teacher assistance but also conducted performance evaluations that were far more rigorous and comprehensive than 
those performed by school administrators. Finally, in relation to the improvement that PAR programs can bring to labor-management relationships, Humphrey et al. concluded that the panel of individuals responsible for governing the program in the districts (e.g., union representatives, district and school administrators, consulting teachers) increased the collaboration between the districts and the teacher unions. The increased collaboration existed because PAR panels (a) focused on improving instruction, (b) made certain that the evaluation of participating teachers was evidence-based, and (c) served as a forum at which routine issues could be discussed and solved.

The conclusion that the collaboration between consulting and participating teachers increases instruction quality and enhances student achievement in districts where PAR programs are implemented is also supported by the findings of the study conducted by van Lier (2008). With the intention of showcasing the benefits of PAR to policymakers and other stakeholders, van Lier conducted an inquiry concerning the implementation of PAR programs in four school districts in Ohio: Brunswick, Cincinnati, Columbus, and Toledo. Data provided by the four districts were analyzed via a qualitative approach and summarized in a descriptive manner. In the four districts investigated, all first-year teachers participated in PAR, and administrators referred nonfirst-year teachers into PAR as a consequence of their performance. The four districts' consulting teachers assisted participating teachers through a process of collaboration and reviewed their performances by conducting lengthy and in-depth observations of their instructional practice. Between six and eight percent of first-year teachers participating in the program left their districts voluntarily or were dismissed at the end of their participation. In addition, the number of participating non-first-year teachers ranged from 
one to five percent of all veteran teachers in the district and, according to data supplied by two of the school districts participating in the study, a significant number of them left teaching voluntarily while participating in PAR or were dismissed at the end of their participation in the program. Because PAR not only facilitated the dismissal and voluntary leave of underperforming teachers but also promoted the continuous collaboration between consulting teachers and the participating teachers who stayed in the program, van Lier concluded that PAR has the potential to improve teacher effectiveness and, consequently, enhance student achievement.

\section{Trust as a Means to Exchange Knowledge and Best Practices}

In his review of the literature concerning social network theory, Daly (2012) lists a series of studies that found that trust is fundamental in the exchange of knowledge and best practices among educators and, therefore, is an essential component of social network theory. Furthermore, Daly reviewed five studies that concluded that trust is, in fact, the basis upon which true collaboration is built (Daly, 2012).

The notion that trust is an essential element of true collaboration is supported by the findings of a longitudinal study conducted by Goldstein (2005) in an urban school district in California where PAR was being implemented. The objective of Goldstein's study was to determine whether or not formative and summative assessments could be successfully combined. To reach the desired objective, Goldstein investigated (a) whether or not participating teachers trusted the consulting teachers who were responsible for both their formative and summative assessments and (b) whether or not there was a difference between the participating teachers who trusted their consulting teachers and the participating teachers who did not. In order to conduct her investigation, Goldstein 
employed a mixed-methods approach that combined a survey and follow-up interviews. In the first year, ten consulting teachers and 88 participating teachers participated in the study. During the second year, the number of participants increased to 12 consulting teachers and 139 participating teachers. Twenty-eight individuals completed the survey, and their answers were analyzed via multiple regression, analysis of variance, and multivariate analysis of variance. Out of the 28 respondents, 15 were selected for a follow-up interview (all of them participating teachers). Goldstein concluded that most teachers, regardless of whether their performance had been rated high or low, reported a high degree of trust among the consulting teachers responsible for both their formative and summative assessments. In addition, Goldstein stated that the purpose of teacher evaluation is to improve instruction quality and that all teachers who reported not trusting their consulting teachers had been rated low in their performance and, most likely, would not have improved the quality of their instruction either way. Furthermore, Goldstein found that trust was a predictive factor of the level of support that participating teachers reported having received from their consulting counterparts, which in turn was the only variable found to be statistically significant in determining the likelihood that participating teachers would remain in the teaching profession. These findings led Goldstein to conclude that if the professional development and level of support provided were strong, they compensated for the potential negative effects of combining formative and summative assessments.

Yusko and Feiman-Nemser (2008) also stated that the presence of trust is necessary in order for healthy collaborations to take place. With the goal of determining whether or not teacher collaboration and teacher assessment can coexist and whether or 
not such coexistence interferes with the credibility of teacher performance evaluation systems, Yusko and Feiman-Nemser conducted a PAR study in two school districts (Cincinnati and Santa Cruz) where consulting teachers were responsible for both collaborating with and assessing their participating counterparts. In order to achieve the objective of their investigation, Yusko and Feiman-Nemser employed a qualitative case study design, with multiple layers of data collection. The first layer of data collection included interviews with program stakeholders, analysis of program documentation, and observations of PAR panel meetings and consulting teachers training. The second layer regarded the implementation of the program and involved the observation of consulting teachers working with their participating counterparts in the classroom. The third and final layer involved the analysis of documentation provided by each consulting teacher participating in the study, which included documentation of their work with one successful and one struggling participating teacher for a period of a year and a half. A comparative analysis of the data collected revealed that teacher collaboration and teacher assessment can coexist and that it does not prevent consulting teachers from establishing trustworthy relationships with their participating counterparts. However, the analysis also reviewed that, at times, such coexistence can make the establishment of trustworthy relationships more challenging. In addition, Yusko and Feiman-Nemser concluded that the coexistence of teacher collaboration and teacher assessment can be most effective when consulting teachers (a) assist and assess their participating counterparts using structured and appropriate frameworks and processes, (b) base their decisions on professional teaching standards and have those decisions validated by members of the PAR panel, and (c) are trained and further their training by continuously participating in 
ongoing professional development activities to fulfill their duties. Finally, Yusko and Feiman-Nemser reported that the consulting teachers involved in the program had ample professional expertise and were selected through a rigorous process that not only earned them respect and trust but also added credibility to the teacher performance evaluation system of the districts under investigation.

\section{Evaluation of Teacher Effectiveness and Peer Assistance and Review}

Successful teacher performance evaluation systems are those that implement multiple and thorough classroom observations conducted by expert individuals (DarlingHammond, Amrein-Beardsley, Haertel, \& Rothstein, 2012). Because of administrators' lack of time, however, most classroom observations are not only short but also infrequent (Weisberg et al., 2009). Short classroom observations, in turn, only reflect a small sample of an observed teacher's performance (Blanton et al., 2006; Jones et al., 2013).

Successful teacher performance evaluation systems also align teacher performance evaluation to professional development, thus supporting the professional growth and development of their educators. Traditional models of teacher performance evaluation (e.g., licensing evaluation scores, type of certification, National Board certification, classroom observation, professional development history), however, have failed to determine the professional development needs of teachers (Weisberg et al., 2009) and to improve teachers' instructional practice (Burdette, 2011a).

Peer Assistance and Review, grounded in social network theory, is regarded by many as a potential alternative to counteract the disadvantages of traditional teacher evaluation systems (e.g. Donaldson et al., 2008; Humphrey et al., 2011; Johnson \& Fiarman, 2012; Johnson \& Papay, 2010; Papay \& Johnson, 2012). That potential is 
related to the fact that PAR offers multiple and thorough observations (Goldstein, 2007a; Johnson \& Fiarman, 2012), meaningful feedback (Goldstein, 2007a; Johnson \& Fiarman, 2012), and continuous support in the areas in which teachers need to improve (Johnson \& Fiarman, 2012).

Peer Assistance and Review also is believed to have the potential to increase the credibility of performance evaluation systems as a whole (Weisberg et al., 2009). Weisberg et al. (2009) conducted a study in 12 educational districts across four states (Arkansas, Colorado, Illinois, and Ohio) to investigate the failure of the American public education system to recognize and address variations in teacher effectiveness. On the basis of the survey responses of approximately 15,000 teachers and 1,300 administrators and on the insight of approximately 80 educational stakeholders (e.g., local and state education representatives, leaders of teachers unions, policymakers, advocates), Weisberg et al. reported that (a) beginner teachers received no special attention, (b) $99 \%$ of the teachers were rated "satisfactory" in districts with binary evaluation ratings ("satisfactory" or "unsatisfactory"), and (c) $59 \%$ of the teachers and $63 \%$ of the administrators indicated that their systems did not do enough to identify and recognize highly effective teachers. Furthermore, Weisberg et al. concluded that the inability to recognize variations in teacher effectiveness prevented school districts from identifying specific areas in which their teachers would benefit from professional development. Weisberg et al. also found that poor performance was not addressed - not a single nonprobationary teacher was dismissed as a consequence of poor performance in at least half of the districts investigated. According to Weisberg et al., in order to correct the aforementioned flaws in the country's current teacher evaluation paradigm, educational 
districts should (a) adopt a comprehensive teacher evaluation system, capable of recognizing - in a manner that is fair, accurate, and credible - variations in teacher effectiveness in advancing student achievement; (b) train administrators and other evaluators in evaluating teacher effectiveness and hold them accountable for that evaluation; (c) align teacher evaluation with professional development; and (d) align evaluation of teacher effectiveness with compensation, retention, and dismissal.

Addressing PAR in particular, Weisberg et al. stated that peer evaluators can be used to monitor administrator judgments on a regular basis, which would ultimately increase the credibility of performance evaluation systems as a whole.

\section{Peer Assistance and Review as a Potential Alternative to Counteract the Disadvantages of Traditional Teacher Evaluation Systems}

Goldstein (2004) conducted a study to determine how teachers and principals of an urban school district in California (100 schools; 3,000 teachers; ethnically and economically diverse) perceived the implementation of the PAR program in their school district. An additional purpose of Goldstein's study was to establish whether or not leadership responsibility for teacher evaluation was being shared in the district as a result of the PAR implementation. To achieve these objectives, Goldstein investigated (a) whether or not stakeholders perceived the role of an educator as an evaluator of other educators, (b) whether or not the leadership responsibility for teacher evaluation was being shared and, if it was being share, how it was being shared, and (c) whether or not shared leadership had an effect on the school district.

Over the course of a year and a half, Goldstein (2004) conducted an embedded single-case qualitative design study that included observations of meetings, interviews 
and semi-structured interviews, and a multi-wave survey approach. Nine PAR panel members and 10 consulting teachers participated in the study, and three out of the 10 participating teachers were selected, because of their gender, ethnicity, and experience, to participate in in-depth data collection. During the course of the study, the 10 consulting teachers assisted and evaluated 88 new teachers and three struggling seasoned teachers across 28 schools. Out of the 88 new teachers, 11 were dismissed from the system. In addition, all three struggling seasoned teachers left the classroom voluntarily.

Goldstein (2004) concluded that PAR panel members, principals, and consulting teachers held different perspectives concerning the role of an educator as an evaluator of other educators. Principals, for instance, were the ones less likely to see consulting teachers as the individuals responsible for the evaluation of other teachers. Nevertheless, all stakeholders perceived the collaboration that PAR promoted between principals and consulting teachers as well as between consulting and participating teachers as being beneficial to the school district as a whole. Moreover, Goldstein found that consulting teachers became the individuals solely responsible for evaluating their participating counterparts and for recommending whether or not participating teachers should remain employed or be dismissed from the school district. Nevertheless, even though the PAR panel approved all recommendations made by the consulting teachers, these teachers were reluctant to accept the responsibility of determining the future employment of their participating counterparts. Furthermore, Goldstein determined that, even though most stakeholders affirmed that they would prefer to share their leadership instead of dividing it, the leadership in the school district remained divided. For instance, principals - who had reported not having the needed time to conduct thorough classroom observations - 
found it challenging to relinquish their authority as evaluators to consulting teachers. Finally, the data collected by Goldstein indicated that PAR not only enhanced teacher performance accountability but also increased teacher quality.

Continuing to analyze the data collected in 2004, Goldstein (2007b) sought to determine (a) whether or not leadership could be distributed in order to enhance teacher evaluation and, ultimately, teacher performance and (b) how administrators and consulting teachers could share the responsibility of evaluating the effectiveness of teachers participating in the PAR program. In order to answer those questions, Goldstein used the data collected during a single-case qualitative design investigation, including observations of meetings, surveys, and interviews as well as semi-structured interviews. A total of 19 individuals participated in the study: nine of them were PAR panel members, and the other 10 were consulting teachers. Goldstein found that PAR, by relying on the professional authority of both consulting teachers and administrators to evaluate participating teachers, created multiple opportunities for collaboration between the individuals with direct participation in the implementation of the program in the district. Those collaborations, in turn, made the teacher evaluation process in the district more democratic as well as increased the teachers' level of trust in the district's teacher evaluation system as a whole. Finally, Goldstein found that the collaborations facilitated by PAR not only increased teacher quality but also elevated teacher performance accountability, as evidenced by the data related to student performance on achievement tests.

In a similar study, Goldstein (2007a) inquired about how the following five components differed in the manner in which they are available in traditional teacher 
evaluation systems versus the way in which they are presented in PAR: (a) time available for observations of instructional practice, (b) alignment of professional development to teacher evaluations, (c) transparency of the teacher evaluation process, (d) labor relations in regards to teacher evaluations and the consequences of such evaluations, and (e) accountability. Goldstein concluded that in traditional teacher evaluation systems - in which the administrator is the sole individual responsible for evaluations of teacher effectiveness - the time available for observations of instructional practice is considerably lower than that available in PAR. In PAR, consulting teachers are released from their classroom duties to carry out their role of peer assistant and reviewer on a fulltime basis, which affords them enough time to conduct observations that are lengthier and more thorough. Goldstein also found that in PAR, since participating teachers are supported and evaluated by the same consulting teachers, professional development is aligned to teachers' evaluation of effectiveness, which is contrary to what usually happens in traditional teacher evaluation systems. Moreover, Goldstein established that the level of transparency in PAR is higher than that of traditional teacher evaluation systems. In traditional teacher evaluation systems, teachers not only conduct their practice but also have their practice evaluated in isolation. Conversely, in PAR, the reports that consulting teachers write - using their support and evaluation of participating teachers - are shared and discussed with administrators and other members of the PAR panel. Furthermore, Goldstein determined that labor relations - which are traditionally adversarial - improve in PAR, since union representatives are members of the PAR panel and, therefore, involved in the decision-making process concerning the district's teacher evaluation system and its consequences on teacher tenure. Finally, Goldstein found that 
accountability - which is usually low in traditional teacher evaluation systems, almost all teachers are considered to be effective - is high in PAR. Out of the 88 participating teachers who took part in the study, eleven were dismissed (12.5\%).

Further analyzing the data collected in 2004, Goldstein (2009) investigated how the PAR panel operates and what its effects are on teacher evaluation and personnel outcome. In order to carry out the present investigation, Goldstein observed a total of 311 hours of PAR panel meetings and conducted semi-structured interviews with 10 consulting teachers and nine PAR panel members. After coding and analyzing these observations and interviews, Goldstein concluded that PAR panel members (a) make the teacher evaluation process in their school districts more transparent, (b) support consulting teachers in the assistance and evaluation of participating teachers, and (c) hold consulting teachers responsible for holding their participating counterparts accountable for student achievement. According to Goldstein, the close and constant collaboration between PAR panel members and consulting teachers as well as the high level of accountability required of the latter by the former make the teacher evaluation process more rigorous and evidence-based and, consequently, more reliable.

\section{Peer Assistance and Review and the Performance Evaluation of Special Education}

\section{Teachers}

Concerning special education in particular, teacher performance evaluations should be conducted by evaluators trained to recognize and base their evaluation on the specific role(s) played by special education teachers (CEC, 2012; Sledge \& Pazey, 2013). Nevertheless, school administrators do not have the necessary expertise to evaluate teacher effectiveness as it relates to the education of students with disabilities (Blanton et 
al., 2006; Jones et al., 2013; Sledge \& Pazey, 2013), which decreases the reliability of the performance evaluation of special education teachers (Jones et al., 2013; Sledge \& Pazey, 2013) and prevents the use of data collected during classroom observations to create jobembedded professional development activities that address the specific needs of the teacher being observed (Holdeheide et al., 2010).

The National Comprehensive Center for Teacher Quality, in association with CEC, conducted a survey of more than 1,100 state and district directors of special education and interviewed several administrators with the purpose of (a) defining the challenges associated with the evaluation of special education teachers and (b) identifying promising practices to evaluate members of this category of educators (Holdeheide et al., 2010). The survey responses and interviews indicated that more than half of the districts developed their own teacher performance evaluation system and that an additional third of the districts adopted the state's teacher performance evaluation system with adaptations. Addressing the performance evaluation of special education teachers specifically, almost half of the respondents indicated that they did not think that special education teachers should be evaluated in the same manner as their general education peers. The respondents pointed out, however, that the process of evaluating special education teachers could not be modified because of contractual agreements. According to Holdeheide et al. (2010), one of the reasons why the performance evaluation of special education teachers should be conducted in a manner different from that in which the performance evaluation of general education teachers is conducted is the lack of expertise that administrators - who historically have been responsible for the evaluation of all teachers - have in the area of special education, which decreases the 
integrity and validity of the evaluative process. In addition to lack of expertise, Holdeheide et al. cited administrators' lack of time to conduct thorough evaluations as being detrimental to the performance evaluation of special education teachers. As a solution to these two specific concerns, Holdeheide et al., citing the PAR model used in Toledo, Ohio, suggested that special education teachers should conduct peer-to-peer observations and evaluations of other special education teachers. According to Holdeheide et al., the peer-to-peer evaluation model would not only solve the issues concerning administrators' lack of time and expertise to conduct meaningful evaluation of special education teachers but also increase the amount and significance of the potential feedback and support that special education teachers might receive as a result of their performance evaluation. Holdeheide et al. concluded that the meaningful evaluation and feedback that would be made possible by PAR would be reflected in student achievement gains.

Papay and Johnson (2012) also support the use of peer-to-peer evaluation as a means to provide teachers with meaningful feedback and support. With the goal of assessing the financial and organizational costs and benefits of PAR, Papay and Johnson carried out an investigation in seven school districts where the program was being implemented (Toledo and Cincinnati, OH; Rochester and Syracuse, NY; Minneapolis, MN; San Juan, CA; and Montgomery, MD). Twenty-five individuals - in favor and against PAR - in each district were interviewed during visits that lasted between two and three days. Individuals who participated in the study included union and district representatives, district and school administrators, consulting teachers, and PAR panel members. A semi-structured interview protocol, devised for the particular role and site of 
every study participant, was used with each individual being interviewed. In addition, these interviews were supplemented with reviews of relevant documents. On the basis of their findings, Papay and Johnson concluded that PAR is an expensive program. However, in the long run, by having consulting teachers evaluate and provide participating teachers with meaningful feedback and support, PAR can not only save school districts' money by preventing high levels of teacher turnover but also increase student achievement. An additional benefit of PAR found by Papay and Johnson was the improvement in teacher-administration as well as labor-management relationships, which came as a result of the collaborative processes existent among all parties involved in the implementation of the program.

An additional study whose findings show that PAR can be used to provide meaningful feedback and support and, ultimately, enhance student gains in achievement tests was the one conducted by Koppich (2004) in a school district of Maryland. Koppich's objective was to investigate the multilevel collaboration facilitated by the implementation of PAR in Montgomery County Public Schools. In order to do so, Koppich reviewed several documents regarding the implementation of the program in that district. Koppich also conducted individual as well as group interviews (focus groups) with all members of the PAR panel, with nearly all consulting teachers, with approximately 12 participating teachers and 20 school administrators, and with current and past presidents of educational associations in the district. In addition, in order to corroborate information, Koppich conducted a survey, completed by teachers and school administrators, whose questions mirrored those they had been asked during the interview phase of the study. Furthermore, Koppich used statistical data from districts in which 
PAR programs had been implemented for a considerable amount of time (Cincinnati, Columbus, and Toledo, OH; Poway, CA; and Rochester, NY) as points of comparison. Koppich found that, in Montgomery County Public Schools, PAR is used to support those teachers at risk for losing their job because of the below-average performance of their students on achievement tests as well as those teachers new to the system. In the case of new teachers, Koppich established that PAR also served as a way to induct them into the profession. In addition, Koppich found that student achievement gains had improved in Montgomery County Public Schools because of the implementation of PAR in the district. According to Koppich, that improvement is a consequence of the meaningful feedback and support that participating teachers received from consulting teachers, who were valued for their professionalism and expertise by administrators and by new and seasoned teachers alike. Koppich stated, however, that the improvement in student achievement gains also is a consequence of the increase in the number of underperforming participating teachers who have been let go and who voluntarily have left the system since the implementation of the program in the district. Finally, Koppich concluded that PAR (a) enhanced the credibility of the performance evaluation system in Montgomery County Public Schools (PAR Panel members constantly monitored the evaluation process to ensure that it used evidence-based data, thus making it more objective and less arbitrary) and (b) contributed to professional collaboration not only on the individual but also on the institutional level.

\section{Summary}

Traditional teacher evaluation systems have not been able to predict future teacher performance (Glazerman et al., 2010), to recognize variations in teacher effectiveness 
(Weisberg et al., 2009), to align teacher performance evaluation to professional development, and to provide teachers with the necessary feedback for them to grow in their instructional practice (Burdette, 2011a; Weisberg et al., 2009). As a result, the Obama administration, through Race to the Top, required that teacher evaluation systems significantly base their determination of teacher effectiveness on teachers' value-added to student achievement on standardized assessments (U.S. Department of Education, 2010). Value-added models, however, have faced considerable criticism because (a) students are not assigned to teachers at random, and teachers' value-added cannot be isolated from socio-economic factors (Darling-Hammond et al., 2012); (b) they can only be applied to teachers of grades in, and of subjects on, which students are tested (Corcoran, 2010; Weisberg et al., 2009); and (c) they can lead teachers to "teach to the test" (Corcoran, 2010).

In addition to value-added models, classroom observations are another leading measure of teacher effectiveness (Jones et al., 2013). While value-added models might be able to determine groups of teachers who have contributed to student achievement, classroom observations have the potential to provide reliable reflections of teachers' instructional practice. Typical classroom observations, however, are short and infrequent (Weisberg et al., 2009), are not standardized and reflect a small sample of a teacher's performance (Blanton et al., 2006; Jones et al., 2013), and, particularly in the case of special education teachers, are conducted by individuals who do not have the necessary expertise to evaluate teacher effectiveness as it relates to the education of students with disabilities (Blanton et al., 2006; Jones et al., 2013; Sledge \& Pazey, 2013). 
Peer Assistance and Review, grounded in social network theory, is regarded by many as a potential alternative to counteract the disadvantages of traditional teacher performance evaluation systems. In PAR, the collaboration that exists between consulting and participating teachers is beneficial to student achievement as well as to the professional development of the individuals involved in the collaborative process (Humphrey et al., 2011; Johnson et al., 2010; van Lier, 2008). Furthermore, the quality of such collaboration, such as the level of trust between members of the collaborative dyad, has been proven to improve instruction quality and to increase the likelihood that participating teachers will remain in the teaching profession (Goldstein, 2005) as well as to enhance the credibility of performance evaluation systems as a whole (Yusko \& Feiman-Nemser, 2008).

Peer Assistance and Review also has been found successful in (a) enhancing teacher performance accountability and teacher quality (Goldstein, 2004, 2007b), (b) supplying teachers with continuous assistance in the areas teachers need to improve (Johnson \& Fiarman, 2012), (c) aligning professional development to teacher evaluations (Goldstein, 2007a), and (d) making the teacher evaluation process more rigorous, evidence-based, and reliable (Goldstein, 2009). In addition, PAR has been found effective in (a) performing frequent and thorough observations conducted by individuals with the necessary subject expertise (Goldstein, 2007a; Holdeheide et al., 2010; Johnson \& Fiarman, 2012) and (b) providing teachers with adequate and meaningful feedback (Goldstein, 2007a; Johnson \& Fiarman, 2012; Koppich, 2004; Papay \& Johnson, 2012) areas of particular concern in the performance evaluation of special education teachers. 
Studies that examine and compare how general and special education teachers rate the effects of their participation in a PAR program on specific areas of their teaching area limited. Also restricted are studies that address how special education teachers describe their experience as participating teachers in a PAR program. The present study intends to contribute to the body of literature available on PAR and to begin a discussion addressing the potential that PAR has in solving the specific issues concerning the performance evaluation of special education teachers.

More specifically, the present study will (a) examine and compare how special and general education teachers in a large urban school district in the Southeast region of the United States rate their participation in a PAR program and (b) investigate how special education teachers describe their experience as participating teachers in a PAR program. The examination, comparison, and investigation will be done via a mixedmethods approach that includes a survey instrument and follow-up interviews. Special and general education participating teachers will complete the survey instrument. As for the follow-up interviews, they will be conducted with a subset of participating teachers randomly selected from a pool of special educators who indicate their willingness to be interviewed when completing the survey instrument. 


\section{CHAPTER III}

\section{METHODS}

In the current chapter, the researcher presents an overview of the methods that were used to examine the present study's research questions. The chapter begins with a review of the research questions and continues with a description of the study's setting, participants, data collection methods, and data analysis procedures. A mixed-methods sequential explanatory design was employed by the researcher to (a) examine and compare how special and general education teachers rated their participation in a PAR program and (b) investigate how special education teachers described their participation in a PAR program. The chapter concludes with a summary of the information discussed.

\section{Research Questions}

In the previous chapter, the researcher used the literature review to establish PAR, grounded in social network theory, as a potential alternative to counteract the disadvantages of traditional teacher performance evaluation systems. The researcher also determined that the collaboration that exists between consulting and participating teachers in PAR is beneficial to student achievement and that the level of trust between members of the collaborative dyad improves instruction quality.

In the present study, the researcher chose to focus on how special education teachers participating in PAR described their experience in the program and rated the impact of that experience on specific areas of their teaching. In order to carry out the investigation, the researcher (a) conducted a survey to examine and compare how special and general education teachers rated their participation in a PAR program and (b) used 
semi-structured interviews to investigate, in depth, how special education teachers described their participation in a PAR program. The specific research questions were

1. How do special education teachers and general education teachers rate the extent to which their participation in a PAR program impacts their teaching?

a. Are there differences in how special education teachers and general education teachers rate the extent to which their participation in a PAR program impacts their teaching in targeted areas (i.e., knowledge of learners, instructional planning, instructional delivery and engagement, assessment of learners, communication, learning environment, and overall professionalism)?

b. Are there differences in how special education teachers and general education teachers rate the evaluative feedback and professional development opportunities offered to them during their participation in a PAR program?

2. Is there a statistically significant difference between the manner in which special education teachers and general education teachers rate the extent to which their participation in a PAR program impacts their teaching in targeted areas?

3. How do special education teachers describe their experiences as a participating teacher in a PAR program?

The present study addressed the abovementioned questions particularly as they relate to special education teachers participating in a PAR program being implemented in a large urban school district in the Southeast region of the United States. 


\section{Research Design}

The researcher used a sequential, mixed-methods design to conduct the present study. In the current section, the researcher will explain the rationale for selecting the research design as well as discuss each of the research design's components.

\section{Rationale for Selecting a Sequential, Mixed-Methods Design}

Symonds and Gorard (2010) formally defined mixed methods research as "a

social science research approach that encourages integration of two major methodological approaches: 'quantitative' and 'qualitative'” (p. 121). According to Sweetman, Badiee, and Creswell (2010), the quantitative phase of a mixed-methods design includes the collection of data that are closed-ended, and the qualitative phase involves the gathering of open-ended data. In the present study, the closed-ended type of data was used to compare how special and general education teachers rated their participation in a PAR program. By contrast, the open-ended type of data was used to investigate how special education teachers described their participation in that program.

In addition to including the collection of data that are both quantitative and qualitative in nature, mixed-methods research is characterized by the integration of those two sets of data by either merging or sequentially connecting them (Sweetman et al., 2010). In the present study, the researcher used the closed-ended data collected during the study's quantitative phase to guide the collection of open-ended data during the study's qualitative phase. According to Sweetman et al. (2010), the type of data integration being used by the researcher characterizes a sequential, mixed-methods design.

The researcher used the data collected during the quantitative phase of the study to select a subsample of the target population to recruit as participants in the qualitative 
phase of the study. Furthermore, the researcher used the survey questions used in the quantitative phase as potential interview questions and probes during the study's qualitative phase. According to Hesse-Biber (2010), by doing so, the researcher has the ability to enhance the validity and reliability of the study's findings.

The researcher selected a mixed-methods design to conduct the proposed study because a quantitative or qualitative approach, used in isolation, would not have been effective in addressing the types of research questions being asked. Furthermore, according to Maxwell (2010), by selecting the aforementioned design, the researcher was able to create "a dialogue between different ways of seeing, interpreting, and knowing" (p. 477), which is the central significance of using mixed-methods research.

\section{Phases of the Study}

In a sequential, mixed-methods design, "one form of data collection (either quantitative or qualitative) [helps] inform the other form of data collection (either quantitative or qualitative)" (Sweetman et al., 2010, p. 446). In the current dissertation study, the results of the preliminary analysis (quantitative phase) were linked to the collection of data in the follow-up procedure (qualitative phase). The set of quantitative data was gathered via the use of a survey instrument that was completed by special and general education teachers participating in a PAR program being implemented in the school district. The specific purpose of the survey instrument was to compare how special and general education teachers rated their participation in a PAR program. By contrast, the set of qualitative data was collected via semi-structured interviews conducted with seven participating special education teachers. The particular intent of the semi-structured 
interviews was to investigate how special education teachers described their participation in the program.

Phase 1: Quantitative. Special education teachers work with a heterogeneous subgroup of students. School administrators, usually in charge of conducting classroom observations, lack the necessary expertise to evaluate teacher effectiveness as it relates to the instruction of those students (Blanton et al., 2006; Jones et al., 2013; Sledge \& Pazey, 2013). Lack of expertise on the part of the observer also affects, in a negative manner, the feedback given by them to special education teachers (Burdette, 2011a). Several scholars perceive PAR as a feasible solution to these disadvantages (e.g., Donaldson et al., 2008; Humphrey, Koppich, Bland, \& Bosetti, 2011; Johnson \& Fiarman, 2012; Johnson \& Papay, 2010; Papay \& Johnson, 2012). The perception stems from the fact that, in PAR, participating teachers are (a) observed frequently and in a meaningful manner (Goldstein, 2007; Johnson \& Fiarman, 2012), (b) given ample feedback (Goldstein, 2007; Johnson \& Fiarman, 2012), and (c) provided with continuous assistance in areas in which improvement is needed (Johnson \& Fiarman, 2012). Investigating how special education teachers and general education teachers rate the extent to which their participation in a PAR program impacts their teaching in targeted areas examines how the perspective of special education teachers participating in the program differs from those of general educators. In addition, it presents education stakeholders with additional information on a program that has the potential to measure teacher effectiveness in a manner that recognizes least and most effective teachers and that links teacher effectiveness to improvement in teacher practices and, consequently, to improvement in student learning, especially as it concerns special education teachers. 
In this phase of the study, the software program, Statistical Program for the Social Sciences (SPSS), was used to analyze statistical data gathered via a survey completed by special and general education teachers participating in a PAR program. The researcher used descriptive statistics to explain, illustrate, and summarize how special education teachers and general education teachers rated the extent to which their participation in a PAR program impacted their teaching. Moreover, the researcher conducted $t$-tests for independent samples in order to determine whether or not a statistically significant difference existed between the manner in which special education teachers and general education teachers rated the extent to which their participation in a PAR program impacted their teaching in targeted areas.

Phase 2: Qualitative. Evaluators of special education teachers must be trained not only on the evaluation system itself but also on the particular characteristics of special education practices (CEC, 2012). Moreover, the credibility of the evaluator and the validity of the evaluation can be improved if peer-to-peer observations or evaluators are matched to particular academic disciplines (Holdheide et al., 2010).

In this phase of the study, qualitative methods were used to examine how special education teachers described the evaluative feedback and professional development opportunities offered to them during their participation in a PAR program. The researcher used semi-structured interviews to gain a detailed account and provide a comprehensive description of the perceptions that special education teachers held of their participation in the program. Since this phase of the study was connected to the results of the study's quantitative phase, the use of semi-structured interviews was considered appropriate in 
order to gather comparable data across subjects and to focus on specific topics of interest (Bogdan \& Biklen, 2007).

\section{Setting}

Data for the current dissertation study were collected from special and general education teachers participating in the first four years of implementation of a PAR program in a large urban school district in the Southeast region of the United States (from school year 2012-2013 to school year 2015-2016). On the basis of the 2010 census, $84.6 \%$ of the school district's population belongs to social minority groups and $21 \%$ of them live in poverty (U. S. Census Bureau, 2015). The district's Student Membership Report, released in October of 2016, indicated that $7.1 \%$ of its students are White of NonHispanic origin, $21 \%$ are Black of Non-Hispanic origin, $70.2 \%$ are Hispanic, and 1.8\% belong to other categories, including American Indian, Asian, and multiracial categories. In addition, the report pointed out that $70.7 \%$ of the school district's student population is eligible for free or reduced price lunch.

Since the 2012-2013 school year, the school district where data for the present dissertation study have been collected has implemented a PAR program in a total of nine schools (two elementary schools, three Kindergarten-Eighth [K-8] centers, two middle schools, and two high-schools). Twenty-seven district-based consulting teachers (three per school) provided continuous support and feedback to those nine schools' participating teachers using informal observations conducted throughout the school year. In addition, the 27 consulting teachers conducted one formal observation of the participating teachers' classroom practice. The formal observation is added to formal observation(s) conducted by the participating teachers' administrator; together they count toward $50 \%$ 
of the participating teachers' summative evaluation. The participating teachers 'students' scores on statewide, standardized assessments determine the other $50 \%$.

\section{Participants}

The participants included special education and general education teachers who participated in a PAR program in the school district. Teachers who joined the program during its fifth year of implementation (2016-2017) were not considered as viable candidates for participation in the present study. In the current section, a description of the participants and of the procedures for selecting them is provided.

\section{Phase 1}

Once the dissertation committee, the Florida International University Institutional Review Board, and the school district's Institutional Review Board approved the present dissertation study's proposal, the researcher obtained a list of all special and general education teachers who participated in the first four years of implementation of a PAR program in the district. All special and general education teachers whose names appeared on that list were targeted for Phase 1 of the study. Those teachers provide instruction to students with and without disabilities in Prekindergarten through $12^{\text {th }}$ grade in two elementary schools, three K-8 centers, two middle schools, and two high-schools. Teachers were contacted via a message sent to their work electronic mail address. That message contained an introduction of the researcher and of the study being proposed as well as a link to the survey instrument.

\section{Phase 2}

According to Bogdan and Biklen (2007) and to Rubin and Rubin (2005), the sample size of a qualitative study is determined by the notion of saturation. The 
saturation point is reached when the data being collected becomes redundant (Bogdan \& Biklen, 2007; Rubin \& Rubin, 2005). According to Guest, Bunce, and Johnson (2006), saturation can take place within 12 interviews and major themes can develop within the first six. In the current dissertation study, the saturation point was reached after seven interviews were conducted.

The interviews conducted by the researcher were semi-structured, and the interview participants were selected via purposeful sampling. The researcher purposefully selected participants who indicated on the survey that, during their participation in the implementation of a PAR program at their schools, their primary teaching responsibility was in special education. The interview approach and sampling technique allowed the researcher to gather in-depth and comparable data from special education teachers participating in a PAR program being implemented in the school district.

\section{Data Collection}

In the current section, the researcher explains how data were collected. First, the researcher details the data collection measures used during Phase 1 of the study (i.e., survey instrument, content validity, internal consistency, pilot test, and administration of the survey). Then, the researcher describes the data collection measures used during Phase 2 of the study (i.e., interview protocol and interview procedures).

\section{Phase 1}

The researcher used a survey instrument to collect data on how special and general education teachers rated (a) the evaluative feedback and professional development opportunities offered to them through their participation in a PAR program and (b) the extent to which their participation in a PAR program impacted their teaching 
in targeted areas. The survey questions focused on the potential benefits that the program had on evaluative feedback, professional development, and teacher improvement. In order to establish the validity of the survey, the researcher had it critiqued by eight expert judges. The researcher also piloted the survey in order to ascertain reliability. Finally, the researcher revised the survey questions to conform to the recommendations made by the expert judges and to the findings of the pilot test.

The survey instrument. The survey instrument consisted of two parts and was used to examine participants' views concerning the potential benefits of PAR on evaluative feedback, professional development, and teacher improvement. The researcher used the first part of the survey to collect demographic data about participating teachers' and their work environment. A copy of the survey instrument found in Appendix A includes the following demographic data: (a) participants' gender, (b) race/ethnicity, (c) school level taught, (d) teaching experience, (e) primary teaching assignment, (f) type of certification, (g) teacher preparation, (h) educational level, and (i) school site grade.

The first part of the survey also included three statements regarding participating teachers' level of satisfaction with the evaluative feedback and professional development opportunities offered to them through their participation in a PAR program. The first statement addressed participating teacher's perception of the impact that their participation in a PAR program had in the following areas of their teaching: (a) knowledge of learners, (b) instructional planning, (c) instructional delivery and engagement, (d) assessment of learners, (e) communication, (f) learning environment, and (g) overall professionalism. These areas were selected using indicators of teacher effectiveness considered to be important in the teacher evaluation literature. For instance, 
the Bill \& Melinda Gates Foundation (2013) indicated that, in addition to student achievement, observations of teachers' classroom practice throughout the year (e.g., instructional planning and delivery, development and maintenance of an environment conducive to learning, knowledge and assessment of learners) are true and reliable indicators of teacher effectiveness. Furthermore, Kane et al. (2011) addressed the importance of including teachers' professional growth and overall professionalism as a measure of their effectiveness.

Focusing on the effectiveness of teachers entering the profession specifically, edTPA (formerly known as the Teacher Performance Assessment) assesses teacher candidates' capacity to plan instruction to help students meet learning standards. Moreover, edTPA evaluates teacher candidates' ability to communicate with and differentiate instruction for diverse learners, including students with disabilities as well as English Language Learners (Stanford Center for Assessment, Learning and Equity, 2013).

Finally, speaking to the evaluation of special education teachers in particular, a position statement issued by the CEC (2012) indicated that the evaluation of special education teachers' effectiveness should include multiple measures. Burdette (2011a), citing states that have addressed the evaluation of special education teachers, provided the following examples of such measures: (a) students' achievement on standardized assessments and students' growth determined by multiple years of standardized assessment scores, (b) assessment of learners on curriculum-based measures, 
(c) classroom observations of special education teachers' overall instructional delivery and professionalism, (d) teacher portfolios, (e) students' progress toward IEP goals, and (f) goal-driven professional development.

The second and third statements addressed participating teachers' level of satisfaction with the evaluative feedback and professional development opportunities offered to them by different professionals (i.e., consulting teacher certified in general education, consulting teacher certified in special education, school administrator) throughout their participation in a PAR program. Goldstein (2007a) indicated that, in PAR, since participating teachers are evaluated by and receive support and feedback from the same consulting teachers, professional development is not only aligned to teachers' evaluation of effectiveness but also job embedded. This is important because successful teacher performance evaluation systems support professional growth and development by aligning teacher performance evaluation to professional development. However, traditional models of teacher performance evaluation have been unsuccessful in determining the professional development needs of teachers (Weisberg et al., 2009) and in advancing teachers' instructional practice (Burdette, 2011a).

A Likert scale with four choices $(1=$ Unsatisfied, 2 = Somewhat Satisfied, $3=$ Satisfied, 4 = Very Satisfied) was chosen to measure the respondents' level of satisfaction with the evaluative feedback and professional development opportunities offered to them during their participation in a PAR program. The researcher chose a total of four choices for the scale in order to give respondents the ability to express their level of satisfaction on a continuum going from unsatisfied to very satisfied. A list of statements concerning participating teachers' level of satisfaction is found in Table 1. 
Table 1

Statements Regarding Participating Teachers' Level of Satisfaction with Their

Participation in a PAR Program

1. For the following survey items, please consider your overall feeling of satisfaction with the impact that your participation in the PAR program had on each one of the specified areas of your teaching: (a) knowledge of learners, (b) instructional planning, (c) instructional delivery and engagement, (d) assessment of learners, (e) communication, (f) learning environment, (g) overall professionalism.

2. For the following survey items, please consider your overall feeling of satisfaction with the feedback you received from each one of the specified professionals during your participation in the PAR program: (a) PAR consulting teacher(s), (b) PAR consulting teacher(s) (certified in general education), (c) PAR consulting teacher(s) (certified in special education), and (d) school administrator(s).

3. For the following survey items, please consider your overall feeling of satisfaction with the job embedded professional development opportunities you received from each one of the specified professionals during your participation in the PAR program: (a) PAR consulting teacher(s), (b) PAR consulting teacher(s) (certified in general education), (c) PAR consulting teacher(s) (certified in special education), and (d) school administrator(s).

The researcher used the second part of the survey instrument to examine the impact of PAR on participating teachers' teaching in targeted areas. In this part of the survey, seven sections addressed the following teaching areas: (a) knowledge of learners, (b) instructional planning, (c) instructional delivery and engagement, (d) assessment of learners, (e) communication, (f) learning environment, and (g) overall professionalism. These sections included items that were identified in the literature and on the school district's observation tool used for the evaluation of teachers as essential components of each one of the aforementioned teaching targeted areas. Participating teachers were asked to rate the impact that PAR had on those targeted areas using the following Likert scale: 1 = No Impact, 2 = Little Impact, 3 = Some Impact, $4=$ Substantial Impact. 
The first section contained four factors considered to be essential components of teachers' knowledge of learners. The four factors are listed in Table 2.

Table 2

Factors Regarding PAR's Level of Impact on Participating Teachers' Knowledge of Learners

1. Ability to identify and address the individual differences of my students

2. Ability to identify and address the individual cultures of my students

3. Ability to identify and address the different backgrounds of my students

4. Ability to identify and address the different learning styles of my students

The second section contained two factors considered to be essential components of teachers' instructional planning. The two factors are listed in Table 3.

Table 3

Factors Regarding PAR's Level of Impact on Participating Teachers' Instructional Planning

1. Ability to use appropriate curricula (including state reading requirements, if applicable) to develop lesson plans that include goals and/or objectives, learning activities, assessment of student learning, and home learning in order to address the diverse needs of students

2. Ability to use instructional strategies and resources to develop lesson plans that include goals and/or objectives, learning activities, assessment of student learning, and home learning in order to address the diverse needs of students

The complete survey instrument, which includes sections one and two described above as well as sections three through seven, can be found in Appendix A. Sections three through seven contain items considered to be essential components of (a) teachers' instructional delivery and engagement, (b) teachers' assessment of learners, (c) teachers' 
communication, (d) teachers' learning environment, and (e) teachers' overall professionalism.

Content validity. The survey questions were presented to a panel of eight judges who estimated the content validity of the instrument. The eight judges were selected because of their expertise in the area of evaluation of both general education and special education teacher effectiveness. The eight experts included two administrators, two general education consulting teachers, one special education consulting teacher, one general education department leader, and two special education department leaders. Each expert judge had a minimum of ten years of teaching experience. All eight expert judges were in agreement regarding the content validity of each one of the items in the survey.

Internal consistency. The researcher used an analysis of reliability to determine the internal consistency of the items included in the survey instrument regarding the impact of PAR on participating teachers' practice, which included the following targeted teaching areas: (a) knowledge of learners, (b) instructional planning, (c) instructional delivery and engagement, (d) assessment of learners, (e) communication, (f) learning environment, and $(\mathrm{g})$ overall professionalism. Internal consistency refers to the degree to which items in the survey instrument that are projected to measure the same construct produce similar results. In the present study, the researcher measured the internal consistency among survey instrument items using Cronbach's Alpha, which allowed the multi-level responses being used by the researcher and took into account the sample size as well as the number of possible answers.

The responses to the survey items of the present study were in the same metric. In addition, high scores on the survey items denoted a high score on the underlying 
construct. Therefore, no transformation of items was needed before the researcher used SPSS to assess the consistency among items with Cronbach's Alpha. Cronbach's Alpha ranges from 0 to 1 - higher values indicate greater internal consistency. An alpha value of .70 or higher indicates an acceptable level of internal consistency. Since none of the items yielded an alpha coefficient lower than .84, the researcher included all items in the survey instrument.

The pilot test. The researcher piloted the survey by administering it to 5 veteran general education teachers and 5 veteran special education teachers who participated in the PAR program in the school district. These two specific categories of teachers were chosen to participate in the pilot testing of the survey because they matched the target profile of the study participants. Using the feedback provided by the 10 veteran teachers, the researcher determined that all survey items were clear and applicable and that the approximate completion time of the instrument was 15 minutes.

Administration of survey. A total of 364 teachers were invited to respond to the survey. The researcher sent all these teachers an introductory message (Appendix B) via electronic mail describing the study and asking them to complete the online survey instrument. The online survey instrument was made available via a link provided in the message. In the introductory message, the researcher also (a) included his contact information as well as that of the university, (b) assured potential study participants that their survey responses would remain confidential, and (c) described the expectations held for the participants as well as for the researcher. A week later, the introductory message was followed by a second message (Appendix C) to encourage special education teachers and general education teachers participating in the first four years of implementation of a 
PAR program in the school district (from school year 2012-2013 to school year 20152016) to complete the online survey instrument, thus increasing the rate of response.

A total of 197 responses were received. However, because some of the surveys were not completed in their entirety, only 157 of them were found to be usable, resulting in a $43.1 \%$ response rate.

All survey responses remained confidential. Survey respondents who indicated their willingness to be contacted for a follow-up interview were asked to provide their contact information to the researcher.

\section{Phase 2}

The researcher conducted semi-structured interviews with seven randomly selected special education teachers who participated in the first four years of implementation of a PAR program in the school district (from school year 2012-2013 to school year 2015-2016) and who indicated on the survey instrument their willingness to participate in follow-up interviews. By conducting semi-structured interviews the researcher was able to collect descriptive data in the study participants' own words and use those data to develop an understanding of the participants' interpretation of their participation in the program (Bogdan \& Biklen, 2007). In addition, the researcher was able to provide in-depth and rich descriptions of PAR program characteristics that participants found to impact (a) the teaching of special education teachers in targeted areas and (b) the evaluative feedback and professional development opportunities offered to special education teachers during their participation in the program.

Interview protocol. The semi-structured interviews included an introduction and three additional parts. In the introduction, the researcher explained the purpose of the 
interview to participants and assured them that the content of the interview would be treated with confidentiality. Next, with the goal of developing rapport, the researcher asked the participants general questions regarding their teaching experience as a special education teacher. These questions included their current teaching setting and responsibilities, what they found to be challenging and rewarding in their current assignment, and what they envisioned the perfect circumstances to teach students with disabilities to be.

In the following section of the interview, the researcher concentrated on the participants' experience in the PAR program. The questions asked in this section allowed the researcher to collect contextual information regarding how the participation of special education teachers in the program impacted their teaching in targeted areas (i.e., knowledge of learners, instructional planning, instructional delivery and engagement, assessment of learners, communication, learning environment, and overall professionalism).

In the final section of the interview, the researcher focused on the differences, if any, between the evaluative feedback and professional development opportunities provided to special education teachers by a school administrator and those provided to the same individuals by a consulting teacher. Once the final section of the interview was completed, the researcher asked the participants if some important aspect of their participation in the PAR program was not covered by the interview questions. If participants' responses were affirmative, the researcher asked them to elaborate on the matter. The researcher also asked participants if they wanted to ask him any questions. Table 4 includes the potential interview questions used by the researcher. 
Table 4

Potential Interview Questions Used During Semi-Structured Follow-up Interviews

Tell me about your teaching experience as a special education teacher.

Probes: Describe your current teaching setting and responsibilities.

What do you find to be rewarding in your current teaching assignment?

What do you find to be challenging in your current teaching assignment?

What do you envision the perfect circumstances to teach students with disabilities to be?

Tell me about your participation in the PAR program.

Probes: Tell me about the evaluative feedback and the professional development opportunities offered to you as a result of your participation in the PAR program.

In what ways, if any, do you feel your participation in the PAR program has impacted your knowledge of learners?

In what ways, if any, do you feel your participation in the PAR program has impacted your instructional planning?

In what ways, if any, do you feel your participation in the PAR program has impacted your instructional delivery and planning?

In what ways, if any, do you feel your participation in the PAR program has impacted your ability to assess learners?

In what ways, if any, do you feel your participation in the PAR program has impacted your ability to communicate effectively with students, their parents or families, and other members of the learning community?

In what ways, if any, do you feel your participation in the PAR program has impacted your ability to create a learning environment that is safe and that encourages fairness, respect, and enthusiasm?

In what ways, if any, do you feel your participation in the PAR program has impacted your overall professionalism?

Tell me about the evaluative feedback and the professional development opportunities you received from different professionals during your participation in the PAR program.

Probes: Tell me about the evaluative feedback and the professional development opportunities you received from a school administrator.

Tell me about the evaluative feedback and the professional development opportunities you received from a general education teacher.

Tell me about the evaluative feedback and the professional development opportunities you received from a special education teacher.

Interview procedures. The researcher contacted the selected participants for this

phase of the study to determine the best time and place to conduct the follow-up interviews. Once that determination was made, the researcher traveled to the participants 
and met with them individually. The researcher interviewed the participants using openended questions focused around specific topics related to their participation in the PAR program. A responsive interviewing approach was used by the researcher during the interviews, which means that the researcher looked for depth of understanding instead of breadth, remained flexible with the characteristics of this phase of the research (qualitative phase), and remained aware of the ethical obligation caused by the relationship formed between the participant and the researcher during the interview (Rubin \& Rubin, 2005). By remaining flexible with the characteristics of the qualitative phase of the study, the researcher, throughout the interview, learned about different insights and had to modify his questions as a consequence of what he learned (Rubin \& Rubin, 2005). Finally, the researcher used a digital recording device to capture each interview in its entirety in order to transcribe and code it at a later time.

\section{Data Analysis}

In the current section, the researcher describes the methods that were used to analyze the data. First, the researcher discusses the methods to analyze the data in

Phase 1. Then, the researcher explains the procedures that were used for the Phase 2 data analysis.

\section{Phase 1}

The researcher used SPSS to organize and chart the data collected via the survey instrument. Then, the researcher analyzed the data using the following measures:

(a) demographic items, and (b) perceived level of impact of PAR on targeted areas of teaching. 
The researcher used descriptive statistics (e.g., graphs, measures of variability, measures of central tendency, frequency counts) to analyze demographic items. The researcher lists the categories associated with each demographic item as well as the numerical values assigned to each one of the data groups in Table 5. The categories include participants' gender and race. They also include whether or not participants are of Hispanic or of Spanish origin.

Table 5

Demographic Categories and Data Groups Numerical Value

\begin{tabular}{lc}
\hline Demographic Categories & Numerical Value \\
\hline Gender & 1 \\
Female & 2 \\
Male & \\
Race & 1 \\
African-American or Black & 2 \\
American Indian and Alaskan Native & 3 \\
Asian & 4 \\
Native Hawaiian & 5 \\
Other Pacific Islander & 6 \\
White & 7 \\
Multiracial & 8 \\
Other & \\
Hispanic or Spanish Origin & 1 \\
Yes & 2 \\
No & \\
\hline
\end{tabular}

In a similar manner, the researcher lists the categories associated with each professional and work environment item as well as the numerical values assigned to each one of the data groups in Table 6. The professional items include participants' teaching experience, teacher preparation, and education level. They also include whether or not participants' primary teaching responsibility is in special education and whether or not 
participants' are certified in special education. Furthermore, the work environment categories include participants' school level taught and school grade level.

Table 6

Professional and Work Environment Categories and Data Groups Numerical Value

\begin{tabular}{ll}
\hline Professional and Work Environment Categories & Numerical Value \\
\hline School Level Taught & 1 \\
Preschool & 2 \\
Elementary School & 3 \\
Middle School & 4 \\
High School & 1 \\
Teaching Experience & 2 \\
$<1$ & 3 \\
1 to 2 & 4 \\
2 to 5 & 5 \\
5 to 10 & \\
$>10$ & 1 \\
Primary Teaching Responsibility in Special Education & 2 \\
Yes & \\
No & 1 \\
Certified in Special Education & 2 \\
Yes & \\
No & 1 \\
Teacher Preparation & 2 \\
Traditional 4-Year Program & \\
Alternative Certification & 1 \\
Education Level & 2 \\
Bachelor's & 3 \\
Master's & 4 \\
Specialist & \\
Doctoral & 1 \\
School Site Grade & 2 \\
A & 3 \\
B & 4 \\
C & 5 \\
D &
\end{tabular}

Using the responses from the 4-point Likert-scale survey instrument, the researcher computed the means and standard deviations for the perceived level of impact 
that the PAR program had on the following targeted areas of participating teachers' teaching: (a) knowledge of learners, (b) instructional planning, (c) instructional delivery and engagement, (d) assessment of learners, (e) communication, (f) learning environment, and (g) overall professionalism. The responses from the 4-point Likertscale also were used by the researcher to conduct $t$-tests for independent samples in order to determine whether or not a statistically significant difference existed between the mean survey scores of special and general education teachers. In order to control for Type 1 error, the researcher used the Bonferoni method.

\section{Phase 2}

The researcher used a constant comparative method to analyze the interview data. Once the interviews were conducted, the researcher began data analysis by transcribing the interviews verbatim. While transcribing the interviews, the researcher broke monologues into periodic paragraphs to make the coding process easier. In addition, the researcher left space in the left-hand margin for notes and coding (Bogdan \& Biklan, 2007).

Having listened to the interview recordings and typed a full written version of their content - including moments of silence, pause, and hesitation (which were indicated within brackets) - the researcher looked for recurring issues or events in the data and turned them into focal categories. The researcher looked for as many incidents as possible of the focal categories in the data, paying close attention to the variety of dimensions under each one of the categories. Once having accounted for and described all incidents, the researcher looked for potential relationships. Finally, while continuously paying 
attention to the focal categories, the researcher sorted the data into coding categories (Bogdan \& Biklan, 2007).

Once the process of sorting of the data into coding categories was complete, the researcher analyzed the coded data in five stages. First, the researcher grouped and summarized the data units given the same code, looking for what was present and what was absent in the data in order to generate initial themes. Next, the researcher ranked data units given the same code to create additional themes. Then, the researcher compared data collected among different interviewees to see if it highlighted the generated themes in distinctive ways. Having done so, the researcher weighed and combined distinct versions or explanations of same themes in order to synthesize and fully explain the emerging concept. Finally, the researcher checked his findings for accuracy and consistency, making any necessary adjustments. (Rubin \& Rubin, 2005).

The researcher checked his findings for accuracy and consistency in two ways. First, the researcher evaluated his interpretation of the data in a careful and systematic manner. Then, the researcher shared his interpretation of the data with the "interviewees to make sure they saw themselves and their world in what [the researcher had] written" (Rubin \& Rubin, 2005, p. 71).

\section{Summary}

A mixed-methods sequential explanatory design was selected to examine the present study's research questions. The chosen design was used by the researcher to (a) compare and analyze how special and general education teachers rated their participation in a PAR program and (b) investigate how special education teachers described their participation in a PAR program. The set of quantitative data was gathered 
via the use of a survey instrument during Phase 1 of the study. By contrast, during Phase 2 of the study, the set of qualitative data was collected via semi-structured interviews.

Phase 1 participants were special education and general education teachers who participated in the first four years of implementation of a PAR program in a large urban school district in the Southeast region of the United States. Respectively, Phase 2 participants were seven randomly selected special education teachers who volunteered to participate in follow-up interviews while completing the survey instrument administered during Phase 1 of the study.

The researcher used SPSS to analyze the data collected during Phase 1 of the study and obtain descriptive statistics. These included graphs, measures of central tendency, measures of variability, and frequency counts. Additionally, the researcher conducted $t$-tests using the responses from the 4-point Likert-scale survey instrument to determine whether or not a statistically significant difference existed between the mean survey scores of special and general education teachers.

By contrast, the analysis of the data collected during Phase 2 of the study began with a verbatim transcription of the interviews. Once having transcribed the interviews, the researcher looked for patterns and themes that emerged from the data and sorted them into coding categories. Finally, the researcher checked the data for accuracy and consistency.

The analysis of the data collected during Phase 1 of the study together with that of those gathered during Phase 2 was used to reveal the perception that special education teachers have of their participation in a PAR program and how that perception differs 
from that of general education teachers. The researcher based his final conclusions on both phases of the study. 


\section{CHAPTER 4}

\section{RESULTS}

In the current chapter, the researcher presents the results of the analysis of data collected from special and general education teachers who participated in the first four years of implementation of a PAR program in a large urban school district in the Southeast region of the United States (from the 2012-2013 to the 2015-2016 school year). The teachers responded to survey questions aiming to examine and compare how special and general education teachers rate their participation in a PAR program. The survey was sent to 364 teachers, and 190 responses were received. However, because 33 surveys were not entirely completed, only 157 could be used, resulting in a $43.1 \%$ response rate. Additionally, the researcher discusses data collected via follow-up interviews conducted with seven special education teachers. The data provide an in-depth description of the interviewees' experiences as participating teachers in a PAR program.

The research questions in the present study were the following:

1. How do special education teachers and general education teachers rate the extent to which their participation in a PAR program impacts their teaching?

a. Are there differences in how special education teachers and general education teachers rate the extent to which their participation in a PAR program impacts their teaching in targeted areas (i.e., knowledge of learners, instructional planning, instructional delivery and engagement, assessment of learners, communication, learning environment, and overall professionalism)? 
b. Are there differences in how special education teachers and general education teachers rate the evaluative feedback and professional development opportunities offered to them during their participation in a PAR program?

2. Is there a statistically significant difference between the manner in which special education teachers and general education teachers rate the extent to which their participation in a PAR program impacts their teaching in targeted areas?

3. How do special education teachers describe their experiences as a participating teacher in a PAR program?

The researcher has organized the current chapter into three sections. In the first section, the researcher describes the study sample that was used to collect data during both phases of the study. The researcher describes the quantitative study sample by presenting descriptive statistical analyses, frequency rates, and measures of central tendency for the data collected via the survey instrument. The data include demographic and professional information regarding survey respondents as well as information concerning their work environment and overall feeling of satisfaction with the impact of their participation in the PAR program on targeted areas of their teaching. Following, the researcher describes the qualitative study sample by providing a brief description of the participants. The description includes the participants' race and ethnicity as well as their level of education and school level taught.

In the second section of the current chapter, the researcher addresses the data collected during Phase 1 of the study. That section includes research questions one and two as well as the quantitative analysis of survey responses. 
In the third and last section of the current chapter, the researcher discusses Phase 2 of the study. That section includes research question three as well as the qualitative analysis of the data collected during the follow-up interviews.

\section{Description of Study Sample}

\section{Phase 1}

The researcher made a public records request to the school district and, consequently, was given access to a database containing the names of all special and general education teachers who participated in the first four years of implementation of a PAR program in the educational district. The researcher, then, sent electronic links to the present study's survey to all 364 names found in the database. Of those, 190 surveys were returned, but only 157 (43.1\%) were found to be usable, as 33 of the returned surveys were incomplete and did not address any of the questions providing data for this phase of the study.

The researcher used the first part of the survey to collect demographic and professional data about participating teachers as well as data regarding their work environment and overall feeling of satisfaction with the impact their participation in the PAR program had on their teaching. The data concerning demographic and professional information about the respondents as well as information regarding the respondents' work environment included teachers' gender, race, ethnicity, school level taught, teaching experience, primary teaching responsibility, type of teaching certification, teacher preparation, level of education, and school site grade. Respectively, data regarding the respondents' overall feeling of satisfaction with the impact their participation in the PAR program had on their teaching included information concerning the following targeted 
areas of teaching: (a) knowledge of learners, (b) instructional planning, (c) instructional delivery and engagement, (d) assessment of learners, (e) communication, (f) learning environment, and (g) overall professionalism.

Table 7 shows that the majority of the survey respondents were female $(80.3 \%)$. Male participants comprised $19.8 \%$ of the survey respondents. Regarding the race of the participants, $16.6 \%$ of survey respondents identified themselves as African-American or Black; $68.2 \%$, White; $3.8 \%$, multiracial; and $11.5 \%$ indicated that they belonged to some other race. Additionally, $58 \%$ of the participants identified themselves as being of Hispanic or Spanish origin.

Table 7

Demographic Characteristics of Respondents

\begin{tabular}{lcc}
\hline Demographic Characteristics & $\mathrm{N}$ & $\%$ \\
\hline Gender & & \\
$\quad$ Female & 126 & 80.3 \\
$\quad$ Male & 31 & 19.8 \\
Race & 26 & 16.6 \\
African-American or Black & 0 & 0 \\
American Indian and Alaskan Native & 0 & 0 \\
Asian & 0 & 0 \\
Native Hawaiian & 0 & 0 \\
Other Pacific Islander & 107 & 68.2 \\
White & 6 & 3.8 \\
Multiracial & 18 & 11.5 \\
Other & & \\
Hispanic or Spanish Origin & 91 & 58 \\
Yes & 66 & 42.5 \\
No & & \\
\hline
\end{tabular}

The survey also contained items concerning the professional characteristics of the participants as well as the characteristics of the participants' work environment. Those items included questions regarding (a) the school level taught, (b) the participants' 
teaching experience, (c) their primary teaching responsibility, (d) their certification area, (e) their teacher preparation, (f) their education level, and (g) the grade assigned to their school site by the Florida Department of Education School Accountability Report. Table 8 summarizes those data.

Table 8

General Professional and Work Environment Characteristics of Participants

\begin{tabular}{lcc}
\hline Professional and Work Environment Characteristics & $\mathrm{N}$ & $\%$ \\
\hline School Level Taught & 4 & 2.6 \\
Preschool & 51 & 32.5 \\
Elementary School & 47 & 29.9 \\
Middle School & 55 & 35 \\
High School & & \\
Teaching Experience & 0 & 0 \\
<1 & 0 & 0 \\
1 to 2 & 5 & 3.2 \\
2 to 5 & 28 & 17.8 \\
5 to 10 & 124 & 79 \\
>10 & & \\
Primary Teaching Responsibility in Special Education & 21 & 13.4 \\
Yes & 136 & 86.6 \\
No & & \\
Certified in Special Education & 43 & 27.4 \\
Yes & 114 & 72.6 \\
No & & \\
Teacher Preparation & 111 & 70.7 \\
Traditional 4-Year Program & 46 & 29.3 \\
Alternative Certification & & \\
Education Level & 50 & 31.9 \\
Bachelor's & 85 & 54.1 \\
Master's & 14 & 8.9 \\
Specialist & 8 & 5.1 \\
Doctoral & & 4.5 \\
School Site Grade & 7 & 55.4 \\
A & 54 & .6 \\
B & 1 & 5.1 \\
C & 8 & \\
D & & \\
F & & \\
\hline
\end{tabular}


The percentage of respondents teaching elementary $(32.5 \%)$, middle $(29.9 \%)$, and high school (35\%) was similar. However, the percentage of respondents teaching preschool $(2.55 \%)$ was substantially lower than the other three groups. None of the respondents had less than two years of teaching experience, and the majority had more than ten $(79 \%)$. Out of the 157 respondents, $27.4 \%$ of them were certified in special education; however, only $13.4 \%$ had their primary teaching assignment in this area. The majority of the respondents were certified via a traditional four-year university teacher preparation program $(70.7 \%)$, and $54.1 \%$ of them had a master's degree.

In the state of Florida, the Florida Department of Education, on a yearly basis, assigns a grade to each school using the student data reported by the schools to the state in the previous academic year. That grade ranges from A to F and indicates the school's measured ability to meet its students' academic needs and to make satisfactory yearly progress. During the 2016-2017 school year, schools designated as "B" schools had the majority of the respondents (55.4\%), followed by "C" schools with $34.4 \%$ of them. Schools designated as " $\mathrm{D}$ " schools had the least respondents (.6\%), and schools designated as "A" and "F" had $4.5 \%$ and $5.1 \%$ of the respondents respectively. After responding to questions concerning their personal and professional characteristics as well as the characteristics of their work environment, participants answered seven questions regarding their overall feeling of satisfaction with the impact of their participation in the PAR program on specific areas of their teaching. Table 9 shows the mean scores and standard deviations for the data collected via those seven questions. 
Table 9

Mean Scores for Level of Satisfaction with PAR Impact on Specific Areas of Teaching

\begin{tabular}{lccccc}
\hline Specific Areas of Teaching & $\mathrm{N}$ & Min. & Max. & Mean & SD \\
\hline $\begin{array}{l}\text { Ability to Create a Safe, Fair, Respectful, } \\
\text { and Stimulating Learning Environment }\end{array}$ & 157 & 1 & 4 & 3.45 & .74 \\
$\begin{array}{l}\text { Assessment of Learners } \\
\text { Communication with Students, Parents, }\end{array}$ & 157 & 1 & 4 & 3.26 & .72 \\
Staff, and Community Members & & 1 & 4 & 3.22 & .80 \\
Instructional Delivery and Engagement & 157 & 1 & 4 & 3.43 & .71 \\
Instructional Planning & 157 & 1 & 4 & 3.41 & .75 \\
Knowledge of Learners & 157 & 1 & 4 & 3.28 & .76 \\
Overall Professionalism & 157 & 1 & 4 & 3.55 & .69 \\
\hline
\end{tabular}

The survey responses provided by participants indicated that, overall, the respondents were satisfied with the impact of their participation in the PAR program on targeted areas of their teaching. The fact that the ratings ranged from 3.22 (out of 4.0) to 3.55 indicates that respondents were satisfied with the impact of their participation in the PAR program on all seven targeted areas of their teaching. Additionally, the fact that standard deviations ranged from 0.69 to 0.80 indicates that the variability in responses was small. The high mean combined with the low standard deviation implies that few respondents disagreed with the majority that was satisfied with the impact of their participation in the program on targeted areas of their teaching.

Overall, respondents were satisfied the most with the impact of their participation in the PAR program on their overall professionalism $(M=3.55)$. Next, respondents indicated they were satisfied the most with the impact of their participation in the PAR program on their ability to create a safe, fair, respectful, and stimulating learning environment $(\mathrm{M}=3.45)$. This rating was followed closely by the ratings given by respondents to their level of satisfaction with the aforementioned impact on the following 
two targeted areas of their teaching: (a) instructional delivery and engagement $(M=3.43)$ and (b) instructional planning $(M=3.41)$. Then, respondents were satisfied the most with the impact of their participation in the PAR program on their knowledge of learners $(M=3.28)$ and assessment of learners $(M=3.26)$. Finally, respondents indicated that they were satisfied the least with the impact of their participation in the program on their communication with students, parents, staff, and community members $(M=3.22)$.

\section{Phase 2}

The researcher conducted semi-structured interviews with special education teachers who indicated on their survey response their willingness to be interviewed. Those interviews provided in-depth data concerning the interviewees' experience as a participating teacher in the PAR program.

A total of 20 teachers volunteered to participate in the follow-up interviews, and the researcher conducted interviews with seven of those volunteers. All seven participants taught in urban public schools where the majority of the students were Hispanic and/or Black. One of the participants taught preschool. Two taught in an elementary setting. One other participant taught in a middle school environment. Finally, three participants taught in a high school setting.

Three of the participants taught in self-contained special education classrooms, while the remaining four taught in an inclusion setting. One of the participants had a bachelor's degree. Five others held a master's degree. Finally, the last participant had a doctoral degree. 
The distribution described in the above paragraphs occurred by chance. In addition, in order to ensure confidentiality, the researcher assigned each one of the interview participants a pseudonym.

\section{Phase 1 Data Analysis and Results}

\section{Research Question 1}

The present study's first question and sub questions addressed how special and general education teachers rated the impact of their participation in a PAR program on their teaching. The question was the following: how do special education teachers and general education teachers rate the extent to which their participation in a PAR program impacts their teaching? Additionally, the two sub questions were the following: (a) are there differences in how special education teachers and general education teachers rate the extent to which their participation in a PAR program impacts their teaching in targeted areas (i.e., knowledge of learners, instructional planning, instructional delivery and engagement, assessment of learners, communication, learning environment, and overall professionalism) and (b) are there differences in how special education teachers and general education teachers rate the evaluative feedback and professional development opportunities offered to them through a PAR program?

Impact on targeted areas of teaching. Using the literature review, the researcher included 20 survey questions that addressed targeted areas of teaching. The researcher divided the areas into components and listed the components in a high to low range within each one of the seven areas. Table 10 presents the means and standard deviations reflecting how special education teachers rated the impact of their participation in a PAR program on targeted areas of their teaching. 
Table 10

Mean Scores for Special Education Teachers' Rating of PAR Impact on Targeted Areas

\begin{tabular}{|c|c|c|}
\hline Targeted Area & $M$ & $\mathrm{SD}$ \\
\hline \multicolumn{3}{|l|}{ Knowledge of Learners } \\
\hline Ability to identify and address the individual differences of students & 3.40 & .62 \\
\hline Ability to identify and address the individual cultures of students & 3.26 & .75 \\
\hline $\begin{array}{l}\text { Ability to identify and address the individual backgrounds of } \\
\text { students }\end{array}$ & 3.23 & .71 \\
\hline $\begin{array}{l}\text { Ability to identify and address the individual learning styles of } \\
\text { students }\end{array}$ & 3.47 & .62 \\
\hline \multicolumn{3}{|l|}{ Instructional Planning } \\
\hline $\begin{array}{l}\text { Ability to use appropriate curricula to develop lesson plans that } \\
\text { address the diverse needs of students }\end{array}$ & 3.40 & .65 \\
\hline $\begin{array}{l}\text { Ability to use instructional strategies and resources to develop } \\
\text { lesson plans that address the diverse needs of students }\end{array}$ & 3.40 & .65 \\
\hline \multicolumn{3}{|l|}{ Instructional Delivery and Engagement } \\
\hline $\begin{array}{l}\text { Ability to promote learning by demonstrating accurate content } \\
\text { knowledge }\end{array}$ & 3.44 & .73 \\
\hline $\begin{array}{l}\text { Ability to promote learning by addressing academic needs through a } \\
\text { variety of appropriate instructional strategies and technologies that } \\
\text { engage learners }\end{array}$ & 3.56 & .54 \\
\hline \multicolumn{3}{|l|}{ Assessment of Learners } \\
\hline $\begin{array}{l}\text { Ability to gather, analyze, and use data (including current state } \\
\text { assessment data, as applicable) to measure learner progress }\end{array}$ & 3.37 & .72 \\
\hline $\begin{array}{l}\text { Ability to gather, analyze, and use data (including current state } \\
\text { assessment data, as applicable) to guide instruction }\end{array}$ & 3.35 & .71 \\
\hline $\begin{array}{l}\text { Ability to gather, analyze, and use data (including current state } \\
\text { assessment data, as applicable) to provide timely feedback }\end{array}$ & 3.33 & .71 \\
\hline \multicolumn{3}{|l|}{ Communication } \\
\hline Ability to communicate effectively with students & 3.37 & .72 \\
\hline $\begin{array}{l}\text { Ability to communicate effectively with students' parents or } \\
\text { families }\end{array}$ & 3.30 & .70 \\
\hline $\begin{array}{l}\text { Ability to communicate effectively with staff and other members of } \\
\text { the learning community }\end{array}$ & 3.44 & .62 \\
\hline \multicolumn{3}{|l|}{ Learning Environment } \\
\hline Ability to create a safe learning environment & 3.47 & .69 \\
\hline Ability to create a learning environment that encourages fairness & 3.51 & .62 \\
\hline Ability to create a learning environment that encourages respect & 3.51 & .59 \\
\hline Ability to create a learning environment that encourages enthusiasm & 3.49 & .62 \\
\hline \multicolumn{3}{|l|}{ Overall Professionalism } \\
\hline Ability to comply with legal, ethical, and professional standards & 3.53 & .62 \\
\hline Ability to engage in continuous professional growth & 3.63 & .53 \\
\hline
\end{tabular}


Special education teachers. The survey responses provided by special education teachers indicated that their participation in a PAR program had a substantial impact on their teaching. The value rating provided by special education teachers for the impact that their participation in a PAR program had on the components of all targeted areas of teaching were above a mean rating of 3.0 - the threshold for the substantial impact rating. The fact that the ratings ranged from 3.23 (out of 4.0) to 3.63 indicates that special education teachers considered their participation in a PAR program to have an impact on all targeted areas of teaching components. Additionally, the fact that standard deviations ranged from 0.53 to 0.75 indicates that the variability in responses was small. The high mean combined with the low standard deviation implies that few special education teachers disagreed with the majority that considered their participation in the program to have a substantial impact on the components of targeted areas of their teaching.

Overall, special education teachers considered their ability to engage in continuous professional growth to be the component that was impacted the most by their participation in the PAR program $(M=3.63)$. This component is listed under the overall professionalism targeted area of teaching. Next, special education teachers rated their ability to promote learning by addressing academic needs through a variety of appropriate instructional strategies and technologies that engage learners to be the second component to be the most impacted by their participation in the program $(M=3.56)$. This component falls under the instructional delivery and engagement targeted area of teaching.

The components to be considered the least impacted by special education teachers were the following: (a) their ability to identify and address the individual backgrounds of students $(M=3.23)$, (b) their ability to identify and address the individual cultures of 
students $(M=3.26)$, (c) their ability to communicate effectively with students' parents or families $(M=3.30)$, (d) their ability to gather, analyze, and use data (including current state assessment data, as applicable) to provide timely feedback $(M=3.33)$, and (e) their ability to gather, analyze, and use data (including current state assessment data, as applicable) to guide instruction $(M=3.35)$. The first two components are those listed under the knowledge of learners targeted area of teaching. The third component falls under the area of communication. Finally, the last two components are listed under assessment of learners.

Knowledge of learners. The first targeted teaching area was knowledge of learners. Within this area, respondents indicated that their ability to identify and address the individual learning styles of students $(M=3.47)$ was the component to be impacted the most by their participation in the PAR program. The mean rating of this component was followed closely by the one corresponding to their ability to identify and address the individual differences of students $(M=3.40)$. Conversely, their ability to identify and address the individual cultures of students was the component to be impacted the least $(M=3.26)$.

Instructional planning. Instructional planning was the second targeted teaching area. Within this area, respondents indicated that their ability to use appropriate curricula to develop lesson plans that address the diverse needs of students and their ability to use instructional strategies and resources to develop lesson plans that address the diverse needs of students were equally impacted by their participation in the PAR program $(M=3.40)$. 
Instructional delivery and engagement. Within the third targeted teaching area, instructional delivery and engagement, respondents indicated that their ability to promote learning by addressing academic needs through a variety of appropriate instructional strategies and technologies that engage learners was the component to be impacted the most by their participation in the PAR program $(M=3.56)$. Conversely, their ability to promote learning by demonstrating accurate content knowledge was considered by the respondents to be the component to be impacted the least $(M=3.44)$.

Assessment of learners. Assessment of learners was the fourth targeted teaching area. Overall, respondents rated the components found in this area as three of the six components to be the least impacted by their participation in the PAR program. The mean rating of the three components were the following: (a) their ability to gather, analyze, and use data (including current state assessment data, as applicable) to measure learner progress $(M=3.37)$, (b) their ability to gather, analyze, and use data (including current state assessment data, as applicable) to guide instruction $(M=3.35)$, and (c) their ability to gather, analyze, and use data (including current state assessment data, as applicable) to provide timely feedback $(M=3.33)$.

Communication. Within the fifth targeted teaching area, communication, respondents indicated that their ability to communicate effectively with staff and other members of the learning community was the component to be impacted the most by their participation in the PAR program $(M=3.44)$. Conversely, respondents indicated that their ability to communicate effectively with students $(M=3.37)$ and their ability to communicate effectively with students' parents or families $(M=3.30)$ were the components to be impacted the least by their participation in the program. 
Learning environment. Learning environment was the sixth targeted teaching area. Within this area, respondents indicated that their ability to create a learning environment that encourages fairness and their ability to create a learning environment that encourages respect were the two components to be impacted the most by their participation in the PAR program $(M=3.51)$. These components were followed by their ability to create a learning environment that encourages enthusiasm $(M=3.49)$. The component to be considered as the least impacted by the respondents was their ability to create a safe learning environment $(M=3.47)$.

Overall professionalism. Overall professionalism was the seventh and last targeted teaching area. Within this area, respondents considered their ability to engage in continuous professional growth to be the component most impacted by their participation in the PAR program $(M=3.63)$. Conversely, respondents considered their ability to comply with legal, ethical, and professional standards to be the component impacted the least $(M=3.53)$.

General education teachers. The survey responses provided by general education teachers indicated that their participation in a PAR program had a substantial impact on their teaching. The value rating provided by general education teachers for the impact that their participation in a PAR program had on the components of all targeted areas of teaching were above a mean rating of 3.0 - the threshold for the substantial impact rating. Table 11 presents the means and standard deviations reflecting how general education teachers rated the impact of their participation in a PAR program on targeted areas of their teaching. 
Table 11

Mean Scores for General Education Teachers' Rating of PAR Impact on Targeted Areas

\begin{tabular}{|c|c|c|}
\hline Targeted Area & $\mathrm{M}$ & $\mathrm{SD}$ \\
\hline \multicolumn{3}{|l|}{ Knowledge of Learners } \\
\hline Ability to identify and address the individual differences of students & 3.36 & .76 \\
\hline Ability to identify and address the individual cultures of students & 3.18 & .90 \\
\hline Ability to identify and address the individual backgrounds of students & 3.20 & .87 \\
\hline $\begin{array}{l}\text { Ability to identify and address the individual learning styles of } \\
\text { students }\end{array}$ & 3.38 & .78 \\
\hline \multicolumn{3}{|l|}{ Instructional Planning } \\
\hline $\begin{array}{l}\text { Ability to use appropriate curricula to develop lesson plans that } \\
\text { address the diverse needs of students }\end{array}$ & 3.45 & .75 \\
\hline $\begin{array}{l}\text { Ability to use instructional strategies and resources to develop lesson } \\
\text { plans that address the diverse needs of students }\end{array}$ & 3.45 & .75 \\
\hline \multicolumn{3}{|l|}{ Instructional Delivery and Engagement } \\
\hline $\begin{array}{l}\text { Ability to promote learning by demonstrating accurate content } \\
\text { knowledge }\end{array}$ & 3.39 & .83 \\
\hline $\begin{array}{l}\text { Ability to promote learning by addressing academic needs through a } \\
\text { variety of appropriate instructional strategies and technologies that } \\
\text { engage learners }\end{array}$ & 3.47 & .73 \\
\hline \multicolumn{3}{|l|}{ Assessment of Learners } \\
\hline $\begin{array}{l}\text { Ability to gather, analyze, and use data (including current state } \\
\text { assessment data, as applicable) to measure learner progress }\end{array}$ & 3.39 & .80 \\
\hline $\begin{array}{l}\text { Ability to gather, analyze, and use data (including current state } \\
\text { assessment data, as applicable) to guide instruction }\end{array}$ & 3.44 & .74 \\
\hline $\begin{array}{l}\text { Ability to gather, analyze, and use data (including current state } \\
\text { assessment data, as applicable) to provide timely feedback }\end{array}$ & 3.38 & .79 \\
\hline \multicolumn{3}{|l|}{ Communication } \\
\hline Ability to communicate effectively with students & 3.31 & .88 \\
\hline Ability to communicate effectively with students' parents or families & 3.11 & .96 \\
\hline $\begin{array}{l}\text { Ability to communicate effectively with staff and other members of } \\
\text { the learning community }\end{array}$ & 3.29 & .85 \\
\hline \multicolumn{3}{|l|}{ Learning Environment } \\
\hline Ability to create a safe learning environment & 3.36 & .88 \\
\hline Ability to create a learning environment that encourages fairness & 3.38 & .85 \\
\hline Ability to create a learning environment that encourages respect & 3.41 & .87 \\
\hline Ability to create a learning environment that encourages enthusiasm & 3.44 & .81 \\
\hline \multicolumn{3}{|l|}{ Overall Professionalism } \\
\hline Ability to comply with legal, ethical, and professional standards & 3.38 & .89 \\
\hline Ability to engage in continuous professional growth & 3.56 & .70 \\
\hline
\end{tabular}


The fact that the ratings ranged from 3.11 (out of 4.0) to 3.56 indicates that general education teachers considered their participation in a PAR program to have an impact on all targeted areas of teaching components. Additionally, the fact that standard deviations ranged from 0.70 to 0.96 indicates that the variability in responses was small. The high mean combined with the low standard deviation implies that few general education teachers disagreed with the majority that considered their participation in the program to have a substantial impact on the components of targeted areas of their teaching.

Overall, general education teachers considered their ability to engage in continuous professional growth to be the component that was impacted the most by their participation in the PAR program $(M=3.56)$. This component is listed under the overall professionalism targeted area of teaching. Next, general education teachers rated their ability to promote learning by addressing academic needs through a variety of appropriate instructional strategies and technologies that engage learners to be the second component to be the most impacted by their participation in the program $(M=3.47)$. This component falls under the instructional delivery and engagement targeted area of teaching.

The components to be considered the least impacted by general education teachers were the following: (a) their ability to communicate effectively with students' parents or families $(M=3.11)$, (b) their ability to identify and address the individual cultures of students $(M=3.18)$, (c) their ability to identify and address the individual backgrounds of students $(M=3.20)$, (d) their ability to communicate effectively with staff and other members of the learning community $(M=3.29)$, and (e) their ability to communicate effectively with students $(M=3.31)$. The first, fourth, and fifth components 
are those listed under the communication targeted area of teaching, while the second and third components are listed under knowledge of learners.

Knowledge of learners. Overall, this targeted teaching area, knowledge of learners, had two of the five components listed by general education teachers as the least impacted by their participation in the PAR program. Within this area, respondents indicated that their ability to identify and address the individual learning styles of students $(M=3.38)$ was the component to be impacted the most by their participation in the PAR program. The mean rating of that component was followed closely by the one corresponding to their ability to identify and address the individual differences of students $(M=3.36)$. By contrast, their ability to identify and address the individual cultures of students was the component to be impacted the least $(M=3.18)$.

Instructional planning. Within this area, instructional planning, respondents indicated that their ability to use appropriate curricula to develop lesson plans that address the diverse needs of students and their ability to use instructional strategies and resources to develop lesson plans that address the diverse needs of students were equally impacted by their participation in the PAR program $(M=3.45)$.

Instructional delivery and engagement. Within the third targeted teaching area, instructional delivery and engagement, respondents indicated that their ability to promote learning by addressing academic needs through a variety of appropriate instructional strategies and technologies that engage learners was the component to be impacted the most by their participation in the PAR program $(M=3.47)$. Conversely, their ability to promote learning by demonstrating accurate content knowledge was considered by the respondents to be the component to be impacted the least $(M=3.39)$. 
Assessment of learners. Within the fourth targeted teaching area, assessment of learners, respondents rated their ability to gather, analyze, and use data (including current state assessment data, as applicable) to guide instruction as the component to be the most impacted by their participation in the PAR program $(M=3.44)$. That component was followed closely by their ability to gather, analyze, and use data (including current state assessment data, as applicable) to measure learner progress $(M=3.39)$ and by their ability to gather, analyze, and use data (including current state assessment data, as applicable) to provide timely feedback $(M=3.38)$.

Communication. Overall, this targeted teaching area, communication, had three of the five components listed by general education teachers as the least impacted by their participation in the PAR program. Within this area, respondents indicated that their ability to communicate effectively with students was the component to be impacted the most by their participation in the PAR program $(M=3.31)$. That component was followed closely by their ability to communicate effectively with staff and other members of the learning community $(M=3.29)$. Finally, respondents indicated that their ability to communicate effectively with students' parents or families $(M=3.11)$ was the component to be impacted the least by their participation in the program.

Learning environment. Within this area, learning environment, respondents indicated that their ability to create a learning environment that encourages enthusiasm was the component to be impacted the most by their participation in the PAR program $(M=3.44)$. That component was followed closely by their ability to create a learning environment that encourages respect $(M=3.41)$. The components to be considered as the least impacted by the respondents were their ability to create a learning environment that 
encourages fairness $(M=3.38)$ and their ability to create a safe learning environment $(M=3.36)$.

Overall professionalism. This targeted teaching area, overall professionalism, had the component to be considered by respondents as the most impacted by their participation in the PAR program overall. That component was their ability to engage in continuous professional growth $(M=3.56)$. Within this area, respondents considered their ability to comply with legal, ethical, and professional standards to be the component impacted the least $(M=3.38)$.

Differences between special and general education teachers. The survey responses provided by both special education and general education teachers indicated that their participation in a PAR program had a substantial impact on their teaching. Special education teachers' ratings ranged from 3.23 (out of 4.0) to 3.63, and general education teachers' ratings ranged from 3.11 (out of 4.0) to 3.56. The value rating provided by both special education and general education teachers for the impact that their participation in a PAR program had on the components of all targeted areas of teaching were above a mean rating of 3.0 - the threshold for the substantial impact rating. That indicates that both special education and general education teachers considered their participation in a PAR program to have an impact on all targeted areas of teaching components. Table 12 presents a comparison between the mean scores reflecting how special education and general education teachers rated the impact of their participation in the PAR program on targeted areas of their teaching. 
Table 12

Mean Scores for Special and General Education Teachers' Rating of PAR Impact on

\section{Targeted Areas}

\begin{tabular}{|c|c|c|}
\hline Targeted Area & SE & GE \\
\hline \multicolumn{3}{|l|}{ Knowledge of Learners } \\
\hline Ability to identify and address the individual differences of students & 3.40 & 3.36 \\
\hline Ability to identify and address the individual cultures of students & 3.26 & 3.18 \\
\hline Ability to identify and address the individual backgrounds of students & 3.23 & 3.20 \\
\hline Ability to identify and address the individual learning styles of students & 3.47 & 3.38 \\
\hline \multicolumn{3}{|l|}{ Instructional Planning } \\
\hline $\begin{array}{l}\text { Ability to use appropriate curricula to develop lesson plans that address } \\
\text { the diverse needs of students }\end{array}$ & 3.40 & 3.45 \\
\hline $\begin{array}{l}\text { Ability to use instructional strategies and resources to develop lesson } \\
\text { plans that address the diverse needs of students }\end{array}$ & 3.40 & 3.45 \\
\hline \multicolumn{3}{|l|}{ Instructional Delivery and Engagement } \\
\hline $\begin{array}{l}\text { Ability to promote learning by demonstrating accurate content } \\
\text { knowledge }\end{array}$ & 3.44 & 3.39 \\
\hline $\begin{array}{l}\text { Ability to promote learning by addressing academic needs through a } \\
\text { variety of appropriate instructional strategies and technologies that } \\
\text { engage learners }\end{array}$ & 3.56 & 3.47 \\
\hline \multicolumn{3}{|l|}{ Assessment of Learners } \\
\hline $\begin{array}{l}\text { Ability to gather, analyze, and use data (including current state } \\
\text { assessment data, as applicable) to measure learner progress }\end{array}$ & 3.37 & 3.39 \\
\hline $\begin{array}{l}\text { Ability to gather, analyze, and use data (including current state } \\
\text { assessment data, as applicable) to guide instruction }\end{array}$ & 3.35 & 3.44 \\
\hline $\begin{array}{l}\text { Ability to gather, analyze, and use data (including current state } \\
\text { assessment data, as applicable) to provide timely feedback }\end{array}$ & 3.33 & 3.38 \\
\hline \multicolumn{3}{|l|}{ Communication } \\
\hline Ability to communicate effectively with students & 3.37 & 3.31 \\
\hline Ability to communicate effectively with students' parents or families & 3.30 & 3.11 \\
\hline $\begin{array}{l}\text { Ability to communicate effectively with staff and other members of the } \\
\text { learning community }\end{array}$ & 3.44 & 3.29 \\
\hline \multicolumn{3}{|l|}{ Learning Environment } \\
\hline Ability to create a safe learning environment & 3.47 & 3.36 \\
\hline Ability to create a learning environment that encourages fairness & 3.51 & 3.38 \\
\hline Ability to create a learning environment that encourages respect & 3.51 & 3.41 \\
\hline Ability to create a learning environment that encourages enthusiasm & 3.49 & 3.44 \\
\hline \multicolumn{3}{|l|}{ Overall Professionalism } \\
\hline Ability to comply with legal, ethical, and professional standards & 3.53 & 3.38 \\
\hline Ability to engage in continuous professional growth & 3.63 & 3.56 \\
\hline
\end{tabular}


Standard deviations among special education teachers' ratings ranged from 0.53 to 0.75 , and those among general education teachers ranged from 0.70 to 0.96 . That indicates that the variability in responses among special education teachers and among general educations teachers was small. The high mean combined with the low standard deviation implies that few special and general education teachers disagreed with the majority that considered their participation in the program to have a substantial impact on the components of targeted areas of their teaching.

Overall, both special education $(M=3.63)$ and general education teachers $(M=3.56)$ considered their ability to engage in continuous professional growth to be the component that was impacted the most by their participation in the PAR program. This component falls under the overall professionalism targeted area of teaching. Special education and general education teachers also agreed on the next component to be the most impacted by their participation in the program. Both groups of teachers rated their ability to promote learning by addressing academic needs through a variety of appropriate instructional strategies and technologies that engage learners to be the component to be the second most impacted by their participation in the program. This component is listed under the instructional delivery and engagement targeted area of teaching. The mean score for special education teachers' ratings was 3.46, and the one for the ratings of general education teachers was 3.47 .

Regarding the components to be considered the least impacted by the respondents' participation in the PAR program, special education and general education teachers agreed that the following components were three of the five components to be the least impacted: (a) their ability to communicate effectively with students' parents or 
families, (b) their ability to identify and address the individual cultures of students, and (c) their ability to identify and address the individual backgrounds of students. The mean score for special education teachers' ratings of the component ability to communicate effectively with students' parents or families was 3.30, and the one for general education teachers was 3.11. The mean score for special education teachers' ratings of the component ability to identify and address the individual cultures of students was 3.26 , and the one for general education teachers was 3.18. Finally, the mean score for special education teachers' ratings of the component ability to identify and address the individual backgrounds of students was 3.23 , and the one for general education teachers was 3.20 . The component ability to communicate effectively with students' parents or families falls under the targeted teaching area of communication, while the components (a) ability to identify and address the individual cultures of students and (b) ability to identify and address the individual backgrounds of students fall under knowledge of learners.

Still on the subject of components to be considered the least impacted by the respondents' participation in the PAR program, special education and general education teachers disagreed on two of the five components to be considered the least impacted by their participation. The final two components to be considered by special education teachers to be the least impacted by their participation fall under the assessment of learners targeted area of teaching. Conversely, the final two components to be considered by general education teachers to be the least impacted by their participation in the program fall under the teaching targeted area of communication.

The mean scores for special education teachers' ratings of the two assessment of learners components considered by them to be two of the five least impacted by their 
participation in the program were the following: (a) ability to gather, analyze, and use data (including current state assessment data, as applicable) to provide timely feedback $(M=3.33)$, and (b) ability to gather, analyze, and use data (including current state assessment data, as applicable) to guide instruction $(M=3.35)$. By contrast, the mean scores for general education teachers' ratings of the same two components were the following: (a) ability to gather, analyze, and use data (including current state assessment data, as applicable) to provide timely feedback $(M=3.38)$, and (b) ability to gather, analyze, and use data (including current state assessment data, as applicable) to guide instruction $(M=3.34)$. It is important to note that the component ability to gather, analyze, and use data (including current state assessment data, as applicable) to guide instruction, which was considered by special education teachers as one of the five components to be the least impacted by their participation in the PAR program, is the same component considered by general education teachers to be one of the five most impacted by their participation in the program.

Finally, mean scores for general education teachers' ratings of the communication components considered by them to be two of the five least impacted by their participation in the program were the following: (a) ability to communicate effectively with staff and other members of the learning community $(M=3.29)$, and (b) ability to communicate effectively with students $(M=3.31)$. By contrast, the mean scores for special education teachers' ratings of the same two components were the following: (a) ability to communicate effectively with staff and other members of the learning community ( $M=3.44)$, and (b) ability to communicate effectively with students $(M=3.37)$. 


\section{Evaluative feedback and professional development opportunities. The}

researcher categorized the evaluative feedback and professional development opportunities offered to participants according to the professional (consulting teacher or administrator) providing the feedback and professional development to participating teachers during their participation in the PAR program. Furthermore, the researcher further classified the consulting teachers providing evaluative feedback and professional development opportunities according to their teaching certification (unknown, special education, or general education). Finally, the researcher listed each one of the categories in a high to low range.

Special education teachers. The survey responses provided by special education teachers indicated that they were satisfied with the evaluative feedback offered to them during their participation in the PAR program. The value ratings provided by special education teachers for their level of satisfaction with the evaluative feedback received were above a mean rating of 3.0 - the threshold for the very satisfied rating. The fact that ratings ranged from 3.25 (out of 4.0) to 3.69 indicates that special education teachers were satisfied with the evaluative feedback provided to them during their participation in the program in spite of the professional from whom they received the feedback.

Additionally, the fact that standard deviations ranged from 0.54 to 0.65 indicates that the variability in responses was small. The high mean combined with the low standard deviation implies that few special education teachers disagreed with the majority that was satisfied with the evaluative feedback offered to them during their participation in the program. Table 13 presents the means and standard deviations reflecting how special 
education teachers rated the evaluative feedback offered to them during their

participation in the PAR program.

Table 13

Special Education Teachers' Mean Scores for Level of Satisfaction with Evaluative Feedback

\begin{tabular}{lccccc}
\hline Specific Professional & N & Min. & Max. & Mean & SD \\
\hline Consulting Teacher & & & & & \\
$\quad$ Teaching Certification Unknown & 12 & 1 & 4 & 3.25 & .60 \\
$\quad$ Certified in General Education & 26 & 1 & 4 & 3.69 & .54 \\
$\quad$ Certified in Special Education & 14 & 1 & 4 & 3.43 & .65 \\
School Administrator & 43 & 1 & 4 & 3.37 & .65 \\
\hline
\end{tabular}

Evaluative feedback. Overall, special education teachers were satisfied the most with the evaluative feedback received from a consulting teacher certified in general education $(M=3.69)$. Next, special education teachers indicated that they were satisfied the most with the evaluative feedback provided by a consulting teacher certified in special education $(M=3.43)$. Then, special education teachers were satisfied the most with the feedback received from an administrator $(M=3.37)$. Finally, special education teachers indicated they were the least satisfied with the evaluative feedback they received from a consulting teacher whose area of certification was unknown to them $(M=3.25)$.

Professional development opportunities. The survey responses provided by special education teachers indicated that they were satisfied with the professional development opportunities offered to them during their participation in the PAR program. The value ratings provided by special education teachers for their level of satisfaction with the professional development opportunities received were above a mean rating of 3.0 - the threshold for the very satisfied rating. The fact that ratings ranged from 3.08 
(out of 4.0) to 3.69 indicates that special education teachers were satisfied with the professional development opportunities provided to them during their participation in the program in spite of the professional who offered the professional development opportunity to them. Additionally, the fact that standard deviations ranged from 0.46 to 0.65 indicates that the variability in responses was small. The high mean combined with the low standard deviation implies that few special education teachers disagreed with the majority that was satisfied with the professional development opportunities offered to them during their participation in the program. Table 14 presents the means and standard deviations reflecting how special education teachers rated the professional development opportunities offered to them during their participation in the PAR program.

Table 14

Special Education Teachers' Mean Scores for Level of Satisfaction with Professional Development Opportunities

\begin{tabular}{llllll}
\hline Specific Professional & N & Min. & Max. & Mean & SD \\
\hline Consulting Teacher & & & & & \\
Teaching Certification Unknown & 12 & 1 & 4 & 3.08 & .49 \\
Certified in General Education & 26 & 1 & 4 & 3.69 & .46 \\
Certified in Special Education & 14 & 1 & 4 & 3.36 & .61 \\
School Administrator & 43 & 1 & 4 & 3.40 & .65 \\
\hline
\end{tabular}

Overall, special education teachers were satisfied the most with the professional development opportunities received from a consulting teacher certified in general education $(M=3.69)$. Next, special education teachers indicated that they were satisfied the most with the professional development opportunities provided by an administrator $(M=3.40)$. Then, special education teachers were satisfied the most with the professional development received from a consulting teacher certified in special education $(M=3.36)$. 
Finally, special education teachers indicated they were the least satisfied with the professional development opportunities they received from a consulting teacher whose area of certification was unknown to them $(M=3.08)$.

General education teachers. The survey responses provided by general education teachers indicated that they were satisfied with the evaluative feedback offered to them during their participation in the PAR program. The value ratings provided by general education teachers for their level of satisfaction with the evaluative feedback received were above a mean rating of 3.0 - the threshold for the very satisfied rating. The fact that ratings ranged from 3.35 (out of 4.0) to 3.71 indicates that general education teachers were satisfied with the evaluative feedback provided to them during their participation in the program in spite of the professional from whom they received the feedback.

Additionally, the fact that standard deviations ranged from 0.57 to 0.80 indicates that the variability in responses was small. The high mean combined with the low standard deviation implies that few general education teachers disagreed with the majority that was satisfied with the evaluative feedback offered to them during their participation in the program.

Evaluative feedback. Overall, general education teachers were satisfied the most with the evaluative feedback received from a consulting teacher certified in general education $(M=3.71)$. Next, general education teachers indicated they were satisfied the most with the evaluative feedback provided by a consulting teacher certified in special education $(M=3.57)$. Then, general education teachers were satisfied the most with the feedback received from an administrator $(M=3.40)$. Finally, general education teachers indicated they were the least satisfied with the evaluative feedback they received from a 
consulting teacher whose area of certification was unknown to them $(M=3.35)$. Table 15

presents the means and standard deviations reflecting how general education teachers rated the evaluative feedback offered to them during their participation in the PAR program.

Table 15

General Education Teachers' Mean Scores for Level of Satisfaction with Evaluative Feedback

\begin{tabular}{lccccc}
\hline Specific Professional & N & Min. & Max. & Mean & SD \\
\hline Consulting Teacher & & & & & \\
Teaching Certification Unknown & 34 & 1 & 4 & 3.35 & .80 \\
Certified in General Education & 80 & 1 & 4 & 3.71 & .57 \\
Certified in Special Education & 14 & 1 & 4 & 3.57 & .62 \\
School Administrator & 114 & 1 & 4 & 3.40 & .76 \\
\hline
\end{tabular}

Professional development opportunities. The survey responses provided by general education teachers indicated they were satisfied with the professional development opportunities offered to them during their participation in the PAR program. The value ratings provided by general education teachers for their level of satisfaction with the professional development opportunities received were above a mean rating of 3.0 - the threshold for the very satisfied rating. The fact that ratings ranged from 3.21 (out of 4.0) to 3.49 indicates that general education teachers were satisfied with the professional development opportunities provided to them during their participation in the program in spite of the professional who offered the professional development opportunity to them. Additionally, the fact that standard deviations ranged from 0.77 to 0.96 indicates that the variability in responses was small. The high mean combined with the low standard deviation implies that few general education teachers disagreed with the 
majority that was satisfied with the professional development opportunities offered to them during their participation in the program. Table 16 presents the means and standard deviations reflecting how general education teachers rated the professional development opportunities offered to them during their participation in the PAR program.

Table 16

General Education Teachers' Mean Scores for Level of Satisfaction with Professional Development Opportunities

\begin{tabular}{lccccc}
\hline Specific Professional & N & Min. & Max. & Mean & SD \\
\hline Consulting Teacher & & & & & \\
Teaching Certification Unknown & 34 & 1 & 4 & 3.21 & .83 \\
Certified in General Education & 80 & 1 & 4 & 3.49 & .77 \\
Certified in Special Education & 14 & 1 & 4 & 3.29 & .96 \\
School Administrator & 114 & 1 & 4 & 3.25 & .79 \\
\hline
\end{tabular}

Overall, general education teachers were satisfied the most with the professional development opportunities offered by a consulting teacher certified in general education $(M=3.49)$. Next, general education teachers indicated they were satisfied the most with the professional development opportunities provided by a consulting teacher certified in special education $(M=3.29)$. Then, general education teachers were satisfied the most with the professional development received from an administrator $(M=3.25)$. Finally, general education teachers indicated they were the least satisfied with the professional development opportunities offered by a consulting teacher whose area of certification was unknown to them $(M=3.21)$.

Differences between special and general education teachers. The survey responses provided by both special education and general education teachers indicated that they were substantially satisfied with the evaluative feedback and professional 
development opportunities offered to them during their participation in the PAR program. Regarding the evaluative feedback received, special education teachers' ratings ranged from 3.25 (out of 4.0) to 3.69 , and general education teachers' ratings ranged from 3.35 (out of 4.0) to 3.71. The value rating provided by both special education and general education teachers for their level of satisfaction with the evaluative feedback offered to them during their participation in the PAR program, in spite of the professional providing the feedback to them, were above a mean rating of 3.0 - the threshold for the very satisfied rating. Standard deviations among special education teachers' ratings ranged from 0.54 to 0.65 , and the ones among general education teachers ranged from 0.57 to 0.80 . That indicates that the variability in responses among special education teachers and among general educations teachers was small. The high mean combined with the low standard deviation implies that few special and general education teachers disagreed with the majority that were substantially satisfied with the evaluative feedback offered to them during their participation in the program. Table 17 presents a comparison between the mean scores reflecting how special and general education teachers rated their level of satisfaction with the evaluative feedback provided.

Table 17

Mean Scores for Special and General Education Teachers' Rating of Level of Satisfaction with Evaluative Feedback

\begin{tabular}{lcc}
\hline Specific Professional & SE & GE \\
\hline Consulting Teacher & & \\
Teaching Certification Unknown & 3.25 & 3.35 \\
Certified in General Education & 3.69 & 3.71 \\
Certified in Special Education & 3.43 & 3.57 \\
School Administrator & 3.37 & 3.40 \\
\hline
\end{tabular}


Evaluative Feedback. Overall, both special education $(M=3.69)$ and general education teachers $(M=3.71)$ were satisfied the most with the evaluative feedback offered to them by a general education consulting teacher during their participation in the PAR program. Next, special education $(M=3.43)$ and general education teachers $(M=3.57)$ also agreed that, following the feedback offered by a general education consulting teacher, the evaluative feedback with which they were satisfied the most was the one provided by a special education consulting teacher. Then, both special education $(M=3.37)$ and general education teachers $(M=3.40)$ were the most satisfied with the evaluative feedback offered by a school administrator. Finally, the evaluative feedback received from a consulting teacher whose area of certification was unknown to them was the one with which special education $(M=3.25)$ and general education teachers $(M=3.35)$ were the least satisfied.

Professional development opportunities. Overall, both special education $(M=3.69)$ and general education teachers $(M=3.49)$ were satisfied the most with the professional development opportunities offered to them by a general education consulting teacher during their participation in the PAR program. Next, special education teachers indicated that, following the professional development opportunities offered by a general education consulting teacher, the professional development opportunities with which they were satisfied the most were the ones provided by a school administrator $(M=3.40)$. However, general education teachers indicated that, following the professional development opportunities offered by a general education consulting teacher, the professional development opportunities with which they were satisfied the most were the ones provided by a special education consulting teacher $(M=3.29)$. Then, special education teachers were satisfied the most with the professional development opportunities offered 
by a special education consulting teacher $(M=3.36)$, and general education teachers with the ones offered by a school administrator $(M=3.25)$. Finally, the professional development opportunities received from a consulting teacher whose area of certification was unknown to them were the ones with which special education $(M=3.08)$ and general education teachers $(M=3.21)$ were the least satisfied. Table 18 presents a comparison between the mean scores reflecting how special education and general education teachers rated their level of satisfaction with the professional development opportunities provided to them during their participation in the PAR program.

Table 18

Mean Scores for Special and General Education Teachers' Rating of Level of Satisfaction with Professional Development Opportunities

\begin{tabular}{lcc}
\hline Specific Professional & SE & GE \\
\hline Consulting Teacher & & \\
Teaching Certification Unknown & 3.08 & 3.21 \\
Certified in General Education & 3.69 & 3.49 \\
Certified in Special Education & 3.36 & 3.29 \\
School Administrator & 3.40 & 3.25 \\
\hline
\end{tabular}

\section{Research Question 2}

The present study's second question addressed whether or not a statistically significant difference existed between the ratings given by special and general education teachers to the impact that their participation in the PAR program had on their teaching. The specific question was the following: is there a statistically significant difference between the manner in which special education teachers and general education teachers rate the extent to which their participation in a PAR program impacts their teaching in targeted areas? 
In order to answer the question, the researcher conducted an independent samples $t$-test to evaluate the difference between the means of the ratings given by special education teachers and the ones given by general education teachers to the impact that their participation in the PAR program had on specific components of targeted areas of their teaching. The seven targeted teaching areas were the following: (a) knowledge of learners, (b) instructional planning, (c) instructional delivery and engagement, (d) assessment of learners, (e) communication, (f) learning environment, and (g) overall professionalism.

In order to evaluate the assumption that the population variances for the two groups were equal - one of the underlying assumptions of the independent samples $t$-test - the researcher conducted a Levene's Test for Equality of Variances. The F value for Levene's test for the components of the targeted teaching areas ranged from 0.007 to 4.478. Additionally, the significance value ranged between 0.036 and 0.932 .

In order for the homogeneity of variance assumption to be met, the significance value associated with the F value for Levene's test must be greater than 0.05 . Out of the 20 components of the targeted teaching areas, 18 had a significance value greater than 0.05. However, the following two components did not: (a) ability to create a learning environment that encourages respect (Sig. $=0.036$ ) and (b) ability to comply with legal, ethical, and professional standards (Sig. $=0.041$ ). Therefore, the standard $t$ value is reported for the 18 components whose significance value was greater than 0.05 . However, the $t$ value that does not assume equal variances is reported for the two components whose significance value was less than 0.05 . The components that fall under each one of the targeted areas of teaching are listed in Table 19. 
Table 19

Components of Targeted Areas of Teaching

\begin{tabular}{|c|c|}
\hline Targeted Area & Component \\
\hline Knowledge of & a Ability to identify and address the individual differences of students \\
\hline \multirow[t]{3}{*}{ Learners } & b Ability to identify and address the individual cultures of students \\
\hline & $\begin{array}{l}\text { c Ability to identify and address the individual backgrounds of } \\
\text { students }\end{array}$ \\
\hline & $\begin{array}{l}\text { d Ability to identify and address the individual learning styles of } \\
\text { students }\end{array}$ \\
\hline \multirow{3}{*}{$\begin{array}{l}\text { Instructional } \\
\text { Planning }\end{array}$} & e Ability to use appropriate curricula to develop lesson plans that \\
\hline & address the diverse needs of students \\
\hline & $\begin{array}{l}\text { f Ability to use instructional strategies and resources to develop } \\
\text { lesson plans that address the diverse needs of students }\end{array}$ \\
\hline Instructional & $\mathrm{g}$ Ability to promote learning by demonstrating accurate content \\
\hline Delivery and & knowledge \\
\hline Engagement & $\begin{array}{l}\mathrm{h} \text { Ability to promote learning by addressing academic needs through } \\
\text { a variety of appropriate instructional strategies and technologies } \\
\text { that engage learners }\end{array}$ \\
\hline \multirow[t]{3}{*}{$\begin{array}{l}\text { Assessment of } \\
\text { Learners }\end{array}$} & $\begin{array}{l}\text { i Ability to gather, analyze, and use data (including current state } \\
\text { assessment data, as applicable) to measure learner progress }\end{array}$ \\
\hline & $\begin{array}{l}\mathrm{j} \text { Ability to gather, analyze, and use data (including current state } \\
\text { assessment data, as applicable) to guide instruction }\end{array}$ \\
\hline & $\begin{array}{l}\mathrm{k} \text { Ability to gather, analyze, and use data (including current state } \\
\text { assessment data, as applicable) to provide timely feedback }\end{array}$ \\
\hline \multirow[t]{3}{*}{ Communication } & 1 Ability to communicate effectively with students \\
\hline & $\begin{array}{l}\mathrm{m} \text { Ability to communicate effectively with students' parents or } \\
\text { families }\end{array}$ \\
\hline & $\begin{array}{l}\mathrm{n} \text { Ability to communicate effectively with staff and other members of } \\
\text { the learning community }\end{array}$ \\
\hline Learning & o Ability to create a safe learning environment \\
\hline \multirow[t]{3}{*}{ Environment } & $\mathrm{p}$ Ability to create a learning environment that encourages fairness \\
\hline & $\mathrm{q}$ Ability to create a learning environment that encourages respect \\
\hline & $r$ Ability to create a learning environment that encourages enthusiasm \\
\hline Overall & s Ability to comply with legal, ethical, and professional standards \\
\hline Professionalism & $\mathrm{t}$ Ability to engage in continuous professional growth \\
\hline
\end{tabular}

Table 20 presents the independent samples $t$-test resulting data. Furthermore,

Table 21, presents the specific $t$ value for each one of the 20 components associated with the targeted areas of teaching. 
Table 20

Independent Samples t-test Resulting Data

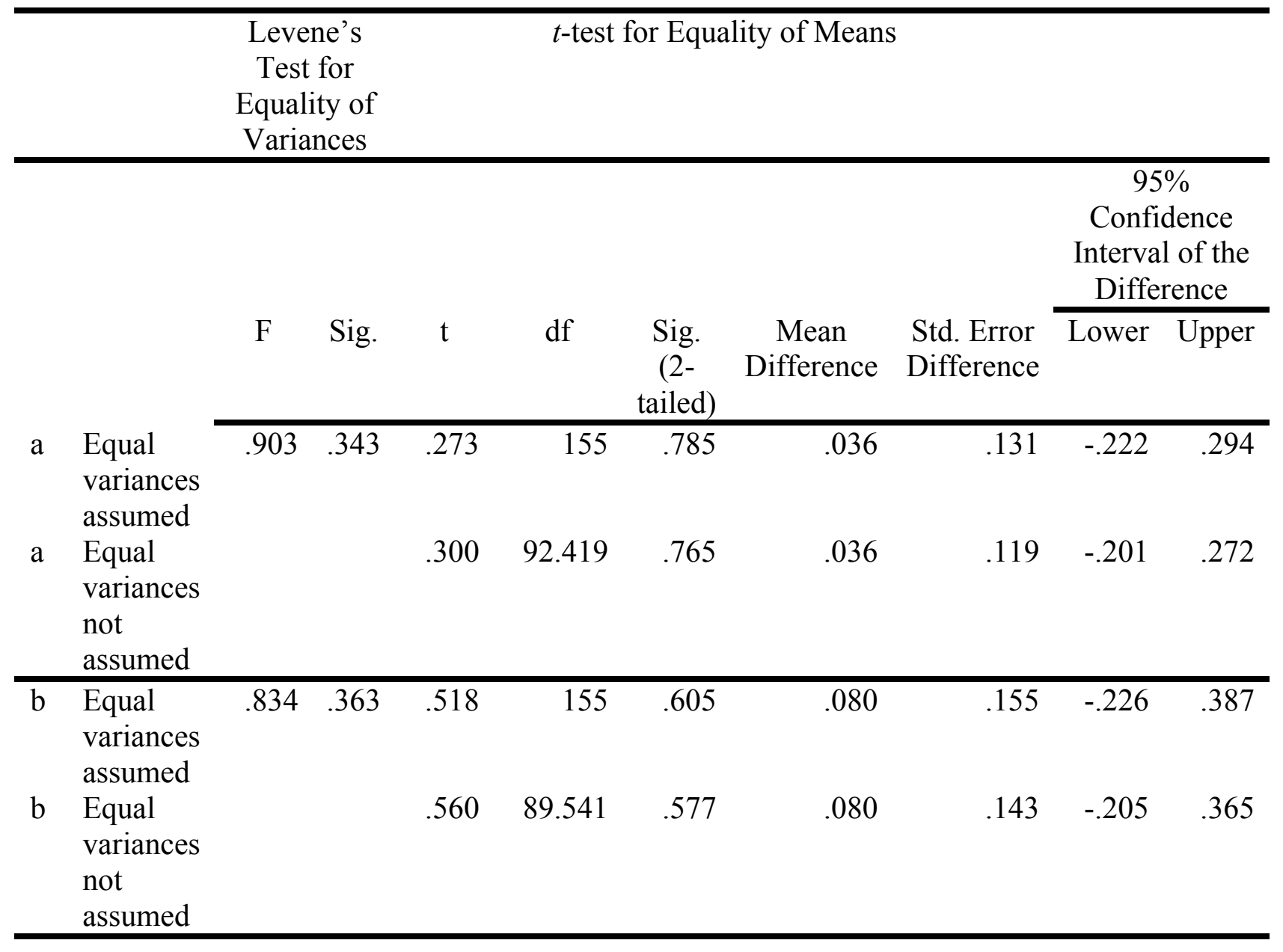




\begin{tabular}{|c|c|c|c|c|c|c|c|c|c|c|}
\hline $\mathrm{c}$ & $\begin{array}{l}\text { Equal } \\
\text { variances } \\
\text { assumed } \\
\text { Equal } \\
\text { variances } \\
\text { not } \\
\text { assumed }\end{array}$ & 2.116 & .148 & .225 & 91.424 & .822 & .031 & .149 & -.241 & .326 \\
\hline $\mathrm{d}$ & $\begin{array}{l}\text { Equal } \\
\text { variances } \\
\text { assumed } \\
\text { Equal } \\
\text { variances } \\
\text { not } \\
\text { assumed }\end{array}$ & 1.058 & .305 & .662 & 92.990 & .509 & .088 & .133 & -.175 & .350 \\
\hline $\mathrm{e}$ & $\begin{array}{l}\text { Equal } \\
\text { variances } \\
\text { assumed } \\
\text { Equal } \\
\text { variances } \\
\text { not } \\
\text { assumed }\end{array}$ & .184 & .669 & -.399 & 85.801 & .691 & $\begin{array}{l}-.052 \\
-.052\end{array}$ & .131 & $\begin{array}{l}-.310 \\
-.296\end{array}$ & .192 \\
\hline $\mathrm{f}$ & $\begin{array}{l}\text { Equal } \\
\text { variances } \\
\text { assumed } \\
\text { Equal } \\
\text { variances } \\
\text { not } \\
\text { assumed }\end{array}$ & .342 & .559 & -.423 & 85.801 & .673 & -.052 & .123 & -.296 & .192 \\
\hline
\end{tabular}




\begin{tabular}{|c|c|c|c|c|c|c|c|c|c|c|}
\hline $\mathrm{g}$ & $\begin{array}{l}\text { Equal } \\
\text { variances } \\
\text { assumed } \\
\text { Equal } \\
\text { variances } \\
\text { not } \\
\text { assumed } \\
\end{array}$ & .694 & .406 & .386 & 85.611 & .691 & .056 & .145 & -.230 & .342 \\
\hline $\mathrm{h}$ & $\begin{array}{l}\text { Equal } \\
\text { variances } \\
\text { assumed } \\
\text { Equal } \\
\text { variances } \\
\text { not } \\
\text { assumed } \\
\end{array}$ & 2.289 & .132 & .688 & 100.542 & .700 & 0.84 & .123 & -.158 & .327 \\
\hline $\mathrm{i}$ & $\begin{array}{l}\text { Equal } \\
\text { variances } \\
\text { assumed } \\
\text { Equal } \\
\text { variances } \\
\text { not } \\
\text { assumed }\end{array}$ & .118 & .732 & -.099 & 83.377 & .921 & $\begin{array}{l}-.014 \\
-.014\end{array}$ & .140 & $\begin{array}{l}-.291 \\
-.280\end{array}$ & .252 \\
\hline $\mathrm{j}$ & $\begin{array}{l}\text { Equal } \\
\text { variances } \\
\text { assumed } \\
\text { Equal } \\
\text { variances } \\
\text { not } \\
\text { assumed }\end{array}$ & .007 & .932 & -.691 & 77.679 & .492 & -.090 & .130 & -.348 & .169 \\
\hline
\end{tabular}




\begin{tabular}{|c|c|c|c|c|c|c|c|c|c|c|}
\hline $\mathrm{k}$ & $\begin{array}{l}\text { Equal } \\
\text { variances } \\
\text { assumed } \\
\text { Equal } \\
\text { variances } \\
\text { not } \\
\text { assumed }\end{array}$ & .147 & .702 & -.392 & 83.243 & .709 & -.052 & .138 & -.324 & .221 \\
\hline 1 & $\begin{array}{l}\text { Equal } \\
\text { variances } \\
\text { assumed } \\
\text { Equal } \\
\text { variances } \\
\text { not } \\
\text { assumed } \\
\end{array}$ & 1.475 & .226 & .431 & 91.642 & .667 & .065 & .151 & -.233 & .339 \\
\hline $\mathrm{m}$ & $\begin{array}{l}\text { Equal } \\
\text { variances } \\
\text { assumed } \\
\text { Equal } \\
\text { variances } \\
\text { not } \\
\text { assumed } \\
\end{array}$ & 3.331 & .070 & 1.164 & 102.838 & .246 & .188 & .162 & $\begin{array}{l}-.131 \\
-.091\end{array}$ & .468 \\
\hline $\mathrm{n}$ & $\begin{array}{l}\text { Equal } \\
\text { variances } \\
\text { assumed } \\
\text { Equal } \\
\text { variances } \\
\text { not } \\
\text { assumed }\end{array}$ & 2.083 & .151 & 1.071 & 101.743 & .286 & .152 & .142 & -.095 & .434 \\
\hline
\end{tabular}




\begin{tabular}{|c|c|c|c|c|c|c|c|c|c|c|}
\hline $\mathrm{O}$ & $\begin{array}{l}\text { Equal } \\
\text { variances } \\
\text { assumed } \\
\text { Equal } \\
\text { variances } \\
\text { not } \\
\text { assumed }\end{array}$ & 1.799 & .182 & .703 & 94.652 & .483 & .105 & .150 & -.191 & .402 \\
\hline $\mathrm{p}$ & $\begin{array}{l}\text { Equal } \\
\text { variances } \\
\text { assumed } \\
\text { Equal } \\
\text { variances } \\
\text { not } \\
\text { assumed } \\
\end{array}$ & 2.794 & .097 & 1.073 & 102.157 & .286 & .134 & .143 & $\begin{array}{l}-.149 \\
-.114\end{array}$ & $\begin{array}{l}.418 \\
.383\end{array}$ \\
\hline$q$ & $\begin{array}{l}\text { Equal } \\
\text { variances } \\
\text { assumed } \\
\text { Equal } \\
\text { variances } \\
\text { not } \\
\text { assumed } \\
\end{array}$ & 4.478 & .036 & .690 & 110.905 & .491 & .099 & .144 & $\begin{array}{l}-.185 \\
-.142\end{array}$ & .341 \\
\hline r & $\begin{array}{l}\text { Equal } \\
\text { variances } \\
\text { assumed } \\
\text { Equal } \\
\text { variances } \\
\text { not } \\
\text { assumed }\end{array}$ & 1.405 & .238 & .363 & 96.459 & .717 & .050 & .137 & -.221 & .320 \\
\hline
\end{tabular}




\begin{tabular}{|c|c|c|c|c|c|c|c|c|c|c|}
\hline $\mathrm{S}$ & $\begin{array}{l}\text { Equal } \\
\text { variances } \\
\text { assumed } \\
\text { Equal } \\
\text { variances } \\
\text { not } \\
\text { assumed }\end{array}$ & 4.247 & .041 & 1.058 & 107.264 & .292 & .158 & .149 & -.137 & .452 \\
\hline $\mathrm{t}$ & $\begin{array}{l}\text { Equal } \\
\text { variances } \\
\text { assumed }\end{array}$ & 2.066 & .153 & .561 & 155 & .576 & .067 & .119 & -.168 & .301 \\
\hline $\mathrm{t}$ & $\begin{array}{l}\text { Equal } \\
\text { variances } \\
\text { not } \\
\text { assumed }\end{array}$ & & & .633 & 99.025 & .528 & .067 & .105 & -.142 & .275 \\
\hline
\end{tabular}


Table 21

Specific $t$ Value of Targeted Areas of Teaching Components

\begin{tabular}{|c|c|c|c|}
\hline & Component & $t$ & $p$ \\
\hline $\mathrm{a}$ & $\begin{array}{l}\text { Ability to identify and address the individual differences of } \\
\text { students }\end{array}$ & $t(155)=.27$ & $p=.79$ \\
\hline $\mathrm{b}$ & $\begin{array}{l}\text { Ability to identify and address the individual cultures of } \\
\text { students }\end{array}$ & $t(155)=.52$ & $p=.61$ \\
\hline $\mathrm{c}$ & $\begin{array}{l}\text { Ability to identify and address the individual backgrounds of } \\
\text { students }\end{array}$ & $t(155)=.21$ & $p=.84$ \\
\hline $\mathrm{d}$ & $\begin{array}{l}\text { Ability to identify and address the individual learning styles } \\
\text { of students }\end{array}$ & $t(155)=.66$ & $p=.51$ \\
\hline & $\begin{array}{l}\text { Ability to use appropriate curricula to develop lesson plans } \\
\text { that address the diverse needs of students }\end{array}$ & $t(155)=-.40$ & $p=.69$ \\
\hline f & $\begin{array}{l}\text { Ability to use instructional strategies and resources to develop } \\
\text { lesson plans that address the diverse needs of students }\end{array}$ & $t(155)=-.40$ & $p=.69$ \\
\hline $\mathrm{g}$ & $\begin{array}{l}\text { Ability to promote learning by demonstrating accurate content } \\
\text { knowledge }\end{array}$ & $t(155)=.39$ & $p=.70$ \\
\hline $\mathrm{h}$ & $\begin{array}{l}\text { Ability to promote learning by addressing academic needs } \\
\text { through a variety of appropriate instructional strategies and } \\
\text { technologies that engage learners }\end{array}$ & $t(155)=.69$ & $p=.49$ \\
\hline $\mathrm{i}$ & $\begin{array}{l}\text { Ability to gather, analyze, and use data (including current } \\
\text { state assessment data, as applicable) to measure learner } \\
\text { progress }\end{array}$ & $t(155)=-.10$ & $p=.92$ \\
\hline & $\begin{array}{l}\text { Ability to gather, analyze, and use data (including current } \\
\text { state assessment data, as applicable) to guide instruction }\end{array}$ & $t(155)=-.68$ & $p=.50$ \\
\hline $\mathrm{k}$ & $\begin{array}{l}\text { Ability to gather, analyze, and use data (including current } \\
\text { state assessment data, as applicable) to provide timely } \\
\text { feedback }\end{array}$ & $t(155)=-.37$ & $p=.71$ \\
\hline 1 & Ability to communicate effectively with students & $t(155)=.43$ & $p=.67$ \\
\hline & $\begin{array}{l}\text { Ability to communicate effectively with students' parents or } \\
\text { families }\end{array}$ & $\begin{array}{l}t(155)= \\
1.16\end{array}$ & $p=.25$ \\
\hline & $\begin{array}{l}\text { Ability to communicate effectively with staff and other } \\
\text { members of the learning community }\end{array}$ & $\begin{array}{l}t(155)= \\
1.07\end{array}$ & $p=.29$ \\
\hline & Ability to create a safe learning environment & $t(155)=.70$ & $p=.48$ \\
\hline & $\begin{array}{l}\text { Ability to create a learning environment that encourages } \\
\text { fairness }\end{array}$ & $t(155)=.94$ & $p=.35$ \\
\hline $\mathrm{q}$ & $\begin{array}{l}\text { Ability to create a learning environment that encourages } \\
\text { respect }\end{array}$ & $t(111)=.82$ & $p=.42$ \\
\hline $\mathrm{r}$ & $\begin{array}{l}\text { Ability to create a learning environment that encourages } \\
\text { enthusiasm }\end{array}$ & $t(155)=.36$ & $p=.72$ \\
\hline $\mathrm{S}$ & $\begin{array}{l}\text { Ability to comply with legal, ethical, and professional } \\
\text { standards }\end{array}$ & $\begin{array}{l}t(107)= \\
1.24\end{array}$ & $p=.22$ \\
\hline & Ability to engage in continuous professional growth & $t(155)=.56$ & $p=.58$ \\
\hline
\end{tabular}


The results shown in Tables 20 and 21 indicate that the independent-samples $t$-test conducted for all 20 components of the seven targeted areas of teaching - regardless of whether or not the $t$ value assumed equal variances - were not significant. The statement holds true for any level of significance, from 0.001 to 0.20 . Therefore, there is no statistically significant difference between the manner in which special education teachers and general education teachers rate the extent to which their participation in a PAR program impacts their teaching in targeted areas.

\section{Phase 2 Data Analysis and Results}

\section{Research Question 3}

The third research question addresses the experience of being a participating teacher in a PAR program from the perspective of special education teachers. The specific research question is the following: how do special education teachers describe their experiences as a participating teacher in a PAR program?

In order to analyze the qualitative data collected to address this research question, the researcher utilized methods recommended by Rubin and Rubin (2005). First, the researcher transcribed the recorded interviews verbatim. Next, the researcher reviewed the transcripts and made notations. Then, via inductive analysis, the researcher analyzed the patterns and themes that emerged from the data. Subsequently, the research categorized the themes and coded them accordingly. Finally, the researcher grouped the codes and charted them on a spreadsheet. The researcher went through several iterations of this process, while continuously searching for systematic relationships among participants' statements and refining the data. The following eight themes emerged from 
the iterative qualitative process: (a) consulting teachers, (b) consulting teachers' consistency, (c) consulting teachers' area of certification, (d) formal observations, (e) feedback, (f) embedded professional development, (g) professional development, and (h) new teachers.

Seven special education teachers described, through semi-structure interviews, their experience as a participating teacher in the PAR program implemented in their school district. They talked about the relationship they developed with their consulting teachers and the consistency with which they received classroom support from those individuals. They discussed whether or not having a consulting teacher certified in special education mattered. They described the formal observations of their practice conducted by their consulting teachers, and they compared and contrasted them to the ones carried out by their school administrators. They also talked about the feedback received as a result of the observations and about the embedded professional development opportunities that it triggered. In addition, while reflecting on embedded professional development, the participating special education teachers being interviewed discussed professional development activities offered to their school faculty as a whole. Finally, a few of the interviewees added thoughts about the use of PAR with new teachers.

The analysis of the data indicated that the special education teachers who were interviewed considered their participation in the PAR program to have been beneficial to their teaching practice regardless of the type of teaching certification held by their consulting teacher. Nevertheless, special education teachers felt that their participation in the program would have been more beneficial, had their consulting teacher been an 
educator certified in special education. The interviewees also mentioned the importance of having consistency in the support received by their consulting teachers. In addition, the participating special educators considered the formal observations conducted by, and the feedback received from, their consulting teachers to be more thorough and meaningful than those carried out and that given by their school administrators. Furthermore, they considered the embedded professional development opportunities that resulted from those observations and feedback to have been helpful in improving their practice. They also considered the professional development offered to school faculty as a whole to make staff more cohesive. Finally, a few of the interviewees added that they thought that a program such as PAR would be beneficial to new teachers.

Participant profiles. In the current section, the researcher presents the reader with information concerning participants' background and general characteristics. In order to maintain confidentiality, the researcher chose to identify each participant by a specific pseudonym and not to share specific details regarding participants' school site.

Amelia has been teaching for quite some time and intends to retire in a couple of years. In her current position - which she has held for the past ten years - Amelia teaches students with various exceptionalities in a middle school self-contained setting. Amelia has taught special education throughout her entire career, and it is in this field of knowledge that she has earned her doctorate. In spite of her accomplishments, however, she described herself in the following manner, "I am humble. I am a simple teacher."

Beatriz is a veteran teacher who has been teaching students with intellectual disability in a self-contained setting for over 25 years. She teaches at the same high school where she began her career many years ago. Beatriz is very animated and speaks 
very quickly. Every now and then, she said, "I hope I didn't go too fast. Slow me down." Beatriz has a master's degree in special education and has been searching for a scholarship to pursue a doctorate in the same field. She is a practical person and values both her professional and personal time. She illustrated that by saying,

I went to one [of the professional developments], and I didn't go to the rest of them, because I just felt it wasn't worth my time. Seeing where I am, with what I make, my daily rate teaching, I really don't want to take my personal time to come and sit for something that is not important to me.

Brenda has been teaching reading to students with and without disabilities in a high school inclusive setting for the past seven years. She has a master's degree in special education and a specialization in reading. Brenda is mild mannered and soft-spoken. She believes in collaboration among teachers and across academic departments. However, she feels that is not the reality at the school where she works. Brenda expressed her concern with the lack of collaboration at her school site in the following manner,

Other schools might be different than ours, but I know our school is very broken as far as departments are concerned.... Even in a faculty meeting they end up kind of sitting with each other. You know what I mean?

Claudia has been teaching for 13 years. She teaches students with and without disabilities in an inclusive elementary school setting. She has always been in an elementary school, and she intends to keep it that way. Claudia expresses herself in an optimistic manner. She is the type of person who always sees the glass halfway full. Claudia believes in building relationships with people, in seeing the person in the professional. She thinks that makes a difference. Claudia said the following about her consulting teachers, "I feel like if I were to see them, you know, along somewhere having 
dinner with their families, I would stop and say, 'Hello'. And, you know, 'How is everything going?"”

Crystal has a master's degree in special education and teaches high school math to students with and without disabilities. She has been teaching for 17 years - all of them in a high school inclusive setting. Crystal is a confident professional who constantly seeks growth. She expressed her desire for continuous improvement in the following passage of her interview, "Okay, but, how can you help me? How can I improve? It's great that you think what I'm doing is good. But how can I improve myself? Because I do want to be better."

Fabiola is a National Board Certified teacher who has taught preschool her entire career. She has a master's degree in early childhood education and has taken additional courses to add the Preschool with Disabilities endorsement to her teaching certificate. After teaching preschool to students with and without disabilities in an inclusive setting for more than 30 years, Fabiola is getting ready to retire in two years. Fabiola has enjoyed her career as a teacher and truly loves what she does. However, Fabiola has noticed that a lot has changed since she began her career, and she is concerned about teachers and how they are being evaluated. Fabiola said:

I feel for teachers right now but, particularly, [Exceptional Student Education] ESE teachers. I think that they're just, like, working with so little. So little time, so little. So, I, I. Maybe, the question would be: Do you feel like? I don't know. Support for teachers is a whole other thing. But, if you're going to evaluate them, how about evaluating the program?... I'm saying, you're evaluating the teacher, the ESE teacher, but where does the program get evaluated? They're trying to teach within. I mean, in the school, that's what I'm talking about. I mean, the amount of time that they get to see a child, and the pullout schedules, their tools, and, and, and. I mean, we can evaluate someone all we want, but if they don't have this foundation to do the work that they do. You know? 
Priscilla has a bachelor's degree in special education and has been teaching for 27 years. She has taught in different special education settings, from self-contained to inclusion, and in different school levels, from elementary to high school. She currently teaches in a self-contained setting for students with intellectual disability in a high school and also serves as her department's chairperson. Priscilla is very careful with her words and is concerned that someone might think she is saying something bad about somebody else. This carefulness can be noted when she made the following observation about her consulting teachers,

That was the only part that I found that was, you know. And they, they were very. They were always here if I needed anything. So, I don't want to come across negative that they weren't, they weren't here; they were. But it was limited because of the dynamics of my position.

Table 22 summarizes the general demographic, professional, and work environment characteristics related to the participants.

Table 22

Summary of Participants' General Characteristics

\begin{tabular}{|c|c|c|c|c|c|c|c|c|}
\hline Pseud. & Gender & Race & Hisp. & $\begin{array}{l}\text { School } \\
\text { Level } \\
\text { Taught }\end{array}$ & $\begin{array}{l}\text { Educational } \\
\text { Setting }\end{array}$ & $\begin{array}{l}\text { Years } \\
\text { of Exp. }\end{array}$ & Ed. Level & $\begin{array}{l}\text { Sch. } \\
\text { Grd. }\end{array}$ \\
\hline Amelia & Female & White & $\overline{\mathrm{N}}$ & $\bar{M}$ & $\begin{array}{l}\text { Self- } \\
\text { contained }\end{array}$ & $>10$ & Doctoral & $\bar{C}$ \\
\hline Beatriz & Female & White & Y & $\mathrm{H}$ & $\begin{array}{l}\text { Self- } \\
\text { contained }\end{array}$ & $>10$ & Master's & $\mathrm{C}$ \\
\hline Brenda & Female & White & $\mathrm{N}$ & $\mathrm{H}$ & Inclusion & 5 to 10 & Master's & $\mathrm{C}$ \\
\hline Claudia & Female & White & Y & E & Inclusion & $>10$ & Master's & $\mathrm{C}$ \\
\hline Crystal & Female & White & Y & $\mathrm{H}$ & Inclusion & $>10$ & Master's & $\mathrm{C}$ \\
\hline Fabiola & Female & White & Y & $\mathrm{P}$ & Inclusion & $>10$ & Master's & $\mathrm{C}$ \\
\hline Priscilla & Female & White & $\mathrm{N}$ & $\mathrm{H}$ & Inclusion & $>10$ & Bachelor's & $\mathrm{C}$ \\
\hline
\end{tabular}

Note. Pseud. = Pseudonym; Hisp. $=$ of Hispanic origin; Years of Exp. = Years of

Experience; Ed. Level = Education Level; Sch. Grd. = School Grade; $\mathrm{Y}=\mathrm{Yes} ; \mathrm{N}=$ No; $\mathrm{H}=$ High School; $\mathrm{M}=$ Middle School; $\mathrm{E}=$ Elementary School; $\mathrm{P}=$ Preschool. 
Consulting teachers. The interactions between special education participating teachers and consulting teachers were one of the foci of the semi-structured interviews conducted as part of the qualitative phase of the present study. The researcher was interested in knowing how well one group of professionals interacted with the other. Moreover, the researcher wanted to inquire about any potential benefits resulting from that interaction. Furthermore, the researcher had the intent to find out from the interviewees what they considered to be positive and negative as well as advantageous and disadvantageous regarding the potential support they received from their consulting teachers during their participation in the program.

The seven special educators who participated in the PAR program, and who agreed to be interviewed, indicated that their consulting teachers were likeable and professional. Furthermore, they shared they felt very comfortable working with them. Beatriz, for instance, said, "I had a good experience because the teachers that came in were very likeable. You know, I felt very comfortable talking to them.”

Claudia also mentioned how comfortable she felt with her consulting teachers, and she added, "They had a lot of great information to share". In her interview, Claudia shared the following,

We became very comfortable - at least, I became very comfortable - with [the consulting teachers] that were in and out of our classrooms.... Aside from the fact that they were helping us professionally, they were there to just, kind of, pat us on the back and continue to remind us that what we're doing is important and that it matters.

The interviewees not only found their consulting teachers to be likable and professional, but they also considered them to be resourceful and reliable. Amelia used the following words when describing how she felt about her consulting teachers, 
It was great. These women, men were absolutely wonderful.... They came in and asked what I needed in my classroom.... One of the [consulting] teachers came in, and she came to my class every single day.... It was a delightful experience.

Priscilla also used the word wonderful when talking about her consulting teachers.

Priscilla described their resourcefulness and reliability in the following manner,

They were wonderful.... "Anything you need... let me know." And they did come in and say... "What trials do you have? Tell me what you find the most difficult [about] your job". So...whatever I said, they did come back with ideas and certain things to support.

Two of the participating special education teachers being interviewed, Brenda and Crystal, when addressing the resourcefulness of their consulting teachers, added that these individuals were well-versed in educational technology and software and used such knowledge to provide support in the classroom. Beatriz, for instance, shared,

[My consulting teacher] happened to be very good with software and data, and he really helped me in terms of coming up with some instruments that I can use to collect data for my students. So, that was phenomenal, because he actually asked me, "What're we doing? What're we observing?" and was able to formulate with me... a spreadsheet that I can use to track my students' skills.

In turn, Crystal, when mentioning how technologically savvy her consulting teacher was, said that individual not only used her knowledge of technology to assist in the classroom but also utilized it toward the benefit of the students. Crystal's specific words were,

[My consulting teacher] came in, and she gave me a lot of ideas and, you know, how to use more technology in my classroom, which I thought was great... She had me use all kinds of stuff and gizmos. She even helped me use the white board more. So, it was more interactive for the students.

Consulting teachers' consistency. During the interviews, while talking about the advantages and disadvantages of working with a consulting teacher, the topic of 
consistency emerged as a common theme. The participating special educators indicated that, when the consulting teachers were consistent in their provision of support, having them in their classrooms was beneficial not only to them, the teachers, but also to their students. However, when there was no consistency in the support provided, it became pointless and, sometimes, even more challenging to have the consulting teacher in the classroom. For instance, Brenda said, "I would've been the same teacher with or without them, honestly." In addition, Crystal mentioned, "It was just very sporadic. There is a lot going on in my room, and to add an additional adult in my room."

Brenda and Fabiola mentioned that, at first, during the first years of implementation of the program, consistency was there. The consulting teachers were constantly in the classrooms, providing support to participating teachers and even to participating teachers' students. However, according to the two participating special education teachers, that changed overtime. Brenda and Fabiola shared they believed the change occurred because of a shift in priority, initiated by both their school's administration and the district leadership. Fabiola shared the following regarding how the manner in which her administration made use of the consulting teachers at her school changed overtime,

At first, when [the consulting teachers] started, it seemed like the administration were using them in a good way. And, then, I think they were using them, kind of abusing them, their work... Even [make them] run faculty meetings. And there was no follow through.

Brenda's perception of the shift in priority was similar to Fabiola's. However, Brenda felt that, instead of having been set forth by her school's administration, the change in priority was initiated at the district level. Brenda's exact words were, 
At some point in this process - I think I've been part of it for four years - I felt... they weren't as accessible as they had been that first year we had them here, at [my school]. That first year... I feel like I talked to them all the time... I was kind of brainstorming with them a lot more. And I felt like there was some point when they kind of were not available as much anymore. They were available for district stuff.

Amelia also noticed a shift in priority at her school. However, unlike Brenda and Fabiola, Amelia did not think it was entirely negative. In fact, she felt that it was helpful to have her consulting teachers assist her in completing the documentation necessary for her annual evaluation. In addition, unlike Brenda and Fabiola, Amelia did not think that the consistency of support provided by consulting teachers decreased at her school. She simply thought it was refocused toward mandated documentation used as part of the district's teacher effectiveness evaluation process. Amelia's precise words were,

Last year was just two [consulting teachers]. They were spread pretty thin... [My consulting teachers] came to my class almost every single day... to give myself confidence in the process of [completing the needed documentation for evaluation]... They helped me do the paperwork.

Crystal also shared that she experienced challenges with the consistency of support provided by her consulting teachers. However, Crystal's challenge was not triggered by a shift in priority originated either at her school or at the district level. Furthermore, unlike Brenda and Fabiola, who had consistency during their first years in the program, Crystal had no consistency in her first year of participation. The lack of consistency led Crystal to make the decision to leave the program during its second year of implementation. Crystal explained that she believed the inconsistency of her first consulting teachers was because of two factors. First, she believed they had too many participating teachers assigned to them. Crystal's specific words were, 
My first year, initially, I think they had set me up with somebody and, for some reason, he had too many people and. So, I got a different [consulting] teacher. She was good... but the consistency, the first year, it wasn't there. It was just very sporadic. There is a lot going on in my room, and to add an additional adult in my room. That's why I made the decision. It wasn't negative. It just wasn't influencing anything enough. That's why I made the decision not to participate the second year.

The second reason believed by Crystal to be one of the factors that contributed to the inconsistency of her first consulting teachers had to do with their area of certification. Crystal believed that, because they were not special education teachers, they did not know much about what was taking place in her classroom and could not provide her with any constructive feedback. Crystal shared the following,

Because the person that I was assigned to was not a special education teacher... they kind of come in and, "Everything you do is fabulous". "Okay, but how can you help me? How can I improve? It's great that you think what I'm doing is good. But how can I improve myself, because I do want to be better?" I just wasn't getting that. It wasn't consistent throughout the year. I went many weeks or sometimes a month or two without talking to that person. When I had the observation from the additional person, that was just strange, because he did not know what was going on in my classroom to begin with. And, then, you come to observe my room and, again, "You are doing such a great job. Everything is fine." But there wasn't anywhere I could improve. And, then, it took very long to get feedback from them. So, I couldn't even remember which lesson I had taught when he had come to observe me. So... it just wasn't consistent enough for me. And I didn't gain enough from it. So, I made the decision not to participate last year. This year, my experience was completely different.

When Crystal rejoined the program, her experience was completely different.

Crystal shared that she had a consulting teacher who consistently provided support to her as well as her students. The consulting teacher assigned to Crystal when she rejoined the program was not certified in special education; however, she was certified in math, which was the core subject area taught by Crystal, and Crystal felt that mattered. Crystal said the following about her second time as a participating teacher in the PAR program, 
The consultant I had was amazing. Constantly coming in and checking on me, "Do you need anything?" She was a math teacher, so she... kind of got where I was coming from, the kinds of things my students needed. And she gave me a bunch of materials I was able to use... that were great resources to me. So, it made such a big difference this year for me... She could name my kids. She knows who my kids are. You know, she really had a handle on what was going on in my room, and she understood what my needs were, and she was just consistent. I saw her at least once a week... It was really very beneficial this year.

Consulting teachers' area of certification. At first, Crystal mentioned that her consulting teachers' lack of certification in special education was one of the reasons why the PAR program did not work for her when she first joined it. Then, when she rejoined the program, Crystal was paired with a consulting teacher who was not certified in special education, but who was certified in the same core subject that she taught, math. This time around, Crystal thought the experience was beneficial. She said, "I think, special education teacher or not, [my consulting teacher] had a strong influence on what happened to my classroom this year, and I appreciated that."

Whether or not consulting teachers supporting participating special educators were certified in special education and whether or not that mattered were two of the areas on which this study focused. Therefore, the researcher asked Crystal to further compare and discuss both of her experiences, the one when she first joined the program and left, and the one when she rejoined the program a year later. Crystal shared,

Good teaching is good teaching, whether you're special ed. or whichever. So, someone can come into your classroom and, if you're not teaching well, whether you're teaching special education students, [they know]. You might just be using different approaches for [special ed. students], and I think that general ed. teachers do that as well. You know... each student is an individual one, whether or not they have an IEP, and you have to use different approaches for all students. So, I would think if it's an experience like the one I had this year, it's definitely beneficial to both, you know, general ed. and special ed..... It makes a big difference if the subject matter kind of lines up. But everyone had a basic understanding of special needs students, and, you know, I think if you come into a 
classroom, you should be aware of that. These are, I'm assuming, veteran teachers and they've probably been through several different types of students, and they're aware of all kinds of different learners.

Crystal was not the only participating teacher to express that the alignment of the certification area of the consulting teacher with that of the participating teacher was helpful. With the exception of Amelia, who said that whether or not her consulting teachers were certified in special education had never occurred to her, and who added that she was grateful for their assistance regardless of their area of certification, all other participating special education teachers who were interviewed for the present study agreed, to one degree or another, with Crystal.

Brenda did not go as far as saying that a certification area alignment between consulting and participating teachers was helpful. However, she did mention that consulting teachers working with participating special educators should have experience working with students with disabilities. Brenda's words were,

I know, for example, one of our peer educators... was a primary teacher in a coteaching classroom setting.... Most of us... have students who are special education in our classrooms, and I feel like, you know, [the consulting teachers] understood the techniques and how to deal with them.... I don't feel like they were disassociated with the special education classroom, like teachers coming from, like, maybe like an AP kind of environment. I don't feel like they were like that.

Unlike Brenda, Claudia did say that a certification area alignment between consulting and participating teachers would be helpful. Claudia shared that her consulting teachers provided her with a lot of assistance. However, she thought that if her consulting teachers and she had shared the same type of certification, the interaction between them would have been even better. Claudia's words were, 
I certainly think that... it would be helpful. I don't think it matters, because, let's say, I'm a special education teacher and my [consulting] teacher is not, but they still offer me a lot of help and a lot of support, you know, it's still great. Now... if we were both in the same field and coming from the same field, it's great, because, then, there is more information to share that, you know, they may know more than me.

Like Crystal, Claudia had a consulting teacher who taught math. She shared that, with the academic demands being placed on students with disabilities, it was helpful to have a consulting teacher with that kind of perspective in the classroom. When talking about this consulting teacher in particular, Claudia used the same expression that Crystal used, "good teaching is good teaching", and she added that she suspected that specific consulting teacher to be certified in special education. Claudia further shared,

I'm not sure, [my consulting teacher] may have been certified in special education because, at one point, I believe I was having an issue with one of my more aggressive students, and she told me that she was certified to restrain... I think that, for what I needed, because with special education changing the way it has and the academic demand that has been placed on our students, she was able to come in and, just from her math teacher perspective, she was able to see like where that helped. I think whether you are a special education teacher or a general ed. teacher, good teaching is good teaching, you know. So, and she seemed to have a good handle on how to show things and demonstrate things in different ways.

Unlike Crystal and Claudia, Fabiola did not use the expression, "good teaching is good teaching", when talking about her consulting teachers. Instead, her words were, "there is some kind of universal truth to teaching..." Fabiola had positive experiences with consulting teachers who were both certified and not certified in special education. Even though she considered both kinds of experiences to have been beneficial to her and her students, she did think that having a consulting teacher who was certified in special education made a substantial difference. Fabiola's words were, 
I think [that working with a consulting teacher who shares the same certification area] makes a huge difference. I think it's essential. I mean, I think there are teachers such as [first consulting teacher's name] who is just such an amazing teacher - and she usually teaches high school - that she can translate her knowledge [and] specialize it, because there is some kind of universal truth to teaching, no matter what you're doing. But, I think when I was working with [second consulting teacher's name] who had experience in ESE, it was really helpful. You just know... It's just, like, a specialty.... I think that's a no brainer. Yes, I think... your [consulting] teacher should be certified in the areas you are working in. Absolutely.

Beatriz's perception and experience were similar to Fabiola's. However, unlike

Fabiola, Beatriz did not work with a consulting teacher who was certified in special education. Instead, Beatriz had a consulting teacher who had had experience with inclusion and whose wife was a special education teacher. It was that consulting teacher who Beatriz found to be the most helpful to her and her students. Beatriz recounted her experience with this consulting teacher in the following manner,

I had one really, really good year. The best year that I had was with a teacher who was a general ed. teacher but had serviced a lot of kids in inclusion and... I just got lucky that his wife was also an ESE educator. So, when he came into my room, he was a professional that came in with some background knowledge. So, he was able to understand what I was supposed to do in my own classroom. You know, my kids are very limited. You know, we can't do the traditional things. We have to modify everything for our students. So, he was able to understand what my environment and my academic world looks like.

Still recounting her experience with the same consulting teacher, Beatriz shared that he took advantage of one of the formal observations he had to conduct of her practice and used it to improve the manner in which Beatriz questioned her students. Beatriz's words were,

One of the evaluations, you know, he said to me, "I want you to teach and just tell me what to look for. Let's decide what you want me to focus on." And, even though my kids are very involved, I said, "I want you to look at my questioning, and make sure that I don't skip over a kid, because there are kids that are nonverbal." Sometimes you are teaching, and you want to make sure that you get 
everybody. So, he sat through. He gave me great feedback where, even though my kids are very limited, he was able to tell me, "Okay, your questions are all, you know, at that basic level. And, you know, you only did a few for these kids." And he was able to say, "You know what? Try, how about we ask these types of questions to these three, who are in a small group, and see if they can take it to a higher level?"

Nevertheless, even though she had a positive experience with that consulting teacher, and even though she used the same expression used by both Crystal and Claudia, "good teaching is good teaching," when talking about consulting teachers, Beatriz did not think that the PAR program in which she participated catered to special education teachers. In fact, she considered the fact that most consulting teachers working with special educators were not certified in special education to be the only negative aspect of, and the only thing, she would like to see changed in the program. Beatriz shared,

I don't think the program is catered enough to a special ed. person.... I believe that good teaching is good teaching regardless, but I think there are things that are specific to our environment and our population.... I didn't really gain something that enhanced my specific field unless it's something that I created or I made a connection on my own with.... The only negative thing that I have, personally, with it is that I think, I guess most of the teachers that signed up to do it, not everybody has the background, the SPED [special education] background. So, I think I would've benefited better from a veteran teacher who has dealt with my population for a long time and who knows the research and the new strategies. [Someone who] could've come in and said, "Hey, look what's new. This is what I did in my classroom. This is what I saw at another school." So, in other words, for me, the [consulting teacher] really needs to be someone that understands what I do. So, I think that, for me, it would be better if I had a special ed. person, that, you know, that understands, that was certified, experienced to help me with my unique needs and in the classroom.

Priscilla agreed with Beatriz. The one thing she said she would like to see changed in the program would be the assignment of special education consulting teachers to participating special educators. Even though, like the other interviewees, Priscilla had consulting teachers who she considered to be helpful, Priscilla did not think the 
consulting teachers "really knew the dynamics of [her] position" and, therefore, could not offer more in-depth assistance regarding matters that specifically concern the field of special education.

Priscilla shared that, for one of the formal observations conducted by her consulting teachers, she chose to be observed during an IEP meeting. After asking the student and his parents' permission to have her consulting teachers come to the meeting, Priscilla set up a date and time for the observation to occur. Priscilla felt the consulting teachers provided her with valuable feedback. However, Priscilla thought that the feedback provided, even though beneficial, was lacking in special education substance. Priscilla's precise words were,

They still may not have known the trenches of [what I do], but they would know, you know, the criteria of an IEP, and an IEP meeting, and what to expect, what to look for. I think what they looked for, which was good, they looked for the professionalism of conducting a meeting. But they really didn't know, you know, or be able to pinpoint all the intricacies of what goes on in an IEP meeting, what should be covered, and what is, you know, law-abiding, and that kind of a thing.... They just didn't. They were just not prepared for it. So, that would be the only thing that I would say that I'd like changed.

Formal observations. Beatriz and Priscilla used the formal observation conducted by their consulting teachers as a means to improve their teaching. They saw in that observation an opportunity to have a peer observe an area of their practice that they felt was important and on which they wanted to improve. Beatriz said the following regarding that experience, "I think it's important when you have your colleagues coming in and seeing what you're doing and people that are in the trenches being part of that evaluation system. To me, it makes sense." Beatriz further shared that, by having the 
work she carries out in her classroom be observed by her consulting teachers, she felt validated. Beatriz exact words were,

I felt very validated in the sense that I'm able to show someone from the outside what I do, that they can understand that education for special kids is just as rigorous. You know, requires that high level of evaluation and preparation.

Similar to Beatriz and Priscilla, Crystal and Fabiola also saw the formal observation conducted by their consulting teachers as an opportunity for improvement. Furthermore, like Beatriz, Fabiola also used the word validated when describing how she felt having her practice observed by her consulting teachers. Fabiola's precise words were, "Even for me, as a veteran teacher, it was a very good experience. It validated what I was doing. And it helps me kind of refocus and reflect on what I could do better."

Respectively, regarding the opportunity for improvement in targeted areas of her practice, and also making a comparison between formal observations conducted by consulting teachers to the ones carried out by administrators, Crystal shared, "The approach of [the consulting teachers] is more, 'how can I help you?' Whereas being observed by an administrator is more [about] how you are doing, not what you can do to improve." Beatriz, Priscilla, and Crystal indicated that one of the reasons they saw the formal observation conducted by their consulting teachers as an opportunity for targeted growth was the fact that they felt very comfortable with those individuals, and they felt they could approach them, their consulting teachers, with their needs.

Similar to Beatriz, Priscilla, and Crystal, Claudia said that she felt very comfortable being observed by her consulting teachers. In fact, she shared that she felt substantially more comfortable being observed by those individuals than by her administrators. Claudia's words were, 
I can tell you that, because I was already very comfortable with them, that it almost felt like they were there just visiting, that it was another visit. So, it didn't faze me. I handed in my plans and my schedule, and they got there and just enjoyed the class, really, enjoyed the dynamics and everything else that was going on. And that was a very positive experience for me. My other experiences, when we'll have an administrator come in, and I am creeping up on my words and, you know, be overwhelmed when, really, this is second nature to me, this is what I do. So, this is that, that initial feeling of being watched, you know. When [the consulting teachers] observed me, it was good, it was positive, and... I felt this is just another day, another visit.

Further discussing her formal observation and comparing and contrasting the one conducted by her consulting teachers to the one carried out by a member of her administration, Claudia shared,

It also depends on the person, you know, which particular administrator and which [consulting] teacher, because every relationship is different. Right? But I think there is a difference because I feel, like, we have more of... an even level of communication... I feel like I can approach our [consulting] teachers... in a way that [is] more, how do I explain? Teacher-to-teacher versus teacher-to-boss. You know what I'm saying? While I do have some kind of, what's the word? Confidence to approach my administrator concerning certain things, I don't necessarily talk to them about everyday teacher things. You know what I'm saying? Whereas, with my [consulting] teachers, I did have that comfortableness, if you can say that, for I could ask questions and I could kind of just vent if I needed to. Not necessarily a bad vent, but just, "Wow, this is overwhelming. What can I do to fix it or to unload?" You know, my load of things to do.... You wouldn't necessarily do that with your boss, with your administrator.

In the same manner as Claudia, Beatriz and Fabiola, when discussing the formal observations conducted by their consulting teachers, also compared those observations to the ones carried out by their administrators. Neither Beatriz nor Fabiola expressed any signs of discomfort regarding being observed by members of their administration. However, they both thought that, contrary to their administrators, their consulting teachers were more connected to the reality of, and interested in, what took place in their 
classrooms. In addition, they felt that the observations conducted by their consulting

teachers were more focused and detailed. Fabiola's words were,

[Name of first consulting teacher] and [name of second consulting teacher] sat for an extended period of time in my classroom... observing me and writing down everything I was doing. They were very alert, very in tune with what was going on. And I could tell, when they shared the observation with me, they were really looking at the interaction between me and the kids, looking to see how engaged the students were, noticing what kind of questioning I was using. I mean, it was a very detailed experience. Whereas, when my administrators come in, it's kind of like. Well, they enjoy coming in into my classroom, so it's a positive thing. But... sometimes, it's less than five minutes. And, sometimes, it can be, like, twelve minutes. It looks like they write something down. But, sometimes they do and, sometimes, they don't.... And, sometimes, I will tell you this, they say, "I was in your classroom; wasn't I?"

Beatriz, in turn, shared,

You know, my administration, they know what I do, and they know what is expected. I am a chairperson. I'm a veteran teacher. So, I don't have any reservations about what an administrator would see in my classroom. I've never had a negative experience with that. And I didn't have a negative experience either with the [consulting] teachers that came in, because even though they weren't necessarily experts in my area, they did understand. You know, teaching is teaching, kind of. So, they were very open and, actually, they were very interested to see such a different environment and, you know, what goes on with my kids. So, for me, it was a very positive experience on both ends.

Further comparing the formal observations conducted by her consulting teachers to those carried out by her administrators, Beatriz used the following words to express why she thought it was valuable to have consulting teachers conduct formal observations and be involved in the evaluation process,

An administrator... might be removed, you know, years removed. They may not necessarily be in connection with the everyday going on, and teaching in a classroom, and the stressors, and things that are going on. So, I think there is a big value to have, you know, your peers and your colleagues involved in that process.

Feedback. The value of having consulting teachers conduct observations and be part of the evaluation process was also seen in the feedback they had to offer, especially 
when that feedback was compared to a potential feedback given by school administrators. All participating special education teachers who were interviewed for the present study indicated that the feedback they received from their consulting teachers was detailed and constructive. Amelia, for instance, said that the feedback she received from her consulting teachers was "indispensable [and] pinpointed". She further explained,

[The consulting teachers] come in. They've told me. They've given me what are some good times. And I tell them. And they come in, and they take notes. And they make points. And, then, we go over each point. And they help [me] improve. And [they] give me all the points: "I like this. Try this with this." I mean, one, two, sometimes three pages long. And we go over each point, because I want always [to] improve.

Brenda and Claudia agreed with Amelia. Brenda stated that, while giving her feedback, her consulting teachers "went through each of the categories that were on the paper." Claudia, in turn, said that, in addition to providing her with written feedback, her consulting teachers had a supportive and positive conversation about what they had observed with her, using remarks such as, "I love what I saw." Both Brenda and Claudia added that they felt the feedback received from their consulting teachers was better than the one received from their school administrators, who, basically, never took the time to go over what they observed with them.

The lack of constructive and detailed feedback from school administrators, who, in Amelia's words, "have a form that they have to follow, and like anybody else [have] five million other things to do," was a common theme among the participating special education teachers who were interviewed. Fabiola, for instance, stated, "When they have the feedback, it's pretty much reading off the form. It's very shallow.... You just think, 'Well.'” Crystal, in turn, said, 
You know, when you get your evaluation from your administrator it's like, "Here! Sign!" And it's really not much a conversation that goes on about it. Not saying like, "Well, maybe you should try doing this in your classroom. Maybe, you should try this." You know. With [my consulting teacher], every time, we would sit down, and she would talk about, "I noticed that this kid over here was struggling, and maybe you can try this with him. And, how about you showed your lesson this way, using this technology?"

Crystal was not the only interviewee to talk about the conversation that takes place between consulting and participating teachers when the former provides feedback to the latter. Beatriz also mentioned it when talking about feedback. However, Beatriz added a different perspective. Beatriz stated that the conversation took place not only because feedback was being provided but also because her consulting teachers, who were not certified in special education, were curious about aspects of her practice that they noticed while conducting observations of her teaching. Beatriz's precise words were,

With the [consulting teachers], it's feedback, but there is also questioning, because they were curious. And since it's a colleague, you know, they were like, "Oh, you know, I saw you did this in your lesson and does the IEP say [to do that] for the kids? And, where does this come from?"

Embedded professional development. After listening to what the participating special education teachers had to say about the observations conducted by, and the feedback received from, their consulting teachers, the researcher became particularly interested in finding out if embedded professional development opportunities resulted from the observations and feedback. Moreover, if the opportunities had been offered to the interviewees, the researcher was interested in hearing what the participating teachers had to say about them.

The seven special education teachers interviewed for the present study were not only satisfied with but also grateful for the embedded professional development 
opportunities they received throughout their participation in the PAR program. They considered them to be practical and informal. They also felt they helped compensate for the fact that teachers work in isolation.

Crystal expressed her contentment with the embedded professional development she received from her consulting teacher by saying that it was one of the most beneficial professional development opportunities she had had in a long time. Crystal's specific words regarding the matter were,

You know, just working with her and having her come visit, you know, is probably one of the most beneficial professional development opportunities I've had in a very long time, you know. Next to, like, maybe, my CRISS [Creating Independence through Student-owned Strategies] training and things like that, you know. And this was just more consistent - it was constant.... If we would talk about something, a couple of days later she would come back and, "Oh, how did that work out?" You know.... She got the feedback from me, you know. It was definitely a great experience. So, have it embedded, like, here, at school, and being able to come back to her and be, like, “Oh, what about this?"... It was definitely helpful.... Sometimes we are in our own little bubble, and somebody else who can say, "Oh, but what about trying this?".... As long as you are open to that and you are willing to listen, it can definitely help.

Fabiola also expressed her appreciation for the embedded professional

development opportunities received throughout her participation in the program. Similar to Crystal, Fabiola addressed the fact that teachers work in isolation. Fabiola also mentioned that it is beneficial to have a peer, instead of an administrator, observe one's teaching practice and provide feedback. Fabiola shared:

You know, teaching is a very isolated experience, and it's always nice to have someone come in and do some observations and give you feedback. So, just having feedback is always a welcome thing and a chance to discuss issues coming up in the classroom.... Administrators come in, and they observe but don't really talk about the nuts and bolts of what we do. So, these particular peer reviewers that were coming in were National Board Certified Teachers. So, I feel that we have a common language, and that was nice. I appreciated that, cause I was a National Board Certified Teacher for ten years a while back. 
Fabiola added that the embedded professional development offered to her as a

participating teacher was substantially informal. She said, "it was basically us just

chatting". Fabiola gave the following example,

There was one year when I was really wanting to do a better job doing science journals with the kids and, and connecting them to our school garden. So, [my consulting teacher] was very helpful in helping me in kind of imagining what that would be like, and what kind of materials to use, and schedules of when they would do it.

Similar to Fabiola, Priscilla also mentioned the informal aspect of the embedded professional development offered to her. Priscilla said,

They did do it informally, at the beginning, with the interview, like, "Where do you find is the most challenging part of your job? Or what do you feel you would need support in?" So, I kind of gave them the one scenario at the time, which was, you know, a little trying. And they did come back with, "Okay, try this. Try this."

Professional development. Even though the interviews focused on the embedded professional development offered to participating teachers, the professional development provided to groups of individuals at the schools that participated in the PAR program were a recurring theme in the interviews conducted by the researcher. The seven special education teachers who participated in the semi-structured interviews considered those activities to be of high quality. They also felt that they were instrumental in making their school faculty more cohesive.

Amelia, for instance, mentioned that the fact that professional development activities were provided as part of the PAR program at her school site was beneficial to the school's entire professional community. Brenda added that they made her school "more of a collaborative kind of learning environment" and that they "brought departments together.” Brenda’s exact words were, 
It was, like, they would have professional developments here, and you would have all the departments kind of together, and we were all part of this [PAR] program, and we would be sharing ideas and collaborating. Whereas, on a regular day, without the [PAR] program, I don't feel like those teachers would be getting together.

The ability of the PAR program to bring departments together was also addressed by Beatriz. Commenting on the quality of the professional development activities offered by the program to her school faculty and on the benefit of those activities to the school professional environment, Beatriz said,

The PDs were very good, very high level. I think it really made people kind of reach out of their bureaucratical boxes as teachers because, you know, we are so tied to our curriculum and teachers manuals and all that. It kind of took us to a higher level. So, I thought it was good.... I think [the program] was great in terms of not just the evaluation but peer relationships: connections with your colleagues, you know, getting the school more connected instead of departmentalized, seeing how everything overlaps and how everything follows, and everything is aligned for all our kids.

New teachers. At the end of each interview, the researcher gave each one of the participating special education teachers the opportunity to share something that had not been addressed throughout the discussion. Amelia, Brenda, Crystal, and Priscilla replied that they felt that everything had been covered and that they did not think they had anything else to add. Beatriz, Claudia, and Fabiola, however, did take the opportunity to mention one thought about the program that had not been addressed throughout their interview, and the three of them pretty much had the same thing to say. Those three participating special education teachers mentioned, in one way or another, that PAR would be beneficial to new teachers. For instance, Claudia stated that "new teachers coming in could really, really benefit from [PAR], from a program like [PAR], at least." Fabiola concurred by saying that "teachers that really struggle with classroom 
management and all the basic stuff that they seem to struggle with, these [consulting teachers] could really help."

Beatriz was in agreement with Claudia and Fabiola. She also thought that PAR would be beneficial to new teachers. However, Beatriz thought that the evaluative aspect of the program should not be emphasized or that it should be changed. Beatriz's words were,

There should be someone that should be open to be able to support especially young teachers in the classroom, without having it be because I signed up, or it was a contract, or not because I've gotta be evaluated...To me, it puts a little bit of pressure, I think, on a new teacher, to have someone else come in... and be evaluated and give you feedback. I think it should be a little more, maybe an instrument that it doesn't imitate what an administrator is going to come in to do, so that you can see it more as a tool for growth. You know? Rather than, "Here's a person that's going to come and look at me like my principal might look at me." I mean, I would think that would be a little bit. You know? Because the form was the same. You know? I'd like to see it different, where it's more of a colleague thing. You know? Here's what I recommend. These are the standards that you targeted. You know?

\section{Summary}

In the current chapter, the researcher presented the results of the analysis of data collected from special and general education teachers who participated in the first four years of implementation of a PAR program in a large urban school district in the Southeast region of the United States (from school year 2012-2013 to school year 20152016). These teachers responded to a survey consisting of questions aiming to examine and compare how special and general education teachers rate their participation in a PAR program. In addition, seven special education teachers, via an interview process, provided an in-depth description of their experiences as participating teachers. 
The first research question was the following: how do special education teachers and general education teachers rate the extent to which their participation in aAR program impacts their teaching? Additionally, the two sub questions were the following: (a) are there differences in how special education teachers and general education teachers rate the extent to which their participation in a PAR program impacts their teaching in targeted areas (i.e., knowledge of learners, instructional planning, instructional delivery and engagement, assessment of learners, communication, learning environment, and overall professionalism) and (b) are there differences in how special education teachers and general education teachers rate the evaluative feedback and professional development opportunities offered to them through a PAR program?

The survey responses provided by both special education and general education teachers indicated that their participation in a PAR program had a substantial impact on their teaching. Special education teachers' ratings ranged from 3.23 (out of 4.0) to 3.63, and general education teachers' ratings ranged from 3.11 (out of 4.0) to 3.56. The value rating provided by both special education and general education teachers for the impact that their participation in a PAR program had on the components of all targeted areas of teaching were above a mean rating of 3.0 - the threshold for the substantial impact rating.

The survey responses provided by both special education and general education teachers also indicated that they were substantially satisfied with the evaluative feedback and professional development opportunities offered to them during their participation in the PAR program. Regarding the evaluative feedback received, special education teachers' ratings ranged from 3.25 (out of 4.0 ) to 3.69 , and general education teachers' ratings ranged from 3.35 (out of 4.0) to 3.71. The value rating provided by both special 
education and general education teachers for their level of satisfaction with the evaluative feedback offered to them during their participation in the PAR program, in spite of the professional providing the feedback to them, were above a mean rating of 3.0 - the threshold for the very satisfied rating.

The second research question was the following: is there a statistically significant difference between the manner in which special education teachers and general education teachers rate the extent to which their participation in a PAR program impacts their teaching in targeted areas? In order to answer the question, the researcher conducted an independent samples $t$-test to evaluate the difference between the means of the ratings given by special education teachers and those given by general education teachers to the impact that their participation in the PAR program had on targeted areas of their teaching.

The results of the independent-samples $t$-test conducted for the components of all targeted areas of teaching were not significant. The statement holds true for any level of significance, from 0.001 to 0.20 . Therefore, there is no statistically significant difference between the manner in which special education teachers and general education teachers rate the extent to which their participation in a PAR program impacts their teaching in targeted areas.

The third and final research question was the following: how do special education teachers describe their experiences as a participating teacher in a PAR program? In order to answer the question, the researcher conducted semi-structured interviews with seven special education teachers who participate in the program.

The analysis of the qualitative data collected indicated that that the special education teachers who were interviewed considered their participation in the PAR 
program to have been beneficial to their teaching practice regardless of the type of teaching certification held by their consulting teacher. Nevertheless, special education teachers felt that their participation in the program would have been further beneficial had their consulting teacher been an educator certified in special education. The interviewees also mentioned the importance of having consistency in the support received by their consulting teachers. In addition, the participating special educators considered the formal observations conducted by, and the feedback received from, their consulting teachers to be more thorough and meaningful than those carried out, and that given by, their school administrators. Furthermore, they considered the embedded professional development opportunities that resulted from the observations and feedback to have been helpful in improving their practice. They also considered the professional development offered to school faculty as a whole to make staff more cohesive. Finally, a few of the interviewees added that they thought that a program such as PAR would be beneficial to new teachers. 


\section{CHAPTER 5}

\section{DISCUSSION AND CONCLUSION}

In the current chapter, the researcher discusses the findings of the present dissertation study. First, the researcher provides a summary of the problem of evaluating the teaching effectiveness of special educators. Following the summary, the researcher reviews the purpose of the study. Next, the researcher provides a summary and discussion of the findings pertinent to the three research questions. Then, the researcher acknowledges the limitations of the study and makes recommendations for all stakeholders. Finally, the researcher concludes the current chapter by making suggestions for further research.

\section{Summary of the Investigation}

In the present study, the researcher examined how special and general education teachers in a large urban school district in the Southeast region of the United States rated the extent to which their participation in a PAR program impacted their teaching in targeted areas (i.e., knowledge of learners, instructional planning, instructional delivery and engagement, assessment of learners, communication, learning environment, and overall professionalism). Furthermore, the researcher investigated how special education teachers described their experience as participating teachers in a PAR program.

In order to conduct the present dissertation study, the researcher focused his investigation on three fundamental questions. First, the researcher looked at how special education teachers and general education teachers rated the extent to which their participation in a PAR program impacted their teaching. Moreover, within the primary area of focus, the researcher looked into possible differences regarding how the two 
aforementioned groups of teachers rated (a) the extent to which their participation in a PAR program impacted their teaching in targeted areas and (b) the evaluative feedback and professional development opportunities offered to them during their participation in a PAR program. Next, the researcher explored the potential existence of a statistically significant difference between the manner in which special education teachers and general education teachers rated the extent to which their participation in a PAR program impacted their teaching in targeted areas. Finally, the researcher examined how special education teachers described their experiences as a participating teacher in a PAR program.

The researcher tackled the three fundamental questions from the perspective that PAR, grounded in social network theory, is considered by many to be a viable option to compensate for the disadvantages of traditional teacher evaluation systems (e.g., Donaldson et al., 2008; Humphrey et al., 2011; Johnson \& Fiarman, 2012; Johnson \& Papay, 2010; Papay \& Johnson, 2012). The consideration, in part, is triggered by the fact that PAR uses relationships that promote credibility (Donaldson et al., 2008; Johnson \& Papay, 2010), which, according to studies reviewed by Daly (2012), promotes the examination of instructional practices in a mutual and rigorous manner.

Keeping this framework in mind, the researcher selected a sequential, mixedmethods design to address the study's fundamental questions. The researcher chose this type of design because it enabled him not only to cater to the nature of the study's fundamental questions but also to create "a dialogue between different ways of seeing, interpreting, and knowing " (Maxwell, 2010, p. 477). 
The sequential, mixed-methods design chosen by the researcher consisted of two distinct phases. The first phase was quantitative in nature and comprised close-ended survey questions that aimed to compare how special and general education teachers rated their participation in a PAR program. Conversely, the second phase was qualitative and contained open-ended questions that sought to explore how special education teachers described their participation in the same program. The researcher integrated the two phases by using data collected during the quantitative phase of the study to guide the collection of data during, and the recruitment of participants for, the study's qualitative phase.

\section{Demographics and Level of Satisfaction}

The researcher gathered and analyzed demographic data in order to gain an overall understanding of the respondents. After examining the demographic data collected in the first part of the survey instrument used in the study, the researcher found that, in certain areas, the sample of teachers who responded to the survey differed considerably from the pool of teachers working in the United States. For instance, according to the National Center for Education Statistics (NCES; 2017), only $7.8 \%$ of the nation's teachers are Hispanic. However, $58 \%$ of the survey respondents indicated that they were of Hispanic origin. The disparity is a reflection of the large influx of immigrants from Central and South America into communities served by the school district where the present dissertation study was conducted.

Furthermore, $51 \%$ of the teachers in the country teach in elementary schools, while $49 \%$ teach in middle or high schools (NCES, 2017). By contrast, $32.5 \%$ of the study participants identified themselves as elementary school teachers, while $64.9 \%$ 
indicated they were either middle or high school teachers. The difference might be related to the fact that the PAR program in the school district was not adopted in a manner that was proportionate to the number of elementary and secondary schools in the district. Instead, it was implemented in two elementary schools, three K-8 centers, two middle schools, and two high schools.

Additionally, $42.3 \%$ of the teachers in the country have been teaching for less than ten years, and $9 \%$ of them have been teaching for less than three (NCES, 2017). By contrast, $21 \%$ of the teachers who participated in the present study have been teaching for less than 10 years, $3.2 \%$ of them have been teaching between two and five years, and none of them has been teaching for less than two. The difference might be related to the hiring freeze implemented in the school district during the last few years.

In two areas, however, the sample of survey respondents was considerably similar to the pool of teachers working in the United States. The percentage of participating teachers who indicated that their primary teaching assignment was in special education was $13.4 \%$. Similarly, $12.8 \%$ of the nation's teachers are, primarily, special education teachers (NCES, 2017).

Furthermore, the majority of the teachers who participated in the present study had a master's degree (54.1\%), followed by the percentage of teachers who had a bachelor's (31.9\%). Correspondingly, according to NCES (2017), the most common degree held by teachers across the nation is a master's (47.7\%), followed by a bachelor's $(39.9 \%)$.

Another area targeted in the first part of the survey concerned the respondents' overall feeling of satisfaction with the impact their participation in the PAR program had 
on their teaching. Respondents' ratings ranged from 3.22 (out of 4.0) to 3.55. These ratings indicate that, overall, participants were satisfied with the impact that their participation in the PAR program had on targeted areas of their teaching. The overall level of satisfaction might be a result of the continuous assistance that, as stated by Johnson and Fiarman (2012), a system such as PAR provides to participating teachers in the areas they need to improve.

\section{Research Questions}

The researcher used social network theory as the conceptual framework for the present study, which focused on special and general education teachers' assessment of their participation in a PAR program. Social network theory is grounded in the importance of social relationship patterns that exist between members of a social network and in how those patterns can positively or negatively impact the use of data to support educational improvement (Daly, 2012). In a similar manner, PAR uses social relationships that exist between consulting and participating teachers. These relationships have the potential not only to assist participating teachers in working with underperforming students (Donaldson et al., 2008; Johnson \& Papay, 2010) but also to promote teachers' professional growth and to further the level of professionalism of the educational systems in which PAR has been implemented (Johnson \& Fiarman, 2012).

Traditional teacher evaluation systems have failed to determine teachers' professional development needs and to provide them with opportunities for growth (Weisberg et al., 2009). Peer Assistance and Review, however, as mentioned above, has the potential to assist teachers in working with underperforming students (Donaldson et al., 2008; Johnson \& Papay, 2010), to promote teachers' professional growth, and to 
further the level of professionalism of educational systems (Johnson \& Fiarman, 2012). It was that failure of traditional teacher evaluation systems and this potential of PAR that led the researcher to investigate how special and general education teachers rated the extent to which their participation in a PAR program impacted their teaching.

\section{Impact of the PAR Program on Targeted Areas of Teaching}

The survey responses provided by both special education and general education teachers indicated that their participation in a PAR program had a substantial impact on targeted areas of their teaching. Special education teachers' ratings ranged from 3.23 (out of 4.0) to 3.63, and general education teachers' ratings ranged from 3.11 (out of 4.0) to 3.56 - the threshold for the substantial impact rating was 3.0. In addition, standard deviations among special education teachers' ratings ranged from 0.53 to 0.75 , and those among general education teachers ranged from 0.70 to 0.96 . That indicates that the variability in responses among special education teachers and among general educations teachers was small. The high mean combined with the low standard deviation implies that few special and general education teachers disputed that their participation in the program had an impact on targeted areas of their teaching.

Both special education $(M=3.63)$ and general education teachers $(M=3.56)$ considered their ability to engage in continuous professional growth to be the component that was impacted the most by their participation in the PAR program. Furthermore, both special education $(M=3.46)$ and general education teachers $(M=3.47)$ rated their ability to promote learning by addressing academic needs through a variety of appropriate instructional strategies and technologies that engage learners to be the second component most impacted by their participation in the program. 
Special and general education teachers rated a total of 20 components. Even though the components did not rank in the same manner using the ratings given by the two groups of teachers, an independent-samples $t$-test conducted for all 20 components of the seven targeted areas of teaching indicated that there was no statistically significant difference between the manner in which special education teachers and general education teachers rated the extent to which their participation in a PAR program impacted their teaching in targeted areas.

The findings of the data analysis detailed above should serve to reinforce the fact that PAR, grounded in social network theory, is regarded by many as a viable option to compensate for the disadvantages of traditional teacher evaluation systems (e.g., Donaldson et al., 2008; Humphrey et al., 2011; Johnson \& Fiarman, 2012; Johnson \& Papay, 2010; Papay \& Johnson, 2012). The two teaching components considered by both special and general education teachers to be the ones most impacted by their participation in a PAR program correspond to areas that traditional teacher performance evaluation systems have failed to address. Therefore, the present study also should serve to support the implementation of a system such as PAR as a manner in which to counteract the fact that, as stated by Burdette (2011a) and Weisberg et al. (2009), traditional teaching evaluation systems have failed to align teacher performance evaluation to professional development and to provide teachers with the necessary feedback for them to grow in their instructional practice. Furthermore, concerning the performance evaluation of special education teachers in particular, the findings of the present research should serve to substantiate the fact that a system such as PAR has the potential to counterweigh the fact that, as indicated by Burdette, traditional teaching evaluation systems have failed to 
provide special educators with feedback that could assist them in improving their educational practice and, thus, the achievement of students with disabilities.

The two teaching components considered by both special and general education teachers to be the ones most impacted by their participation in a PAR program also are in alignment with the findings obtained from the analysis of the data collected via the present study's semi-structured interviews. Regarding their ability to engage in continuous professional growth, all interviewees indicated they were not only satisfied with but also grateful for the embedded professional development opportunities received throughout their participation in the program. They also stated that the feedback received from their consulting teachers was detailed and constructive. Furthermore, one participant in particular expressed her contentment with the embedded professional development she received from her consulting teacher by saying that it was one of the most beneficial professional development opportunities she had had in a long time.

Concerning their ability to promote learning by addressing academic needs through a variety of appropriate instructional strategies and technologies that engage learners, a number of the teachers who were interviewed indicated that their consulting teachers were well-versed in educational technology and software and used such knowledge to provide support in the classroom. One interviewee in particular stated that her consulting teacher not only used her knowledge of technology to assist in the classroom but also utilized it toward the benefit of the students.

The findings of the quantitative and qualitative data analysis described above should serve to reinforce the findings of Humphrey et al. (2011), Johnson et al. (2010), and van Lier (2008). These authors concluded that the collaboration that exists between 
consulting and participating teachers in a PAR program are beneficial to student achievement as well as to the professional development of the individuals involved in the collaborative process.

\section{Evaluative Feedback and Professional Development Opportunities}

The survey responses provided by both special and general education teachers indicated that they were substantially satisfied with the evaluative feedback and professional development opportunities offered to them during their participation in the PAR program. The level of satisfaction remained high regardless of the professional providing feedback and professional development opportunities to participating teachers. Regarding the evaluative feedback received, special education teachers' ratings ranged from 3.25 (out of 4.0) to 3.69 , and general education teachers' ratings ranged from 3.35 (out of 4.0) to 3.71 - the threshold for the very satisfied rating was 3.0. In addition, standard deviations among special education teachers' ratings ranged from 0.54 to 0.65 , and those among general education teachers ranged from 0.57 to 0.80 . In a similar manner, concerning the professional development opportunities offered during their participation in the program, special education teachers' ratings ranged from 3.08 (out of 4.0 ) to 3.69 , and general education teachers' ratings ranged from 3.21 (out of 4.0) to 3.49. In addition, standard deviations among special education teachers' ratings ranged from 0.46 to 0.65 , and those among general education teachers ranged from 0.77 to 0.96 . The range of the standard deviations indicates that the variability in responses among special education teachers and among general educations teachers was small. The high mean combined with the low standard deviation implies that few special and general education teachers disagreed with the majority that was satisfied with the evaluative feedback 
received and the professional development opportunities offered to them during their participation in the program.

One of the concerns with traditional teacher performance evaluation systems is that it has failed to align teacher performance evaluation to professional development and to provide teachers with the necessary feedback for them to grow in their instructional practice (Burdette, 2011a; Weisberg et al., 2009). The fact that the participants of the present study were substantially satisfied with the evaluative feedback and professional development opportunities offered to them during their participation in the PAR program should serve to reinforce the findings of other studies that consider PAR to be a tool to address that concern. For instance, Goldstein (2007a) and Johnson and Fiarman (2012) found that, in PAR, adequate feedback is provided to participating teachers. In addition, Johnson and Fiarman indicated that participating teachers receive continuous assistance in the areas in which they need to improve.

Satisfaction with the evaluative feedback and professional development opportunities offered during participation in the PAR program was also expressed by the special education teachers who participated in the semi-structured interviews conducted by the researcher. The seven special education teachers interviewed for the present study were satisfied with the embedded professional development opportunities they received throughout their participation in the program. They considered the opportunities to be practical and informal and to help compensate for the fact that teachers work in isolation.

Regarding the evaluative feedback received during participation in the program, the interviewees indicated they were satisfied with the feedback received from their consulting teachers. They expressed it was detailed and constructive. However, contrary 
to the findings obtained from the analysis of the quantitative data of the study, the interviewees were not equally satisfied with the evaluative feedback and professional development opportunities offered by different professionals. The participating special education teachers who were interviewed for the present study felt that the feedback received from their consulting teachers was better than the one received from their school administrators, who, according to the interviewees, either never took the time to go over what they observed with the teachers or simply read off of a form.

\section{Special Education Teachers as Participating Teachers in a PAR Program}

Semi-structured interviews were conducted with seven special education teachers who were participating teachers in the PAR program implemented in the school district. The main focus of the interviews was to investigate how special education teachers describe their experiences as participating teachers in a PAR program. In the following sections, the researcher addresses the findings that emerged from the analysis of the qualitative data collected throughout the interview process.

Consulting teachers. All interviewees stated that their consulting teachers were

likeable, professional, resourceful, and reliable. The statement might be an indication that the educators who served as consulting teachers during the implementation of the PAR program in the school district were selected through and open and rigorous process, which according to Donaldson et al. (2008) and Johnson and Papay (2010) brings credibility to the collaborative relationships between PAR consulting and participating teachers. Furthermore, it should serve to support the finding of Yusko and FeimanNemser (2008), who pointed out that the level of trust between members of the 
collaborative dyad has been proven to enhance the credibility of performance evaluation systems.

The special education teachers who were interviewed also added that their consulting teachers were well-versed in educational technology and software and used such knowledge to provide support in the classroom. This finding should serve to reinforce the potential of PAR to elevate instruction quality (Goldstein, 2005). It also should serve to validate the importance of having teachers participate in, and bring their knowledge, to the teacher evaluation process. As stated by Johnson and Fiarman (2012), when consulting teachers bring their perspective into teacher evaluation systems, the credibility of those systems is enhanced as a whole.

Consulting teachers' consistency. The special education teachers interviewed for the present study indicated that the level of consistency with which their consulting teachers provided them with support made a difference to them and their students. When the consulting teachers were consistent, the interviewees felt they had a positive effect not only on them, the special education teachers, but also on their students with disabilities. Conversely, when the consulting teachers were not consistent, the same interviewees pointed out that having consulting teachers in their classroom actually made things more challenging for them. For instance, one of the interviewees, who partially blamed her consulting teachers' lack of consistency on the fact that they had too many participating teachers assigned to them, decided to end her participation in the PAR program. This finding should serve to support the conclusion at which Johnson et al. (2010) arrived. Johnson et al. indicated that some districts in which PAR was implemented assigned their consulting teachers a caseload that was so large that it made 
it impossible for their consulting teachers to provide the participating teachers assigned to them with the support they needed.

Consulting teachers' area of certification. The Council for Exceptional Children (2012) and Sledge and Pazey (2013) recommended that individuals trained to recognize the specific roles played by special education teachers be the ones responsible for conducting the performance evaluation of those professionals. However, school administrators, who are typically responsible for the performance evaluation of teachers, do not have the necessary expertise to evaluate teacher effectiveness as it relates to the education of students with disabilities (Blanton et al., 2006; Jones et al., 2013; Sledge \& Pazey, 2013). As a solution, Holdeheide et al. (2010), citing the PAR model used in Toledo, Ohio, suggested that special education teachers be the ones conducting peer-topeer observations and evaluations of other special education teachers.

The findings of the present dissertation study should serve to reinforce the recommendation made by CEC (2012) and Sledge and Pazey (2013) as well as to support the solution recommended by Holdeheide et al. (2010), especially when applied to the implementation of PAR programs. Six out of seven special education teachers interviewed for the qualitative phase of the present dissertation study indicated that the alignment of the certification area of the consulting teacher with that of the participating teacher would be helpful. The interviewees stated that, even though they found the assistance provided by their consulting teachers to be beneficial not only to them but also to their students, if they and their consulting teachers had shared the same type of certification, the interaction between consulting and participating teachers would have been even better. One interviewee in particular had two consulting teachers: one was 
certified in special education, and the other one was not. The interviewee considered both consulting teachers to be very good at providing feedback and assistance; however, she stated that the fact that one of them was certified in special education made a substantial difference. A couple of other interviewees who had consulting teachers whom they considered to be good at providing feedback and assistance, but who were not certified in special education, indicated that their assistance was somewhat restricted because their knowledge of special education was limited. In fact, the two interviewees considered the lack of consulting teachers certified in special education to be the only negative aspect the program.

Formal observations. Weisberg et al. (2009) found that typical classroom observations are short and infrequent. One of the reasons for their being brief and sporadic is the fact that administrators lack the necessary time to conduct thorough observations, which according to Holdeheide et al. (2010) is detrimental to the performance evaluation of special education teachers. A system such as PAR is regarded as a potential solution for this challenge. According to Goldstein (2007a), Holdeheide et al., and Johnson and Fiarman (2012), PAR has been found effective in performing frequent and thorough observations that are conducted by individuals with the necessary subject area expertise.

The findings of the present dissertation study support the conclusion at which Goldstein (2007a), Holdeheide et al. (2010), and Johnson and Fiarman (2012) arrived. The special education teachers who participated in the interviews conducted for the qualitative phase of the present study stated that, contrary to their administrators, their consulting teachers were more connected to the reality of, and interested in, what took 
place in their classroom. Moreover, the participating special education teachers indicated that the observations conducted by their consulting teachers were more focused and detailed. As a consequence, they saw the observations conducted by their consulting teachers not only as an opportunity for improving in their practice but also as a way to feel validated.

The findings of the present dissertation study also support the conclusion of PAR studies that found that trust is a significant prerequisite for the collaboration between consulting and participating teachers to succeed in promoting professional growth and in generating increase in student achievement (Goldstein, 2005; Johnson et al., 2010; Yusko \& Feiman-Nemser, 2008). The present study's interviewees indicated they felt comfortable approaching their consulting teachers with their needs and being observed by them, which led to growth in targeted areas of their teaching.

Feedback and embedded professional development. Humphrey et al. (2011), addressing the contributions that PAR programs make to professional development and the teaching culture, indicated that PAR provides an adequate amount of teacher assistance and conducts performance evaluations that are far more rigorous and comprehensive than the ones carried out by school administrators. In addition, Humphrey et al. concluded that the implementation of peer evaluation in conjunction with peer collaboration improves instructional practice and, consequently, increases student achievement. Furthermore, van Lier (2008) found that the continuous collaboration between consulting and participating teachers in PAR programs has the potential to improve teacher effectiveness. 
The findings resulting from the analysis of the qualitative data of the present dissertation study reinforce the conclusions at which Humphrey et al. (2011) and van Lier (2008) arrived. The special education teachers who participated in the semi-structured interviews conducted by the researcher indicated that the feedback provided by their consulting teachers came in the form of a supportive and positive conversation about what had been observed. Furthermore, the interviewees stated that the feedback given to them by their consulting teachers was better than the one received from their school administrators, who, for the most part, are too busy to provide detailed and constructive criticism. In addition, the participating special educators found the embedded professional development provided to them as a result of the peer assistance and evaluation process to be practical and informal yet beneficial. They added that it helped compensate for the fact that teachers work in isolation.

Professional development. According to Johnson et al. (2010) the success of PAR lies in part on the program's collaborative intent. PAR studies have found that the program's implementation improves relationships between (a) districts and teacher unions (Goldstein, 2007a; Humphrey et al., 2011; Papay \& Johnson, 2012) and (b) teachers and administrators (Papay \& Johnson, 2012).

The findings of the present dissertation study should serve to reinforce the collaborative intent of PAR and its positive effect on relationships. However, the type of relationship improvement that has emerged from the analysis of the qualitative data of the present study does not address the aforementioned types of rapport. Instead, it points out that the program has the potential to increase the collaboration among schools' academic departments and faculty members. According to the present study's interviewees, the 
provision of professional development to schools' faculty as a whole - which appears to be a distinctive characteristic of the manner in which PAR was implemented in the school district - brought departments together and made their schools a more collaborative learning environment.

New teachers. Goldstein (2005) and Johnson et al. (2010) found that a system such as PAR, because of the amount and quality of collaboration that exists between consulting and participating teachers, increases the retention of good teachers and the quality of instruction in districts where the program is implemented. Furthermore, Koppich (2004), addressing the implementation of PAR in Montgomery County Public Schools, stated that PAR serves as a way to induct new teachers into the profession.

During the semi-structured interviews conducted for the second phase of the present study, three of the interviewees stated that they thought PAR would be beneficial to new teachers. This finding should serve to reinforce the conclusion at which Goldstein (2005) and Johnson et al. (2010) arrived. In addition, it should serve as an indication that PAR, as mentioned by Koppich (2004), has the potential of serving as an induction program for new teachers.

\section{Limitations}

The present study was conducted in a large school district in the Southeast region of the United States. Because of the high concentration of individuals who are Hispanic living in this region of the country, the percentage of teachers who are of Hispanic origin working for the school district is substantially high. Therefore, the sample of participants who completed the present research's survey and participated in its follow-up interviews differs considerably from the workforce of which school districts across the nation are 
comprised. As a consequence, one's ability to generalize the findings of the present dissertation study becomes limited.

The sample of participants who completed the present research's survey and participated in its follow-up interviews also differs from the nation's workforce in the area of teaching experience. None of them had less than two years of teaching experience. As a result, the generalization of the present study's findings becomes limited, especially as the findings relate to the use of PAR with teachers new to the profession.

Generalization of the findings of the present dissertation study is also restricted by the manner in which PAR was implemented in the school district. Because the program was implemented among an equal number of elementary, middle, and high schools, the percentage of study participants in each of the aforementioned school levels is relatively similar. However, the percentage of teachers working at elementary schools across the country is substantially higher than that comprising middle and high school teachers.

Contrary to the fact that the percentage of elementary school teachers who participated in the present study was disproportionate when compared to the rest of the country, the percentage of special education participants was surprisingly similar. Perhaps, the similarity is related to the fact that potential participants who were invited to participate in the present study were informed of the focus of the investigation, which concentrated heavily on the performance evaluation of special education teachers. Nevertheless, the fact that one group of participants was representative of the national norm and the other was not further impacts the generalization of the present study's findings. 
An additional limitation of the present study is the fact that one's ability to generalize its findings has been impacted by the large variety of roles for which special education teachers are responsible. For instance, they may be assigned to (a) grades that range from preschool to $12^{\text {th }}$ grade, (b) educational settings ranging from one end of the least restrictive environment continuum to the other, and (c) students with various disabilities and with mild to severe needs.

The large variety of roles for which special education teachers are responsible also might have skewed some of the findings of the present study. The wide range of responsibilities performed by special education teachers who completed the present study's survey and who participated in the present study's semi-structured interviews might have caused the findings obtained from the analysis of the quantitative data collected during the study, at least in one area, not to have been supported by the findings resulting from the analysis of the study's qualitative data. For instance, survey respondents indicated they were equally satisfied with the evaluative feedback and professional development opportunities offered by different professionals during their participation in the program. Conversely, interview participants stated they felt the feedback received from their consulting teachers was far better than the one received from their school administrators.

The findings of the present study also might have been skewed by the degree level of the individuals who served as participants during the qualitative phase of the research. Even though the degree level of respondents to the present study's survey matched the degree level of the nation's teaching workforce, the degree level of individuals who participated in the study's follow-up interviews did not. The degree level of the 
interviewees was substantially higher. Only one of them did not hold a master's or higher level degree.

A final limitation of the present study is the fact that the researcher had worked as an administrator in the professional development department of the district in which the investigation was conducted. Even though, by the time the collection of data for both phases of the study took place, the researcher (a) made it known to participants he was no longer an employee of the district, (b) never took part in the implementation of the PAR program in the district, and (c) assured participants their identity would be kept confidential, the fact that the researcher was known to participants and, in his previous professional role, might have formed relationships with individuals occupying positions of authority within the district might have had an effect not only on whether or not individuals chose to take part but also in how they participated in the study.

\section{Recommendations}

The performance evaluation of teachers should be conducted in a manner that leads to professional growth and, ultimately, to increase in student achievement. A system such a PAR has the potential to achieve that. Peer Assistance and Review gives teachers the opportunity (a) to be frequently and thoroughly observed by a peer who has been selected through a rigorous process, (b) to receive detailed and constructive feedback from the same peer who conducted the observations, and (c) to receive embedded professional development toward areas that, using observations conducted, have been deemed in need of growth.

A system such as PAR also has the potential to improve the manner in which special education teachers are evaluated. Special educators, because of the extensive 
scope encompassed by the variety of roles included in their area of certification (e.g., preschool to $12^{\text {th }}$ grade, self-contained to full inclusion settings, students with various disabilities, students with severe to mild needs), do not fit the mold of the typical teacher on whom performance evaluation systems have been standardized. A system such as PAR, with its frequent and thorough observations, gives consulting teachers ample opportunities to conduct in-depth observations, which in turn enable the observer to capture the nuances of special educators' practices.

However, in order for special education teachers to truly benefit from a system such as PAR, three prerequisites must be in place. First, the caseload assigned to consulting teachers must be reasonable and manageable. Further, consulting teachers' responsibilities should be solely those associated with peer assistance and review. Finally, the area of certification of consulting teachers should align with the certification area of participating teachers to whom consulting teachers have been assigned.

The certification area alignment between consulting and participating teachers should also occur in the event PAR is chosen to serve as the induction program to teachers new to the profession. Even though no participants of the present study were new to the profession, both the literature review and the findings of the present research indicate that a system such as PAR, with its frequent observations, thorough feedback, and embedded professional development, gives new teachers participating in the program the support and assistance needed to succeed in the profession. The support and assistance would be enhanced further, if participating teachers were assigned to consulting teachers with the same certification - someone who truly understands the nuts and bolts of their practice. 
Finally, policymakers, administrators, and support providers should consider the aforementioned recommendations when making decisions regarding the performance evaluation of special education teachers. The present study's recommendations also should be taken into consideration when developing induction programs for beginning special education teachers.

\section{Recommendations for Future Research}

A substantial number of studies have been conducted on PAR. However, research addressing the effect of PAR on the performance evaluation of special education teachers specifically is limited. Therefore, additional empirical investigations into the implementation of the PAR program among special educators are necessary in order to reinforce or, perhaps, contradict the findings of the present dissertation study.

In order to address the multitude of roles performed by individuals with certification in the area of special education, future studies addressing the use of PAR among special educators should focus on groups of participants performing similar roles (e.g., teachers working in self-contained settings, teachers working in inclusive settings, teachers of students working on access points, teachers of students with disabilities working on the standard curriculum). Nevertheless, because of the individualized nature of special education, the responsibilities of special education teachers performing similar roles will vary considerably. Therefore, even if a sufficient sample size of special education teachers with comparable responsibilities is acquired for a significant statistical analysis, follow-up interviews might be necessary to supplement the investigation with the particularities of study participants' roles and responsibilities. 
Also because of the multitude of roles performed by individuals with certification in the field of special education, an additional area of interest for future research should be the alignment of the certification area between consulting and participating teachers. Since the roles and responsibilities of special education teachers vary considerably, it would be beneficial to investigate whether or not having special education consulting teachers assigned to special education participating teachers would be a measure that, alone, would make a difference in the performance evaluation of special educators. Perhaps, consulting and participating teachers sharing the same certification areaspecial education - might not be enough to make a significant difference in the manner in which special education teachers are assisted and evaluated by their peers. If that is the case, it also would be beneficial to examine if a potential alignment between special education consulting and participating teachers who have performed similar roles and responsibilities within the field of special education would make a significant difference when the latter is assisted and evaluated by the former.

Finally, the literature and findings of the present study indicate a potential benefit when PAR is used with teachers new to the profession. However, no participants of the present study had less than two years of teaching. Future research should inquire into the specific use of PAR as an induction program for special education teachers, especially if the area of certification and the roles and responsibilities performed by mentor and mentee are in alignment. Additionally, future research participants should be, or at least include, special education teachers new to the profession. 


\section{Summary}

In the present study, the researcher examined how special and general education teachers in a large urban school district in the Southeast region of the United States rated their participation in a PAR program. Furthermore, the researcher investigated how special education teachers described their experience as participating teachers in that program.

The researcher conducted his investigation from the perspective that PAR, grounded in social network theory, is considered by many to be a viable option to compensate for the disadvantages of traditional teacher evaluation systems (e.g., Donaldson et al., 2008; Humphrey et al., 2011; Johnson \& Fiarman, 2012; Johnson \& Papay, 2010; Papay \& Johnson, 2012). Keeping this framework in mind, the researcher selected a sequential, mixed-methods design to address the study's fundamental questions.

The sequential, mixed-methods design chosen by the researcher consisted of two distinct phases. The first phase was quantitative in nature and comprised close-ended survey questions that aimed to compare how special and general education teachers rated their participation in a PAR program. Conversely, the second phase was qualitative and contained open-ended questions that sought to explore how special education teachers described their participation in the same program.

The survey responses provided by both special education and general education teachers indicated that their participation in a PAR program had a substantial impact on targeted areas of their teaching. Participants' responses also indicated that they were substantially satisfied with the evaluative feedback and professional development 
opportunities offered to them during their participation in the PAR program. In addition, an independent-samples $t$-test indicated that there was no statistically significant difference between the manner in which special education and general education teachers rated the extent to which their participation in a PAR program impacted their teaching in targeted areas.

The two teaching components considered by both special and general education teachers to be the ones most impacted by their participation in a PAR program were the following: (a) their ability to engage in continuous professional growth and (b) their ability to promote learning by addressing academic needs through a variety of appropriate instructional strategies and technologies that engage learners. These findings are in alignment with the findings obtained from the analysis of the data collected via the present study's semi-structured interviews and correspond to areas that traditional teacher performance evaluation systems have failed to address.

The findings obtained from the analysis of the data collected via the semistructured interviews conducted by the researcher also indicated that the educators who served as consulting teachers were selected through and open and rigorous process and were well-versed in educational technology and software, which they used to provide support in the classroom. The findings also pointed out that the level of consistency with which consulting teachers provided participating teachers with support made a difference to the latter and to their students. In addition, the findings suggested that the alignment of the certification area of the consulting teacher with that of the participating teacher would be helpful. Moreover, the findings implied that observations conducted by consulting teachers were more focused and detailed than those conducted by school administrators. 
Furthermore, the findings indicated that the feedback provided by consulting teachers was supportive, positive, and better than the one provided by school administrators and that the embedded professional development provided was practical and informal, yet beneficial. Finally, the findings of Phase 2 of the present dissertation study pointed out that PAR increases the collaboration among schools' academic departments and faculty members and is beneficial to new teachers.

The findings of the present dissertation study - although limited by the fact that (a) the sample of participants differs considerably from the workforce of which school districts across the nation are comprised and (b) the large variety of roles for which special education teachers are responsible - should serve to reinforce and recommend that a system such as PAR be used to give special education teachers (a) the opportunity to be frequently and thoroughly observed by a peer who has been selected through a rigorous process, (b) to receive detailed and constructive feedback from the same peer who conducted the observations, and (c) to receive embedded professional development toward areas that, using observations conducted, have been deemed in need of growth. Furthermore, the findings of the present dissertation study should serve to reinforce and recommend that the caseload assigned to consulting teachers be reasonable and manageable, that consulting teachers' responsibilities be solely those associated with peer assistance and review, and, finally, that the area of certification of consulting teachers align with the certification area of participating teachers to whom consulting teachers have been assigned. 


\section{REFERENCES}

Ahearn, E. (2009). Growth models and students with disabilities: Report of state interviews. Retrieved on March 5, 2014 from http://nasdse.org/DesktopModules/ DNNspotStore/ProductFiles/89_301cac3e-e6aa-437d-875e-049abd89b21d.pdf

Baker-Doyle, K. J., \& Yoon, S. A. (2010). Making expertise transparent: Using technology to strengthen social networks in teacher professional development. In A. J. Daly (Ed.), Social network theory and educational change (pp. 115-126). Cambridge, MA: Harvard Education Press.

Bill \& Melinda Gates Foundation. (2010). MET Project: Working with teachers to develop fair and reliable measures of effective teaching. Retrieved on March 5, 2014 from http://www.metproject.org/downloads/met-framing-paper.pdf

Bill \& Melinda Gates Foundation (2013). Ensuring fair and reliable measures of effective teaching: Culminating findings from the MET Project's Three-Year Study. Retrieved fromhttp://www.metproject.org/downloads/ MET_Ensuring_Fair_and_Reliable_Measures_Practitioner_Brief.pdf

Blanton, L. P., Sindelar, P. T., \& Correa, V. I. (2006). Models and measures of beginning teacher quality. Journal of Special Education, 40(2), 115-127.

Bogdan, R. C., \& Biklen, S. K. (2007). Qualitative research for education: An introduction to theories and methods $\left(5^{\text {th }}\right.$ ed.). Boston, MA: Pearson.

Borgatti, S. P., \& Ofem, B. (2010). Overview: Social network theory and analysis. In A. J. Daly (Ed), The ties of change: Social network theory and application in education (p.17-30). Cambrigdge, MA: Harvard Education Press.

Brownell, M. T., Bishop, A. G., Gersten, R., Klinger, J. K., Penfield, R. D., Dimino, J., Sindelar, P. T. (2009). The role of domain expertise in beginning special education teacher quality. Exceptional Children, 75(4), 391-411.

Brunner, C., Fasca, C., Heinze, J., Honey, M., Light, D., Mandinach, E., \& Wexler, D. (2005). Linking data and learning: The Grow Network study. Journal of Education for Students Placed at Risk, 10(3), 241-267.

Bryk, A. S., \& Schneider, B. (2002). Trust in schools: A core resource for school improvement. New York, NY: Russell Sage Foundation

Burch, P. (2006). The new educational privatization: Educational contrasting and high stakes accountability. Teachers College Record, 108(12), 2582-2610. 
Buzick, H. M., \& Laitusis, C. C. (2010). Using growth for accountability: Measurement challenges for students with disabilities and recommendations for research.

Educational Researcher, 39(7), 537-544.

Burdette, P. (2011b). Performance-based compensation: Focus on special education teachers. Retrieved on March 5, 2014 from http://nasdse.org/DesktopModules/ DNNspotStore/ProductFiles/73_ac5501cf-90bd-44d0-b623-299c57dcb657.pdf

Burdette, P. (2011a). Special education value-added performance evaluation systems: $A$ state-level focus. Retrieved on March 5, 2014 from http://nasdse.org/

DesktopModules/DNNspot-Store/ProductFiles/

67_55c9ed1a-e387-431-b8c2-5eca066ec50e.pdf

Chen, E., Heritage, M., \& Lee, J. (2005). Identifying and monitoring students' learning needs with technology. Journal of Education for Students Placed at Risk, 10(3), 309-332.

Coburn, C. E., Choi, L., \& Mata, W. (2010). "I would go to her because her mind is math": Network formation in the context of a district-based mathematics reform. In A. J. Daly (Ed.), Social network theory and educational change (p. 77-95). Cambridge, MA: Harvard Education Press.

Coburn, C. E., \& Russell, J. L. (2008). District policy and teachers' social networks. Education Evaluation and Policy Analysis, 30(3), 203-235.

Copland, M. A. (2003). Leadership of inquiry: Building and sustaining capacity for school improvement. Education Evaluation and Policy Analysis, 25, 375-395.

Corcoran, S. P. (2010). Can teachers be evaluated by their students' test scores? Should they be? The use of value-added measures of teacher effectiveness in policy and practice. Education policy for action series. Annenberg Institute for School Reform at Brown University. Brown University Box 1985, Providence, RI 02912.

Council for Exceptional Children. (2012). The council on exceptional children's position on special education teacher evaluation. Retrieved on March 5, 2014 from http://www.cec.sped.org/ /media/Files/Policy/ CEC\%20Professional\%20Policies\%20and\%20Positions/ Position_on_Special_Education_Teacher_Evaluation_Background.pdf

Council of Chief State School Officers. (2012). Our responsibility, our promise:

Transforming educator preparation and entry into the profession. Retrieved on March 5, 2014 from http://www.ccsso.org/Documents/2012/

Our\%20Responsibility\%200ur\%20Promise_2012.pdf 
Culbertson, J. (2012). Putting the value in teacher evaluation. Phi Delta Kappan, 94(3), 14-18.

Daly, A. J. (Ed.). (2010). Social network theory and educational change. Cambridge, MA: Harvard Education Press.

Daly, A. J. (2012). Data, dyads, and dynamics: Exploring data use and social networks in educational improvement. Teachers College Record, 114(11), 1-38.

Daly, A. J., \& Chrispeels, J. (2008). A question of trust: Predictive conditions for adaptive and technical leadership in educational contexts. Leadership and Policy in Schools, 7(1), 30-63.

Daly, A. J., \& Finnigan, K. (2010). Understanding network structure to understand change strategy. Journal of Educational Change, 111, 111-138.

Darling-Hammond, L. (2012). The right start: Creating a strong foundation for the teaching career. Phi Delta Kappan, 94(3), 8-13.

Darling-Hammond, L., Amrein-Beardsley, A., Haertel, E., \& Rothstein, J. (2012). Evaluating teacher evaluation. Phi Delta Kappan, 93(6), 8-15.

Datnow, A., Park, V., \& Wohlstetter, P. (2007). Achieving with data: How highperforming school systems use data to improve instruction for elementary students. Los Angeles: University of Southern California, Rossier School of Education, Center on Educational Governance.

Diamond, J. B., \& Cooper, K. (2007). The uses of testing data in urban elementary schools: Some lessons from Chicago. NSSE Yearbook, 106(1), 241-263.

Donaldson, M. L., Johnson, S. M., Kirkpatrick, C. L., Marinell, W. H., Steele, J. L., \& Szczesiul, S. A. (2008). Angling for access, bartering for change: How secondstage teachers experience differentiated roles in schools. Teachers College Record, 110(5), 1088-1114.

Glazerman, S., Loeb, S., Goldhaber, D., Staiger, D., Raudenbush, S., \& Whitehurst, G. (2010). Evaluating teachers: The important role of value-added. Brookings Institution. Retrieved on March 5, 2014 from http://www.brookings.edu/ /media/ research/files/reports/ 2010/11/17\%20evaluating\%20teachers/ 1117_evaluating_teachers.pdf

Goldstein, J. (2004). Making sense of distributed leadership: The case of peer assistance and review. Educational Evaluation and Policy Analysis, 26(2), 173. 
Goldstein, J. (2005). Debunking the fear of peer review: Combining supervision and evaluation and living to tell about it. Journal of Personnel Evaluation in Education, 18(4), 235.

Goldstein, J. (2007b). Distributed accountability: How district leaders create structures to ensure teaching quality. Journal of School Leadership, 17(4), 504.

Goldstein, J. (2007a). Easy to dance to: Solving the problems of teacher evaluation with peer assistance and review. American Journal of Education, 113(3), 479-508.

Goldstein, J. (2009). Designing transparent teacher evaluation: The role of oversight panels for professional accountability. Teachers College Record, 111(4), 893.

Guest, G., Bunce, A., \& Johnson, L. (2006). How many interviews are enough? Field Methods, 18(1), 59-82.

Halverson, R., Grigg, J., Prichett, R., \& Thomas, C. (2007). The new instructional leadership: Creating data-driven instructional systems in school. Journal of School Leadership, 17(20), 159-194.

Heritage, M., \& Yeagley, R. (2005). Data use and school improvement: Challenges and prospects. NSSE Yearbook, 104(2), 320-339.

Hesse-Biber, S. (2010). Qualitative approaches to mixed methods practice. Qualitative Inquiry, 16(6), 455-468.

Holcomb, E. L. (2001). Asking the right questions: Techniques for collaboration and school change $\left(2^{\text {nd }}\right.$ ed.). Thousand Oaks, CA: Corwin Press.

Holdheide, L., Browder, D., Warren, S., Buzick, H., \& Jones, N. (2012, January). Summary of using student growth to evaluate educators of students with disabilities: Issues, challenges, and next steps. Washington, DC: National Comprehensive Center for Teacher Quality. Retrieved on March 5, 2014 from http://www.gtlcenter.org/ sites/default/files/docs/

TQ_Forum_SummaryUsing_Student_Growth.pdf

Holdheide, L., Goe, L., Croft, A., \& Reschly, D. J. (2010). Challenges in evaluating special education teachers and English language learner specialists. Washington, DC: National Comprehensive Center for Teacher Quality. Retrieved on March 5, 2014 from http://www.sharedwork.org/documents/19888/108370/ July2010Brief+Evaluation+Special+Education+Teachers.pdf

Humphrey, D. C., Koppich, J. E., Bland, J. A., \& Bosetti, K. R. (2011). Peer review: Getting serious about teachers'support and evaluation. Menlo Park, CA: SRI International. 
Ikemoto, G. S., \& Marsh, J. A. (2007). Cutting through the "data-driven" mantra: Different conceptions of data-driven decision making. NSSE Yearbook, 106(1), 105-131.

Johnson, S. M., \& Fiarman, S. E. (2012). The potential of peer review. Educational Leadership, 70(3), 20-25.

Johnson, S. M., \& Papay, J. P. (2010). Teacher to teacher: Realizing the potential of peer assistance and review. Washington, DC: Center for American Progress.

Johnson, S.M., Papay, J.P., Fiarman, S.E., Munger, M.S., \& Qazilbash, E.K. (2010). Teacher to teacher: Realizing the potential of Peer Assistance and Review. Washington, DC: Center for American Progress.

Jones, N. D., Buzick, H. M., \& Turkan, S. (2013). Including students with disabilities and English learners in measures of educator effectiveness. Educational Researcher, 42(4), 34.

Keeney, L. (1998). Using data for school improvement: Report on the second practitioners' conference for Annenberg Challenge sites. Tools for Accountability Project, Houston, TX. Retrieved from http://annenberginstitute.org/tools/ using_data.pdf

Kerr, K. A., Marsh, J. A., Ikemoto, G. S., Darilek, H., \& Barney, H. (2006). Strategies to promote data use for instructional improvement: Actions, outcomes, and lessons from three urban districts. American Journal of Education, 112(4), 496-520.

Koppich, J. (2004). Toward improving teacher quality: An evaluation of Peer Assistance and Review in Montgomery County Public Schools. Rockville, MD: Montgomery County Public Schools. Retrieved May 06, 2014, from www.mcps.k12.md.us/ departments/development/documents/pgs/PAR_report_final.doc

Lachat, M. A., \& Smith, S. (2005). Practices that support data use in urban high schools. Journal of Education for Students Placed at Risk. 10(3), 333-349.

Mandinach, E. B., \& Honey, M. (2008). Data driven school improvement: Linking data and learning. New York, NY: Teachers College Press.

Marsh, J. A., McCombs, J. S., \& Martorell, F. How instructional coaches support datadriven decision making: Policy implementation and effects in Florida middle schools. Educational Policy, 24(6), 872-907.

Maxwell, J. A. (2010). Using numbers in qualitative research. Qualitative Inquiry, 16(6), $475-482$. 
Moolenaar, N. M., Daly, A. J., \& Sleegers, P. J. (2010). Occupying the principal position: Examining relationships between transformational leadership, social network position, and schools' innovative climate. Educational Administration Quarterly, 46(5), 623-670.

National Center for Education Statistics. (2010). Characteristics of the 100 largest public elementary and secondary school districts in the United States: 2008-2009. (NCES Report No. 2011-301). Retrieved from https://nces.ed.gov/pubs2010/ 100largest0809/tables/table_a01.asp

Papay, J. P., \& Johnson, S. M. (2012). Is PAR a good investment? Understanding the costs and benefits of teacher peer assistance and review programs. Educational Policy, 26(5), 696-729.

Parise, L., \& Spillane, J. (2010). Teacher learning and instructional change: How formal and on-the-job learning opportunities predict change in elementary school teachers' practice. Elementary School Journal, 110(3), 323-346.

Penuel, W. R., Riel, M., Joshi, A., Pearlman, L., Kim, C. M., \& Frank, K. A. (2010). The alignment of the informal and formal organizational supports for reform: Implications for improving teaching in schools. Educational Administration Quarterly, 46(1), 57-95.

Project on the Next Generation of Teachers. (2009). A user's guide to Peer Assistance and Review. Cambridge, MA: Author. Retrieved from Harvard Graduate School of Education at www.gse.harvard .edu/ ngt/par/resources/users_guide_to_par.pdf

Rubin, H. J., \& Rubin, I. S. (2005). Qualitative interviewing: The art of hearing data $\left(2^{\text {nd }}\right.$ ed.). Thosand Oaks, CA: Sage.

Schildkamp, K., \& Kuiper, W. (2010). Data informed curriculum reform: Which data, what purposes, and promoting and hindering factors. Teaching and Teacher Education, 26(3), 482-496.

Sledge. A., \& Pazey, B. L. (2013). Measuring teacher effectiveness through meaningful evaluation: Can reform models apply to general education and special education teachers? Teacher Education and Special Education, 36(3), 231-246.

Stanford Center for Assessment, Learning and Equity. edTPA. Palo Alto, CA: Author. Retrieved from https://scale.stanford.edu/

Sweetman, D., Badiee, M., \& Creswell, J. W. (2010). Use of the transformative framework in mixed methods studies. Qualitative Inquiry, 16(6), 441-454. 
Symonds, J. E., \& Gorard, S. (2010). Death of mixed methods? or the rebirth of research as a craft. Evaluation \& Research in Education, 23(2), 121-136.

Symonds, K. W. (2004). After the test: Closing the achievement gaps with data. Naperville, IL: Learning Point Associates. Retrieved from http://www.racialequitytools.org/resourcefiles/symonds.pdf

Tschannen-Moran, M. (2004). Trust matters: Leadership for successful schools. San Francisco, Ca: Jossey-Bass.

U.S. Census Bureau. (2015). QuickFacts United States. Washington, DC: Author. Retrieved on July 15, 2015 from http:/www.census.gov/quickfacts/table/ PST045214/00,12086

U.S. Department of Education. (2001). No Child Left Behind Act of 2001. Washington, DC: Author. Retrieved on March 05, 2014 from http://www2.ed.gov/policy/elsec/ leg/esea02/index.html

U.S. Department of Education. (2010). A blueprint for reform: The reauthorization of the elementary and secondary education act. Washington, DC: Author. Retrieved on March 5, 2014 from http://www2.ed.gov/policy/elsec/leg/blueprint/blueprint.pdf

van Lier, P. (2008). Learning from Ohio's best teachers: A homegrown model to improve our schools. Cleveland, OH: Policy Matters Ohio. Retrieved May 06, 2014, from http://www.policymattersohio.org/LearningFromOhiosBest.htm

Wayman, J. C., \& Stringfield, S. (2006). Technology-supported involvement of entire faculties in examination of student data for instructional improvement. American Journal of Education, 112(4), 549-571.

Weisberg, D., Sexton, S., Mulhern, J., \& Keeling, D. (2009). The widget effect: Our national failure to acknowledge and act on differences in teacher effectiveness. New York, NY: The New Teacher Project. Retrieved from http://widgeteffect.org/downloads/TheWidgetEffect.pdf

Young, V. (2008). Supporting teacher's use of data: The role of organization and policy. In E. B. Mandinach \& M. Honey (Eds.). Data driven school improvement: Linking data and learning (pp.87-106). New York, NY: Teachers College Press.

Yusko, B., \& Feiman-Nemser, S. (2008). Embracing contraries: Combining assistance and assessment in new teacher induction. Teachers College Record, 110(5), 923 953. 


\section{APPENDICES}

\section{APPENDIX A}

\section{SURVEY INSTRUMENT}

Special and General Education Teachers' Assessment of Their Participation in a Peer Assistance and Review (PAR) Program

\section{Directions:}

In this survey instrument, you will be asked about your experience as a participating teacher in the PAR program implemented in your school district. Your individual responses will not be shared with anyone or with any organization - please answer as truthfully as possible. Your participation in this survey will assist us in better understanding the effects of PAR on teacher evaluation and professional development.

Part I: Demographic Information and Overall Level of Satisfaction

1. Gender:

$\square$ Female

$\square$ Male

2. Race:

$\square$ African-American or Black
$\square$ American Indian and Alaska Native
$\square$ Asian
$\square$ Native Hawaiian
$\square$ Other Pacific Islander
$\square$ White
$\square$ Multiracial
$\square$ Some Other Race

3. Are you of Hispanic of $\square$ Yes Spanish Origin? $\square \mathrm{No}$

4. School Level Taught: $\quad \square$ Pre-K

$\square$ Elementary
$\square$ Middle School
$\square$ High School


5. Teaching Experience: $\square$ Less than 1 year

$$
\begin{aligned}
& \square 1 \text { to } 2 \text { years } \\
& 2 \text { to } 5 \text { years } \\
& 5 \text { to } 10 \text { years } \\
& \square \text { More than } 10 \text { years }
\end{aligned}
$$

6. Is your primary teaching $\square$ Yes responsibility Special $\square$ No

Education (including consultation, coteaching, resource room, self-contained classroom, separate school, and preschool Special Education)?

7. Are you certified in $\square$ Yes Special Education $\quad \square$ No (includes all types of Special Education certification)?

8. Would you be willing to $\square$ Yes participate in a follow-up $\square$ No interview?

9. If yes, please provide your contact information in the boxes bellow. Name:

Email address:

10. Teacher Preparation: $\quad \square$ Traditional 4-year University Teacher Ed. Program Alternative Certification

11. Level of Education: $\quad$ Bachelor's Degree DMaster's Degree DEducational Specialist Degree DDoctorate Degree

12. School Site Grade: $\quad \square A$

$$
\begin{aligned}
& \square \mathrm{B} \\
& \square C \\
& \square D \\
& \square F
\end{aligned}
$$


For the following survey items, please consider your overall feeling of satisfaction with the impact that your participation in the PAR program had on each one of the specified areas of your teaching.

13. Knowledge of Learners $\quad \square$ Very Satisfied

口Satisfied

DSomewhat Satisfied

口Unsatisfied

14. Instructional Planning $\quad$ Very Satisfied

口Satisfied

DSomewhat Satisfied

UUnsatisfied

15. Instructional Delivery

and Engagement

QVery Satisfied

DSatisfied

$\square$ Somewhat Satisfied

UUnsatisfied

16. Assessment of Learners aVery Satisfied

$\square$ Satisfied

DSomewhat Satisfied

UUnsatisfied

17. Communication with $\quad$ VVery Satisfied

Students, Their Parents, aSatisfied

Staff, and Other $\quad \square$ Somewhat Satisfied

Members of the Learning $\square$ Unsatisfied

Community

18. Ability to Create a Safe, DVery Satisfied

Fair, Respectful, and $\quad \square$ Satisfied

Stimulating Learning $\square$ Somewhat Satisfied

Environment

UUnsatisfied

19. Overall Professionalism aVery Satisfied

DSatisfied

DSomewhat Satisfied

UUnsatisfied 
The following survey question regards the certification area of the consulting teacher who conducted formal observations of your teaching and who provided you with feedback and job embedded opportunities during your participation in the PAR program in your school district.

20. What was the area of certification of the $\square$ General Education consulting teacher(s) $\square$ Special Education

who worked with you $\square$ Both General Education and Special Education during your participation in the PAR program in your school district?

For the following survey items, please consider your overall feeling of satisfaction with the feedback you received from each one of the specified professionals during your participation in the PAR program.

21. PAR Consulting Teacher(s)

22. PAR Consulting Teacher(s) (Certified in General Education)

23. PAR Consulting Teacher(s) (Certified in Special Education

24. School Administrator(s)
$\square$ Very Satisfied
$\square$ Satisfied
$\square$ Somewhat Satisfied
UUnsatisfied

$\square$ Very Satisfied
$\square$ Satisfied
$\square$ Somewhat Satisfied
$\square$ Unsatisfied
$\square$ Very Satisfied
$\square$ Satisfied
$\square$ Somewhat Satisfied
口Unsatisfied

\section{$\square$ Very Satisfied \\ Satisfied \\ $\square$ Somewhat Satisfied \\ 口Unsatisfied}

For the following survey items, please consider your overall feeling of satisfaction with the job embedded professional development opportunities you received from each one of the specified professionals during your participation in the PAR program.

25. PAR Consulting

Teacher(s)

\author{
$\square$ Very Satisfied \\ $\square$ Satisfied \\ $\square$ Somewhat Satisfied \\ UUnsatisfied
}


26. PAR Consulting

Teacher(s) (Certified in

General Education)

DVery Satisfied

DSatisfied

DSomewhat Satisfied

DUnsatisfied

27. PAR Consulting

口Very Satisfied

Teacher(s) (Certified in DSatisfied

Special Education

DSomewhat Satisfied

DUnsatisfied

28. School Administrator(s) aVery Satisfied

口Satisfied

DSomewhat Satisfied

DUnsatisfied 
Part II: PAR's Impact on Specific Teaching Areas

For the following survey items, please consider the level of impact that your participation in the PAR program had on each one of the specified abilities related to specific teaching areas.

Knowledge of Learners

29. Ability to Identify and Address the Individual DSubstantial Impact Differences of Students $\square$ Some Impact $\square$ Little Impact $\square$ No Impact

30. Ability to Identify and $\square$ Substantial Impact Address the Individual $\square$ Some Impact Cultures of Students $\quad \square$ Little Impact $\square$ No Impact

31. Ability to Identify and $\square$ Substantial Impact Address the Individual $\square$ Some Impact Backgrounds of Students $\square$ Little Impact $\square$ No Impact

32. Ability to Identify and $\square$ Substantial Impact Address the Individual $\square$ Some Impact Learning Styles of $\quad \square$ Little Impact Students $\square$ No Impact

Instructional Planning

33. Ability to Use $\square$ Substantial Impact Appropriate Curricula to $\square$ Some Impact Develop Lesson Plans $\square$ Little Impact that Address the Diverse $\square$ No Impact Needs of Students

34. Ability to Use $\square$ Substantial Impact Instructional Strategies and Resources to $\square$ Some Impact Develop Lesson Plans $\square$ Little Impact that Address the Diverse Needs of Students 
Instructional Delivery and Engagement

35. Ability to Promote

Learning by

$\square$ Substantial Impact

Demonstrating Accurate Content Knowledge

口Some Impact

DLittle Impact

DNo Impact

36. Ability to Promote $\quad$ Substantial Impact

Learning by Addressing 口Some Impact

Academic Needs through DLittle Impact

a Variety of Appropriate $\square$ No Impact

Instructional Strategies

and Technologies that

Engage Learners

Assessment of Learners

37. Ability to Gather, Analyze, and Use Data DSome Impact (Including Current State DLittle Impact Assessment Data, as $\quad$ No Impact

Applicable) to Measure

Learner Progress

38. Ability to Gather, Analyze, and Use Data (Including Current State Assessment Data, as Applicable) to Guide Instruction

39. Ability to Gather, Analyze, and Use Data DSubstantial Impact (Including Current State Assessment Data, as 口Some Impact Applicable) to Provide Timely Feedback

Communication with Students, Their Parents, Staff, and Other Members of the Learning Community

40. Ability to Communicate $\square$ Substantial Impact

Effectively with Students DSome Impact

DLittle Impact

口No Impact 
41. Ability to Communicate

Effectively with

DSubstantial Impact

Students' Parents or

Families

口Some Impact

DLittle Impact

DNo Impact

42. Ability to Communicate $\square$ Substantial Impact

Effectively with Staff $\quad$ DSome Impact

and Other Members of DLittle Impact

the Learning Community $\square$ No Impact

Ability to Create a Safe, Fair, Respectful, and Stimulating Learning Environment

43. Ability to Create a Safe $\square$ Substantial Impact

Learning Environment $\square$ Some Impact

DLittle Impact

DNo Impact

44. Ability to Create a DSubstantial Impact

Learning Environment $\square$ Some Impact

that Encourages Fairness DLittle Impact

DNo Impact

45. Ability to Create a Learning Environment

口Substantial Impact

that Encourages Respect DLittle Impact

DNo Impact

46. Ability to Create a

Learning Environment

DSubstantial Impact

that Encourages

DSome Impact

Enthusiasm

DLittle Impact

口No Impact

Overall Professionalism

47. Ability to Comply with $\square$ Substantial Impact

Legal, Ethical, and DSome Impact

Professional Standards $\square$ Little Impact

DNo Impact

48. Ability to Engage in $\square$ Substantial Impact

Continuous Professional $\square$ Some Impact

Growth

DLittle Impact

DNo Impact 


\section{APPENDIX B}

\section{INTRODUCTORY MESSAGE}

\section{Dear Sir or Madam:}

My name is Alex Lopes. I am a doctoral student at Florida International University (FIU). The reason for my contacting you is to request your participation in a brief survey that can be accessed via the electronic link found below. This survey is part of my dissertation study and has been designed to help me answer the following research question: How do special education teachers and general education teachers rate the extent to which their participation in a Peer Assistance and Review (PAR) program impacts their teaching in targeted areas?

In addition, if you are a special education teacher, I would like to have your permission to contact you for a follow-up interview. This interview will last no more than an hour and is intended to help me answer the following research question: How do special education teachers describe their experiences as a participating teacher in a PAR program? If I have your permission, please share your contact information with me by sending a message to the e-mail address listed under my name.

I want to thank you in advance for your time and cooperation. I also want to assure you that your survey responses will remain confidential. Confidentiality also will be extended to those special education teachers willing to participate in the follow-up interview. Thank you very much.

(Electronic link will be entered here.)

Sincerely, Alex Lopes

Florida International University Doctoral Student loralopes@aol.com 


\section{APPENDIX C}

\section{SECOND MESSAGE}

\section{Dear Sir or Madam:}

My name is Alex Lopes. I am a doctoral student at Florida International University (FIU). Last week I contacted you in order to request your participation in a brief survey that can be accessed via the electronic link found below. This survey is part of my dissertation study and has been designed to help me answer the following research question: How do special education teachers and general education teachers rate the extent to which their participation in a Peer Assistance and Review (PAR) program impacts their teaching in targeted areas?

In addition, if you are a special education teacher, I would like to have your permission to contact you for a follow-up interview. This interview will last no more than an hour and is intended to help me answer the following research question: How do special education teachers describe their experiences as a participating teacher in a PAR program? If I have your permission, please share your contact information with me by sending a message to the e-mail address listed under my name.

I want to thank you in advance for your time and cooperation. I also want to assure you that your survey responses will remain confidential. Confidentiality also will be extended to those special education teachers willing to participate in the follow-up interview. Thank you very much.

(Electronic link will be entered here.)

Sincerely, Alex Lopes

Florida International University Doctoral Student loralopes@aol.com 
VITA

\section{ALEXANDRE LOPES}

Born, Petrópolis, Brazil

1994

B.A., Communication

Universidade Federal do Rio de Janeiro

Rio de Janeiro, Brazil

$2005-2012$

Teacher, Prekindergarten Special Education

Miami-Dade County Public Schools

Miami, Florida

2006

$2010-2012$

M.S.Ed., Exceptional Student Education /

Prekindergarten Disabilities

University of Miami

Coral Gables, Florida

Project Rewards and Incentives for School Educators

Teacher Leader

Miami-Dade County Public Schools

Miami, Florida

2012

2012

$2012-2013$

2013 Francisco R. Walker Miami-Dade County

Teacher of the Year Award

Miami-Dade County Public Schools

Miami, Florida

2013 Florida Department of Education

Teacher of the Year Award

Florida Department of Education

Tallahassee, Florida

Christa McAuliffe Ambassador for Education

Florida Department of Education

Tallahassee, Florida

2012

Distinguished Educator Award

University of Florida

Gainesville, Florida

2013

2013 National Teacher of the Year Finalist Award Council of Chief State School Officers

Washington, District of Columbia 
Governor's Shine Award for Inspirational Teaching Governor Rick Scott

Tallahassee, Florida

$2013-2014$

$2014-2016$

2016 - Present

Instructional Supervisor for Teacher Incentive / Retention Miami-Dade County Public Schools

Miami, Florida

Prekindergarten Program for Children with Disabilities Instructional Supervisor Miami-Dade County Public Schools

Miami, Florida

Prekindergarten Exceptional Student Learning Support Curriculum Supervisor

Broward County Public Schools

Fort Lauderdale, Florida

\section{PUBLICATIONS AND PRESENTATIONS}

Lopes, A. (2012). The children lead me one step at a time. In J. T. Wynne, L. D. Delpit, $\&$ R. E. Miles (Eds.), Confessions of a white educator: Stories in search of justice and diversity (pp. 83-85). Dubuque, IA: Kendall Hunt.

Lopes, A. (2012, September 23). Autism: Breaking free the silent child with early intervention, inclusion. The Miami Herald.

Lopes, A. (2016). Diana, Bernard, Ivan e Anika: Leitura em quarto tempos. In M. Amarilha (Ed.), Educação e leitura: Desafios e criatividade (pp. 191-199). Campinas, Brazil: Mercado de Letras. 